\title{
Psychology of Child Well-Being
}

Arne Holte, Margaret M. Barry, Mona Bekkhus, Anne Inger Helmen Borge, Lucy Bowes, Ferran Casas, Oddgeir Friborg, Bjørn Grinde, Bruce Headey, Thomas Jozefiak, Ratib Lekhal, Nic Marks, Ruud Muffels, Ragnhild Bang Nes, Espen Røysamb, Jens C. Thimm, Svenn Torgersen, Gisela Trommsdorff, Ruut Veenhoven, Joar Vitters $\varnothing$, Trine Waaktaar, Gert G. Wagner, Catharina Elisabeth Arfwedson Wang, Bente Wold, and Henrik Daae Zachrisson

\subsection{Introduction: Arne Holte}

This chapter addresses child well-being from a psychological point of view. In doing so, we need to remember that psychology is not one single discipline but

\footnotetext{
A. Holte $(\bowtie)$

Norwegian Institute of Public Health, Oslo, Norway

e mail: arne.holte@fhi.no

M.M. Barry

Health Promotion Research Centre, Galway, Ireland

Discipline of Health Promotion, School of Health Sciences, National University of Ireland, Galway, Ireland

M. Bekkhus • A.I.H. Borge • E. Røysamb

Department of Psychology, University of Oslo, Oslo, Norway

L. Bowes

Centre for Mental Health, Addiction and Suicide Research, School of Social and Community Medicine, University of Bristol, Bristol, UK

F. Casas

Faculty of Education and Psychology, Research Institute on Quality of Life, University of Girona, Girona, Spain

O. Friborg • J.C. Thimm $\bullet$ J. Vitters $\varnothing \bullet$ C.E.A. Wang

Departement of Psychology, University of Troms $\emptyset$, Troms $\varnothing$, Norway

B. Grinde $\bullet$ R. Lekhal $\bullet$ R.B. Nes

Division of Mental Health, Norwegian Institute of Public Health, Oslo, Norway

B. Headey

Melbourne Institute, University of Melbourne, Melbourne, Australia

T. Jozefiak

Department of Child and Adolescent Psychiatry, St. Olav's Hospital Trondheim University Hospital, Trondheim, Norway
} 
covers a wide range of psychological disciplines from evolutionary psychology and behavior genetics via psychometrics to developmental, cognitive, personality, and social psychology all of them relevant to the psychology of child wellbeing. The psychological study of well-being has a history of approximately 2,500 years. The modern psychological study of well-being and its close relatives, resilience, and prosocial behavior belong together under a common umbrella called "positive psychology." In this chapter, we draw upon both of the ancient and the modern tradition. We have addressed the concept of well-being from both a theoretical and an empirical position. Yet, we have to admit that there is no unified way of sorting all the terms associated with the psychological study of well-being. Consequently, terms like happiness, subjective, emotional, affective, cognitive, mental and psychological well-being, life satisfaction, satisfaction with life, quality of life, enjoyment, engagement, meaning, flow, and hedonic balance have not been used consistently trough out the chapter.

A large number of experts on the psychology of child well-being have contributed to the chapter. The chapter starts by framing well-being into the tradition of positive psychology (Wold) and tracing the greater historical lines (Vitters $\varnothing$ ), before we introduce current psychological conceptualizations of well-being (Vitters $\varnothing$ ), resilience (Friborg), and prosocial behavior (Bekkhus and Bowes). We then discuss psychological measurements of well-being in general (Røysamb) and indicators (Casas) and methods of measurement (Casas) used with children and adolescents in special. We ask who we should trust in childrens' own assessments or their parents' (Jozefiak), before we address health and health-related quality of life as indicators of well-being (Holte). We present examples of how well-being is

N. Marks

Centre of Well being, New Economics Foundation, London, UK

R. Muffels

School of Social and Behavioral Sciences and Reflect, Tilburg University, Tilburg, Netherlands

S. Torgersen • T. Waaktaar

Centre for Child and Adolescence Mental Health, Eastern and Southern Norway, Oslo, Norway

G. Trommsdorff

Department of Psychology, University of Konstanz, Konstanz, Germany

R. Veenhoven

Erasmus Happiness Economics Research Organization, Erasmus University, Rotterdam, Netherlands

North West University, Potchefstroom, South Africa

G.G. Wagner

DIW (German Institute for Economic Research), Berlin, Germany

B. Wold

Department of Health Promotion and Development, University of Bergen, Bergen, Norway

H.D. Zachrisson

Norwegian Center for Child Behavioral Development, Oslo, Norway 
distributed among children in different countries (Wold) and ask whether such measurements are valid and what influence them across cultures and countries (Trommsdorff). We continue by on a broad base to single out what affects the experience of well-being generally and among children and adolescents particularly. The issues covered are evolution (Grinde), genes (Nes), cognition (Thimm and Wang), personality (Torgersen and Waaktaar), family (Bowes and Bekkhus), transfer of values between parents and child (Headey, Muffels and Wagner), play (Borge), peer relations (Borge), kindergarten (Zachrisson and Lekhal), and school (Barry). We end the chapter by presenting five ways to practically enhance happiness in everyday life (Nes and Marks) and by guiding you through the world's largest database on happiness the World Database of Happiness (Veenhoven).

\subsection{Conceptualization}

\subsubsection{Positive Psychology: A Framework for Studying Subjective Well-Being: Bente Wold}

Subjective well-being (SWB) is one of the most prominent topics in the study of positive mental health and attracts increasingly more attention in psychology, in particular in the branch of positive psychology. Positive psychology was introduced as a new area of psychology in 1998, when Martin Seligman chose it as the theme for his term as president of the American Psychological Association. According to Seligman (2002b, p. 3), "The aim of positive psychology is to catalyse a change in psychology from a preoccupation only with repairing the worst things in life to also building the best qualities in life." The first Handbook of Positive Psychology (Snyder and Lopez 2002) emerged in 2002, identifying several broad topics to be studied in positive psychology, such as identifying human strengths, fostering wellbeing, resilience, prosocial behavior, and quality of life (QOL). In this perspective, strategies and techniques for enhancing the well-being are educational, relational, social, and political interventions, not clinical treatments.

An important task in positive psychology is to get insights into well-being and QOL in terms of three overlapping paths or pursuits: (1) the pleasant life, or the "life of enjoyment," how people optimally experience, forecast, and savor the positive feelings and emotions that are part of normal and healthy living (e.g., relationships, hobbies, interests, and entertainment); (2) the good life, or the "life of engagement," the beneficial effects of immersion, absorption, and flow that individuals feel when optimally engaged with their primary activities; and (3) the meaningful life, or "life of affiliation," how individuals derive a positive sense of well-being, belonging, meaning, and purpose from being part of and contributing back to something larger and more permanent than themselves (e.g., nature, social groups, organizations, movements, traditions, belief systems).

Among children, the three paths are present in many areas of life, and play is among the most evident. Playing is for children and positive psychology seeks to 
preserve this zest for movement as children grow older (for details, see Sect. 20.4.8). Physical education can illustrate how students could learn to become excited about physical activity through a positive psychology approach. When individuals are aware of, pursue, and blend all three lives (the pleasant life, the engaged life, and the meaningful life), authentic happiness or the full life is more likely to be achieved. Moreover, inherent to positive psychology is the assumption that schools are integral in the promotion of positive human development. Given the need to create and sustain meaningful experiences for all students, the pursuits of positive psychology appear to be a natural match with quality physical education. Interesting, challenging, and pleasurable physical activity would internalize an authentic feeling of happiness in students (Cherubini 2009).

In their chapter on "Positive Psychology for Children," Roberts and colleagues (2002) suggest that the focus in child psychology increasingly has become one of perceiving the competence of the child and his or her family and enhancing growth in psychological domains. The previous perspective of coping as a response to a stressor has been confronted with an increasing recognition that growth and SWB occur through adaptations to an ever-changing environment in a child's life. Child well-being in a positive psychology perspective entails the understanding of positive development resulting from constructive and productive socialization and individuation processes. Through socialization, the child becomes integrated into society as a respected participant, by being able to establish and maintain relations with others, to become an accepted member of society at large, to regulate one's behavior according to society's norms, and generally to get along well with other people. Individuation requires distinguishing oneself from others, by forming a personal identity, developing a sense of self, and finding a special place for oneself within the social network. There is a dialectical interplay between the needs of the child to maintain relations with others and the needs of the child to construct a separate self. Child well-being may be considered as a product of fruitful experiences during socialization and individuation. The task at hand for positive psychologists is to examine how individual and social resources can be strengthened to ensure a positive outcome of these processes.

The process of successful adaptation despite challenging or threatening circumstances, denoted as resilience, has attracted particular interest. The bestdocumented asset of resilient children is a strong bond to a competent and caring adult, who need not be a parent (Masten et al. 2011). According to Masten and colleagues (2011), resilience arises from ordinary protective processes and strengths such as self-regulation skills, good parenting, community resources, and effective schools. Resilient youth have much in common with competent youth who have not faced adversity, in that they share the same assets. For example, youth growing up in an adverse environment characterized by poverty may excel in academic achievement if they experience good parental support.

Resilience may be fostered by risk-focused strategies aimed at reducing the exposure of children to hazardous experiences or asset-focused strategies to increase the amount of, access to, or quality of resources children need for the development of competence. Such strategies may include providing a tutor and 
building a recreation center with structured activities for children or programs intended to improve parental and teacher skills (for details, see Sect. 20.2.4).

According to the self-determination theory (SDT) (Deci and Ryan 2012), child well-being depends on the extent to which the social environment provides opportunities for satisfaction of three innate psychological needs competence, autonomy, and relatedness. When children feel competent, autonomous, and socially accepted, they are more likely to develop self-regulation skills and to be intrinsically motivated for positive behavior, which in turn may instigate feelings of satisfaction and well-being. Prosocial behavior, defined as helping behavior or acts undertaken to protect or enhance the welfare of others, may serve as an example. SDT posits that the degree to which a prosocial act is volitional or autonomous predicts its effect on well-being and that psychological need satisfaction mediates this relation (Weinstein and Ryan 2010). The authors suggest that engaging in prosocial behavior can foster competence, need satisfaction, and wellbeing because helpers are acting on the world in ways that directly result in positive changes. Moreover, helping is inherently interpersonal and thus impacts relatedness by directly promoting closeness to others and cohesiveness or intimacy. Finally, prosocial actions that are volitional also provide opportunities to experience autonomy, need satisfaction, and the positive states that derive from these prosocial actions (for details, see Sect. 20.2.5).

\subsubsection{A Brief History of Well-Being: Joar Vittersø}

Although research on child well-being is a relative newcomer, it is clearly grounded in ideas that are as old as history itself. Systematic thinking on well-being began with the antique concept of eudaimonia, a term frequently rendered in psychological literature as only referring to Aristotle's ideas on happiness. This is misleading since the word was in use over 100 years before Aristotle was born and because Aristotle only formed one of several schools of ancient eudaimonia (McMahon 2006). Competing eudaimonic theories included hedonism, which may sound like a contradiction to modern psychologists. But for the ancients, hedonism was a conceptual option within eudaimonia (Keyes and Annas 2009). One should also bear in mind that the well-being of children was not a matter of interest for the ancient Greeks. Aristotle, for instance, claimed that children could never achieve eudaimonia.

Psychologists often point out that eudaimonia is a combination of "eu" (good) and "daimon" (spirit) and that the daimon part refers to an "inner self" (e.g., Ryan and Deci 2001; A. S. Waterman 1993). Such a translation is unfortunate since the Greek "daimon" referred to the spiritual and immortal part of the person, and it contrasted in this respect the term "eidolon," which was the individual and earthly part of a person. To be eudaimon meant to be fortunate enough to lead a life that was blessed in a spiritual and not an individualistic way (McMahon 2006).

Disagreements existed in the ancient worldview as to what eudaimonia comprised. Radical versions of hedonism, like the one proposed by Aristippus, claimed 
that the goal of life is nothing else than maximizing feelings of pleasure, regardless of its source. This theory from the fourth century BCE banished thought in all its forms as a foreign element in a good life (Watson 1895). A more moderate version of antique hedonism was articulated by Epicurus, who surely prized the pleasures of life but who also believed that the kind of pleasures that we today refer to as satisfaction is needed in order to live a good life. And satisfaction (or "ataraxia" in classic Greek) was not achieved without living virtuously and having friends (Tiberius and Mason 2009).

Aristotle's position was different and more complex. He considered eudaimonia to follow from the "activity of the soul in accordance with virtues" (McGill 1967, p. 17) and that hedonism, in the sense of searching pleasure only for its pleasantness, was a vulgar ideal, one that led people to become as slavish as grazing animals (Aristotle 1996). Different understandings of Aristotle's thinking exist, partly because his writing was, to put it mildly, not always consistent. But philosophers seem to agree that Aristotle considered eudaimonia to depend upon virtuous activities. To be happy, a person must develop wisdom and exercise excellence in virtuous activities so that he (it was always a he in Aristotle's writing) could realize his true and best nature and thus live a complete life (Waterman 2013). The conditions Aristotle considered necessary for the realization of one's potential is more controversial. He did, for example, believe that abundance of possessions and slaves, combined with a noble birth, numerous friends, good friends, wealth, good children, numerous children, a good old age, bodily excellences (such as health, beauty, strength, stature, and fitness for athletic contests), a good reputation, honor, good luck, and virtue were needed in a happy life.

Socrates was supposedly the first individual who believed that humans could exercise some control over their own happiness. Good lives are attainable for those who make good choices. But in order to choose well, one needs insight and it takes an appropriate education to develop such wisdom. With the rise of Utilitarianism, which of course happened much later, wisdom was no longer considered necessary for a good life. The only requirement for happiness was freedom, and this ideology still dominates contemporary thinking, in science as well as in political rhetoric.

Another major development in the history of well-being preceded Utilitarianism by a 100 years or so and came with the early phase of the Enlightenment. Here, not only freedom but also equality and good social networks were considered important for a happy life (cf. the "Liberty, equality and brotherhood" motto for the French revolution). When Thomas Jefferson penned the well-known phrase about happiness in the US Declaration of Independence, he was clearly inspired by this school of thoughts. Indeed, Jefferson launched the idea that the right to the pursuit of happiness is a self-evident truth with both private pleasure and public welfare in mind. He considered the reconciliation of public and private happiness as essential and believed that religion would ensure that "the pursuit of private happiness would not veer off the thoroughfare of the public good" (McMahon 2006, pp. 330 331).

The influence from the Enlightenment and the Utilitarianism can easily be observed in social sciences today. The development of economics, for example, is 
essentially lodged within the ideological legacy of Bentham. Empirical well-being research in psychology was similarly inspired (Bradburn 1969), although the notion of life satisfaction, the essence of which was initially proposed by Epicurus and later by John Stuart Mill, was a major source of inspiration as well (Campbell 1976; Cantril 1965). And even if happiness played a small role in the early years of psychology, it has always been a part of the discipline (Jones 1953). A substantial growth in happiness research began with Jahoda's reflections on positive mental health (Jahoda 1958) and continued with the availability of well-being data from representative samples of the populations in the USA and other countries (Bradburn 1969; Cantril 1965; Nowlis and Nowlis 1956). Part of this development includes the birth of the subdiscipline of child well-being, which arose as a "social indicator" movement (Ben-Arieh 2008), and was pioneered by reports on the "State of the child" from the USA in the 1940s. The interest was also fuelled by the general progress of the concept of children, as evolved in developmental psychology, in the emerging notion of children's rights, and in the expansion of available data. Comprehensive reviews of these trends are provided by Ben-Arieh (Ben-Arieh 2000, 2001, 2005; Ben-Arieh and Frones 2007) and others (Bradshaw and Hatland 2006; Casas 2000; Frones 2007).

\subsubsection{Current Conceptualizations: Joar Vittersø}

There is a confusing mixture of well-being concepts in the happiness literature. The most critical issue in the definitional debates concerns the number of dimensions needed to account for a life well lived. According to radical hedonism, we only need one: the balance of momentary pleasures over momentary pains (the socalled hedonic calculus). Kahneman (1999) positioned himself very close to this hedonic ideal in his early thinking, as he used to argue that happiness is properly understood with reference to the "experiencing self." In this view, a person is happy if engaged (enough of the time) in activities that he or she would rather have continued than stopped. Kahneman later turned around and is now prepared to include life satisfaction the "remembering self" as a second dimension of wellbeing. Hence, we can be happy in our lives or happy with our lives. Kahneman admits, however, that the two notions of happiness are not entirely compatible and that nobody seems to have solved the puzzle of balancing the essence of the experiencing with the essence of the remembering self into a unitary definition of well-being (Kahneman 2012).

The conflict between the experiencing self and the remembering/evaluating self has always been tricky. It can be recognized in the ancient tension between Aristippus and Epicurus and between Bentham and Mill during the advent of Utilitarianism. In modern philosophy, the controversy is sometimes referred to as the distinction between sensory hedonism and attitudinal hedonism (Feldman 2010), and in studies of well-being in the 1960s, Bradburn's was a theory of the experiencing self, while Cantril's was a theory of the evaluative self (Bradburn 1969; Cantril 1965). The two giant volumes on well-being in the 1970s Andrews and Withey (1976) and Campbell, Converse, and Rodgers (1976) clearly struggled with the same problem, and in 
the early 1980s, Veenhoven (1984) attempted to solve the puzzle by including both hedonic level and contentment as elements in his overall concept of a happy life. Diener (1984) did something similar when he claimed that both affective/emotional well-being and evaluative/cognitive well-being were major categories of SWB. A few years ago, Diener mobilized over 50 well-being researchers to sign up in agreement on the following definition of SWB: "Subjective well-being refers to all the various types of evaluations, both positive and negative, that people make of their lives. It includes reflective cognitive evaluations, such as life satisfaction and work satisfaction, interest and engagement, and affective reactions to life events, such as joy and sadness. Thus, SWB is an umbrella term for the different valuations people make regarding their lives, the events happening to them, their bodies and minds, and the circumstances in which they live" (Diener 2006, pp. 399 400).

Life satisfaction is the core concept in theories of SWB. Traditionally, the term referred to a rational comparison of what people have, to what they think they deserve and expect, or to which they may reasonably aspire(Campbell et al. 1976). Following this view, life satisfaction can be precisely defined as the perceived gap between aspiration and achievement, ranging from the perception of fulfillment to that of deprivation (see also Michalos 1985). Versions of the gap approach to life satisfaction are still thriving in some circles, such as the sustainable development movement, whose adherents suggest that satisfaction follows from fulfillment of basic physiological needs (O'Neill 2011), and the group of self-determination theorists, who consider satisfaction to come from fulfillment of basic psychological needs (Ryan and Deci 2001). But within the "Diener camp," life satisfaction is considered to be a report of how a respondent reflectively evaluates his or her life taken as a whole (Eid and Larsen 2008).

The notion that every good element in life can be captured as either a pleasant affect or as an evaluation of life in terms of goodness or badness has been referred to as the hedonic well-being approach (Ryan and Deci 2001). By contrast, competing theories offer taxonomies that go beyond pleasant feelings and judgments of satisfaction. These approaches may be considered eudaimonic in the psychological sense of the term (Tiberius 2013). An early conceptualization within this framework was developed by Sen, who pointed out that even if life satisfaction is important, it cannot possibly be the only element in a good life (Sen et al. 1987). Deprived persons that are overworked or ill can be made satisfied by cultural norms and social conditioning, he argued, and came up with the idea of capabilities in order to remedy this shortcoming. Sen's thinking is difficult to summarize, but very briefly it suggests that a concept of well-being must account for not only feelings and evaluations but also human functioning. To Sen, functioning is about lifestyles: what a person manages to do or to be. A capability, on the other hand, reflects a person's ability to achieve a given functioning. Capabilities reflect a person's freedom of choice between possible life-styles (Sen 2000).

Ryff (1989) has voiced another critique of SWB. She borrowed Bradburn's term "psychological well-being" and replaced his "affect balance" with what she believes are the six dimensions of well-being: self-acceptance, positive interpersonal relations, autonomy, environmental mastery, meaning in life, and personal 
growth. Although it is not quite clear why well-being consists in exactly these six dimensions, Ryff's theory has for two decades spearheaded eudaimonic research. But other scholars have proposed alternative dimensions of well-being. For instance, Keyes (Michalec et al. 2009) developed a taxonomy of flourishing (his term for well-being) with three main categories: (1) emotional well-being (positive affect, happiness, and life satisfaction), (2) functional psychological well-being (the six Ryff dimensions), and (3) functional social well-being (his own five dimensions). The 14 subdimensions can be reduced into a single well-being scale that runs from languishing to flourishing. Huppert has identified ten features of well-being, combining both feeling and functioning (Huppert and So 2013). As previously described, Seligman (2002a) used to think that happiness was a three-dimensional phenomenon, whereas he more recently (Seligman 2011) has proposed a theory of well-being (called flourishing) with five elements: positive emotions (pleasure), engagement (flow), relationships, meaning, and accomplishment (or PERMA for short). Seligman's theory is different from most other theories of well-being in several respects. He has, for instance, introduced a concern for accomplishment rather than for competence, the latter being the established concept of the domain. Seligman further holds emotions and satisfaction as practically overlapping, and he claims that neither is particularly important for well-being.

Other conceptualizations of well-being do indeed exist, such as those proposed by the "Stiglitz commission" (Stiglitz et al. 2009), the self-determination theory (Huta and Ryan 2010), the personal expressiveness approach to eudaimonia (Waterman et al. 2008), the Homeostatically Protected Mood theory of well-being (Cummins 2010), and very many others. Let us now move to the close relatives of the concept of well-being, namely, the concepts of resilience and prosocial behavior.

\subsubsection{Resilience and Adaptation: Oddgeir Friborg}

The concept of resilience was perhaps first introduced by Jack Block (1951). He launched the psychodynamically flavored term ego-resilience representing the ego's ability to self-regulate impulses or behavior in a flexible manner. Although this ability is undoubtedly still highly relevant, resilience is nowadays construed as a phenomenon rather than a set of personality characteristics. It has therefore largely become an atheoretical concept.

One of the first to display a sincere interest in positive outcomes was Emmy Werner (Werner 1993). Her seminal longitudinal study, beginning in the 1950s, aimed to study risks of maladaptation among newborn children on the Island of Kauai. Many of these children grew up under multiple psychosocial risks, for example, poverty, chronic discord, or parental psychopathology. The focus of the study gradually changed as it was discovered that most children evaded the predicted doom of their inheritance and poor psychosocial surroundings. A positive developmental course was the normal (about $70 \%$ ) rather than the abnormal response to adversity (Werner and Smith 1992). Furthermore, it was observed that about half of the adolescents with considerable adjustment problems as teenagers still managed to 
become quite well-functioning adults. Werner's study provides a rich source of insight into protective factors and case examples of positive human development.

What is resilience? It mainly refers to people adapting well despite expectations of the opposite, but it also embraces the developmental processes that facilitate favorable outcomes. As an outcome, resilience refers to a normal development or a successful adaptation despite experiences of significant adversity or trauma (Luthar 2006) or, simply put, normal adjustment despite abnormal circumstances. As a process, resilience refers to a range of psychological traits, skills, abilities, or coping mechanisms underlying favorable developmental trajectories. But resilience is not just about the positive forces within an individual but also about the developmental interplay between individual and environmental factors that together form an even stronger alliance against negative forces in life.

The number of factors identified to act protectively or buffer against stressors or life risks is staggering (Cederblad 2003; Luthar 2006), but they are clustered within three overarching domains: first, a broad set of personal, biological, genetic, temperamental, or dispositional traits, skills, abilities, or attitudes; second, as resources within the family in terms of stability and cohesion providing an environment of emotional closeness, empathy, and support; and third, a plethora of social and environmental resources that reinforce and support a healthy response. Examples may be friends, other family members, colleagues, or people in the neighborhood. It may also be institutions or community facilities offering proper housing, employment, social security, and health-care services (Luthar 2006; Werner 1993).

Resilience processes are inextricably related to the presence of stressors, hazards, or risks and are perhaps even pointless to infer in their absence. It is important to note that individuals characterized as resilient may still suffer from particular vulnerabilities that may create other or later problems, such as bouts of depression (Luthar et al. 1993) or problems with intimacy as adults (Werner and Smith 1992). But very often they do not allow their vulnerabilities to overshadow their behavioral strengths. They optimize the use of the resilience factors that are available to them in order to increase protection and readjustment. To reveal this pattern in research, one would in statistical terms look for an interaction between risk, vulnerability, and resilience factors. An example may be taken from the Dunedin longitudinal study. As expected, it was found that maltreatment or stressful life events early in life increased the risk of depression and suicidal attempts in adulthood. However, those individuals that had two long alleles in the HTTLPR serotonergic genotype were much less likely to suffer from these problems than those having two short alleles (Caspi et al. 2003). These genes were obviously important and protective but far less important for individuals growing up under favorable circumstances.

A later line of research has been concerned with understanding underlying mechanisms. An example is social competence which is found to protect against adult delinquency. This protection appears mediated by a reduced involvement with delinquent peers (Stepp et al. 2011). Hence, social competent adolescents are better able to resist becoming involved in deviant social networks. Studies of mechanisms 
(by examining mediators) are for that reason much more informative with regard to how to build intervention programs rather than just knowing that social competence counts.

A striking feature of the majority of resilience studies is that almost all find a subgroup ranging from about $5075 \%$ that come out favorably despite significant threats. An opportune question is therefore whether this is a universal phenomenon or perhaps an evolutionary property of humans. Do human variants always exist that are able to survive, no matter what dismal circumstances they may be subjected to? This is an intriguing idea that has been popular to many novelists and film directors. However, it rather seems that most of us may not escape psychological damages if the environmental hazards are abysmal enough or lasts long enough.

The studies which may illuminate this question are few, as well as ethically highly controversial. But a study by Egeland, Sroufe, and Erickson (1983) on mothers abusing their children physically and verbally, or who were psychologically unavailable or severely neglectful, showed that almost none of the children as six-year-olds escaped undamaged. Another line of studies deals with the Romanian orphanages which gave up children for adoption to the UK following severe to horrendous institutional deprivation (Rutter et al. 2007). Many of these were adopted to the UK, and all of these were grossly underdeveloped with respect to height and head circumference at entry. Although their developmental catch-up was almost complete in terms of weight and height, head circumference at the age of 11 was still below one standard deviation. As the children were adopted at different ages $(<6,624$, and $>24$ months), the researchers could examine the impact of the duration of deprivation. On the positive side, all of the children had a considerable catch-up in the cognitive test scores (IQ) at age 6 and 11. However, the majority of the children older than 24 months at the time of adoption did not improve beyond an IQ score considered as very impaired $(<70)$ (Beckett et al. 2006). These studies indicate that abysmal social and environmental surroundings are detrimental to human development the longer they are allowed to act.

A final, rare longitudinal study that deserves attention is the study by John Laub on the life course of delinquent teenagers growing up in low-income areas of Boston (Laub and Sampson 2003), following them from childhood to the age of 70. The most striking finding is the diversity in developmental trajectories. The authors reject the notion that early childhood experiences (e.g., antisocial behavior or poor school performance) are sturdy markers of long-term problems and criminal offense. Instead, they point to positive changes as a constant interaction of individual choices and environmental support. Despite early instability and family chaos, those who desisted from crime had some environmental factors in common: employment, military service, marriage, and living arrangements. Entering military service and becoming married represented turning points with respect to a change in antisocial or delinquent behavior. Although work was less influential in changing attitudes and behavior, it represented a strong protective factor in terms of routines, structure, and meaningful activities sustaining desistance from crime. Marriage was particularly protective as it provided limitations to socializing with 
delinquent peers. Enrolment in the military services acted protectively in a similar manner. Studies such as these illustrate the importance of social and structural support systems if a long-term positive adaptation is to be expected.

How do we measure resilience? One option could be to measure the positive outcome per se. However, instruments assessing protective factors are most probably a better approach as they are better suited to study how resilience mechanisms unfold over time. As our knowledge of protective factors has become extensive, it is quite surprising that valid instruments for assessing resilience factors are heavily underdeveloped. In a review of instruments measuring resilience, Ahern, Kiehl, Sole, and Byers (2006) identified six tenable scales. The Resilience Scale for Adults was one of these, which also is developed by the current author (Friborg et al. 2003). It received a good rating and is the only well-validated scale that measures resilience protective factors covering the three overarching clusters mentioned above: intrapersonal resources (positive perception of self, positive perception of future, social competence, and structured style), family cohesion, and social resources. In a range of studies, the RSA appears to be a valid measure predictive of efficient coping following stressful life events (Hjemdal et al. 2007), a higher tolerance of pain and stressful stimuli (Friborg et al. 2006), a more well-adjusted personality profile (Friborg et al. 2005), and less feelings of hopelessness (Hjemdal et al. 2012). It may be recommended for research on resilience and well-being.

\subsubsection{Prosocial Behavior: Mona Bekkhus and Lucy Bowes}

Prosocial behavior is thought to promote healthy development and well-being throughout development. Prosocial behavior is usually defined as voluntary behavior intended to benefit others (Eisenberg et al. 2006) and could reflect either internalized motivated behavior or behavior motivated by a general concern for others' well-being. A number of empirical studies suggest that children begin to act in a prosocial manner very early in life (e.g., Svetlova et al. 2010; van der Mark et al. 2002) and that prosocial behaviors usually increase with age (Benenson et al. 2003). For example, infants have been found to show distress in response to another infant's crying (Zahn-Waxler and Smith 1992), suggesting a predisposition for empathy. In a study examining prosocial behavior in toddlers, Svetlana and colleagues (2010) showed that toddlers as young as 18 months were able to instrumentally help adults and that the tendency to act in a prosocial manner increased significantly from 18 to 30 months of age. Moreover, in their meta-analysis, Eisenberg and Fabes (Eisenberg and Fabes 1998) found that prosocial behavior, such as sharing/donating, helping, and comforting others, was higher in adolescence than in childhood. However, longitudinal studies focusing on interindividual change and stability suggest that there are inconsistencies in the age-related increase in prosocial tendencies (e.g., Carlo et al. 2007; Hay et al. 1999). NantelVivier, Kokko, Caprara, Pastorelli, Gerbino, Paciello, and coworkers (2009) examined prosocial behavior longitudinally across childhood and adolescence using 
a multi-informant, cross-cultural design. Their results indicate stable or declining levels of prosocial behavior over a 5-year period, from 10 to 14 and 15 years of age. Similarly, a study by Côté and colleagues (2002b) found a relatively high degree of stability in helping behavior over a 6-year period (6 12 years), using different raters over the study period. Thus, it appears that, although there are age-related changes in prosocial behavior, there is also a relatively high degree of continuity from childhood to adolescence.

Studies investigating the development of prosocial behaviors have largely focused on environmental influences of parenting, and twin studies have shown that positive and warm parenting promotes children's prosocial behavior (e.g., Eisenberg et al. 2006). However, it is increasingly recognized that environmental influences do not operate isolated from genetic influences (Rutter 2006). Thus, there is a need to focus on susceptibility to environmental influences. Research on parent-by-child temperament interactions, plasticity (Ellis et al. 2011), and differential susceptibility (Belsky et al. 2007) suggests that the characteristics of individuals (and their genotypes) may make them more susceptible to the rearing environment in a "for better or for worse" manner. That is, some children may, due to temperamental or genetic reasons, be more susceptible to both the adverse effects of, for example, parenting and the beneficial effects of supportive rearing (Pluess and Belsky 2009). Emerging evidence suggests that this may also be the case with prosocial behavior. For example, Knafo, Israel, and Ebstein (2011) examined the heritability of children's prosocial behavior in 168 twin pairs. Their findings revealed an interaction pattern suggesting that some children might be more susceptible to their rearing context. That is, for children with the 7-repeat allele (DRD4-III polymorphism), prosocial behavior increased with an increase in maternal positivity. This linear relationship was, however, not found for the 7-repeat absent children. Children with the 7-repeat allele, whose mothers were the most positive, showed the highest levels of prosocial behavior. But children with the 7-repeat allele, whose mothers were the least positive, showed the lowest levels of prosocial behavior. Thus, it is clear that both genetic and environmental factors contribute to explaining individual differences in children's prosocial behavior (for details, see Sect. 20.4.3).

In general, all children can act prosocially, but they differ in the frequency in which they engage in prosocial behavior and in their motives for behaving in a prosocial way. From a public health and well-being perspective, it is often thought that promoting prosocial behavior should encourage healthy development. For example, in a study by Côté and colleagues (2002a), girls who followed an abnormally low prosocial trajectory were at risk for developing conduct disorder in adolescence. The assumption is that promoting prosocial behavior in such groups may reduce the risk of conduct problems. At the opposite end of the continuum, very high prosocial behavior has been found to be a risk for depressive symptoms in 18-year-olds (Gjerde and Block 1991). Thus, both high and very low prosocial behavior may function as an additional risk for mental health, rather than promoting SWB and positive health. 


\subsection{Measurement}

\subsubsection{Measuring Well-Being: Espen Røysamb}

In parallel with the conceptual and theoretical development of the well-being field, recent decades have witnessed an increased focus on measurement issues and methodological challenges. Is happiness measurable? And, if so, to what extent are measures reliable and valid? From a general skepticism toward measuring happiness, psychology has moved into developing and evaluating a number of well-being instruments. Based on recent developments, we now believe that measuring well-being is just as feasible as measuring, for example, mental disorders.

However, in contrast to mental disorders, well-being is typically measured as continuous rather than categorical phenomena. Clinical disorders such as anxiety and depression and neurodevelopmental disorders such as ADHD and autism are regularly defined by a set of criteria or symptoms, with a certain number of fulfilled criteria required to qualify for a diagnosis. Sum scores of symptom items are also used to represent continuous dimensions but then often with cutoff values to indicate severe symptom load or diagnostic level. Well-being instruments are primarily designed to capture degrees of well-being, ranging from low to high without predefined cutoff values.

Whereas the general construct of QOL is sometimes measured by means of external criteria, such as access to education and health care, the psychological perspective on well-being focuses on the subjective or perceived aspects of the good life. Thus, well-being instruments aim to capture positive and negative emotions and cognitive evaluations of life. Accordingly, external factors, such as education and health care, are seen not as components of well-being but rather as possible sources and predictors of well-being.

As outlined, a number of well-being constructs have been developed: SWB, life satisfaction, positive affect, psychological well-being (PWB), mental well-being (MWB), personal well-being (PWB), flow, and hedonic balance. Correspondingly, several self-report instruments have been constructed. Central examples include the Satisfaction with Life Scale (Diener et al. 1985b) tapping the cognitive evaluative component of SWB; the Positive and Negative Affect Schedule (Watson et al. 1988), measuring affective components of SWB; and the Psychological Well-being Scales (Ryff and Keyes 1995), containing six subscales covering the PWB domain. Other examples include the General Happiness Questionnaire, the Authentic Happiness Inventory Questionnaire, the Basic Emotions State Test, the Oxford Happiness Questionnaire, the Personal Well-being Index, and Cantril's Ladder (Diener et al. 2012; Eid and Larsen 2008; Ong and van Dulmen 2007) (for details, see Sect. 20.3.4).

In addition to questionnaire-based self-report instruments, the field has developed several alternative methods. One approach comprises various structured and semi-structured interviews. Another approach includes different versions of the Experience Sampling Method (ESM). The ESM approach aims to capture emotions 
and experiences in situ. Noteworthy are recent developments using modern technology, where research participants are prompted to fill out mini-questionnaires on their smartphones at random times during the day (Killingsworth and Gilbert 2010). A similar approach is seen in the Day Reconstruction Method (Kahneman et al. 2004), in which daily accounts of well-being and experiences are collected.

Valid measurements are essential for representing theoretical constructs and investigating causes and consequences of well-being. Yet measurement is not only an end result of conceptual theorizing but rather a critical feature in theoretical developments. Measurement efforts have contributed substantially to defining and refining constructs, to establishing boundaries between constructs, and also to delineating the underlying structure of well-being. For example, the theoretical distinction between the hedonic dimension of SWB and the eudaimonic dimension of psychological well-being has been supported in studies of the underlying structure of well-being scales (Ryan and Deci 2001) (see also Sect. 20.2.3).

Reliability and validity have been in focus during the development of well-being measures. Researchers have applied state-of-the-art methods, including item response models and structural equation modeling (SEM) to evaluate measurement equivalence, structural validity, and underlying latent structures (Ong and van Dulmen 2007). Thus, the most widespread instruments currently in use have well-established psychometric properties.

As well-being theories mainly have addressed adult well-being, measurement has also primarily been based on adult samples. However, recently there has been an important increase in research on measurement of child well-being (Casas et al. 2012c; Gilman and Huebner 2003). Several questions are being addressed: For which younger age groups may adult instruments be appropriate? For which age groups may adapted versions be feasible? Is the underlying structure of well-being similar among children and adults? As the field is moving forward, we anticipate high attention to measurement issues among children in the years to come, leading to validated instruments for all relevant aspects of well-being in different age groups. We move next to a brief review and outline of some promising developments in the measurement of well-being in children.

\subsubsection{Do We Need Specific Indicators for Children and Adolescents?: Ferran Casas}

May subjective information given by individual adults have any relevance at the macro-social level? Are subjective data from adults valid and reliable? Should we systematically collect some kinds of self-reported information from adults to better understand some social dynamics and some social changes involving them? Could that data from adults be useful for political decision-making? All of these questions were raised during the 1960s, when the so-called social indicators movement was born. One of the outstanding ideas of this movement was that we cannot properly measure social changes with only "objective" 
indicators. Subjective indicators are needed because people's perceptions, beliefs, opinions, attitudes, and evaluations on their social life are also a part of the social reality and have much to do with social changes. Therefore, subjective indicators were proposed, which were considered to be relevant for political decision-making. Due to the lack of tradition of systematically collecting subjective data, a challenge was identified about how to produce them rigorously. Following Bauer's proposals, subjective indicators should not only be "measures" but also other forms of evidence that enable us to assess where we stand and are going with respect to our values and goals and to evaluate specific programs and their impact (Bauer 1966).

More than 30 years later, exactly the same questions raised in the beginning of the last paragraph have been reformulated. The only difference is that the word "adults" has been substituted by "children and adolescents" (Casas 2011). Ben-Arieh (2008) pointed out the emergence of a "child indicators movement." However, once again, our lack of scientific tradition is our main challenge. Do we need specific indicators for children and adolescents? We do not know for sure whether some indicators could be the same. Yet, from a psychological point of view, the more wise answer should be that the kind of relevant data to be collected may change with age. The fact is that national and international systems of statistics now include a large number of survey results from adults, but almost no data is collected systematically from children or adolescents in most countries.

In the international arena, UNICEF's study coordinated by Adamson (2007) marked an important step toward the articulation of objective and subjective indicators for understanding children's living situations in different countries. The study dealt with five major domains for children's well-being, namely, material well-being, health and safety, educational well-being, young people's relationships, behaviors and risks, and SWB. However, that pioneer study faced several limitations: (a) Only very few international databases exist with data provided by children themselves for example, Health Behavior in School-aged Children (HBSC) (www.hbsc.org) and Program for International Student Assessment (PISA) (www.oecd.org/pisa). (b) Data in these databases include a limited number of countries, mostly developed countries. And, (c) the only psychometric scale included in international databases is the single-item scale named the "Cantril's Ladder" (Cantril 1965). Using only a single-item scale for international comparison is too weak a solution when dealing with a young and controversial field of measuring as SWB still is at present. Additionally, it is doubtful that "SWB" should be considered a separate domain in life, rather than including a subjective view in any domain. The number of available multi-item scales to evaluate children's and adolescents' SWB in general (nonclinical) populations is still limited. Much more testing must still be developed between countries, cultures, and languages (Casas et al. 2012c). Scientific research on the psychosocial components of QOL during the 1960s and 1970s soon led from macrosocial studies to micro-social studies of subjective or personal well-being. We were no longer interested only in the general well-being of populations. We also 
wanted to understand in more detail and with more precision the individual functioning that leads to people giving a positive evaluation of their own personal well-being. This made it even clearer that QOL research and therefore well-being research required not only an interdisciplinary approach but also a more micro-focused, even experimental research. Currently, we are still trying to understand the connections between SWB at a macro- and a micro-level. In psychology there is a long tradition of studying children's and adolescents' wellbeing at the micro-level. However like in most human and social sciences our major research has been focused on the negative aspects of well-being. Only very recently have we also been interested in the positive aspects and started to collect self-reported "positive" data from children and adolescents. We have long traditions collecting data from children for individual understanding. However, a feeling of "social and political relevance" of such data has often been missing. When we have asked children and adolescents for their own perceptions and evaluations very often, the data have not been as expected. Sometimes, we have doubted the reliability of the data. Sometimes we have doubted the reliability of the informants. The only evidence being that as researchers we did not have previous experience in asking the children (Casas 2011).

In the adult realm, it was assumed that social indicators could be "subjective" data or data obtained through subjective methods such as questionnaires, interviews, and discussion groups. This led to a debate over the epistemological "objectivity" versus "subjectivity" of the social phenomena being measured. Does "citizen dissatisfaction" with a service exist in the objective sense? If subjective measurement techniques indicate consistent dissatisfaction over time, may we then conclude that majority dissatisfaction "truly exists" and that it may have "real" and "objective" consequences? This debate recalled the famous quote that when people "define situations as real, they are real in their consequences," including social and political consequences (Thomas and Thomas 1928, p. 572).

Although such considerations are also valid when referring to the youngest generations, the obvious political interest in collecting subjective data from children has been slow to develop. Child well-being was initially conceived at both the national and international level as "what follows from objective realities" such as rates of mortality, malnutrition, immunization, and disease. Nobody has denied the high usefulness of these data. What is surprising is that while "subjective adult satisfaction" with services and life conditions has become a very important policy issue, the satisfaction of children and adolescents continues to be treated as irrelevant. Too often, in the social and human sciences, the low reliability and validity of data obtained from children and adolescents are used as excuses to avoid collecting such data. Curiously, only advertisers and marketing experts appear to be interested in this population and to have "overcome" difficulties concerning validity and reliability (Casas et al. 2012b).

In addressing child well-being and QOL, we must not forget that by definition, QOL includes the perceptions, evaluations, and aspirations of everyone involved. We know that different social agents may perceive the same reality differently. This does not mean that some of them are right and all the others are 
wrong. Social realities are often comprised by different perceptions and evaluations of sets of various social agents, where all social agents are relevant for understanding the social dynamics involved. We cannot go on trying to explain social realities involving children based solely on our adult perspectives. Perspectives of children and adolescents are essential to understand their social worlds. In other words, we must not confuse child well-being with adult opinions of child well-being (for details, see Sect. 20.3.5). Both are important, but they are not the same, and both are a part of the complex social reality we call child wellbeing. Therefore, we face the challenge of filling the large gap of information concerning the younger population's point of view of the social reality that affects humanity. Only in the last few decades have scientists become interested in studying child and adolescent well-being from the subjects' own perspective. Until very recently, it was assumed that adult evaluations on children's wellbeing would be valid enough.

A very recent international interdisciplinary initiative is trying to develop childcentered specific subjective indicators. Here they have proposed a new data collection in as many countries as possible using a questionnaire which explores children's activities, perceptions, and satisfactions with regard to their everyday life. A range of life domains and children's opinions on different topics affecting them is considered by means of three psychometric scales (International Survey of Children's Well-Being (ISWeB) (http://childrensworlds.org/). Questions to children have been grouped in 10 sections, including yourself, your home and the people you live with, money and things you have, your friends and other people, the area where you live, the school, how you spend your time, more about you, how you feel about yourself, and your life and your future. In each section, there may be questions on definition of each child's situation, on agreement/disagreement, on frequency, and on satisfaction. Satisfaction items can be grouped into eight life domains, in such a way that an index of each domain can be calculated, including household, material belongings, interpersonal relations, area of living, health, organization of time, school, and personal evaluations (feelings and beliefs). Three adapted versions of existing psychometric scales have been used in this project. These are the Students' Life Satisfaction Scale (SLSS) (Huebner 1991b), the Brief Multidimensional Students' Life Satisfaction Scale (BMSLSS) (Seligson et al. 2003), and the Personal Well-Being Index (PWI) (Cummins et al. 2003). A first publication of results using a slightly modified version of this questionnaire and proposing an overall index on children's SWB has been conducted by UNICEF-Spain: http://www.unicef.es/actualidad-documentacion/publicaciones/ calidad-de-vida-y-bienestar-infantil-subjetivo-en-espana

Researchers need to develop much more research instruments and projects with "children's advice" in order to be able to really capture what is relevant in children's life and for children's well-being from their own perspective (Casas et al. 2012b). Multi-method research, including qualitative data collection from children, is necessary to better understand children's answer to our "adult" questionnaires, based on our worries and aspirations. 


\subsubsection{Measurement of Well-Being in Children and Adolescents: Ferran Casas and Bente Wold}

In the recent years, at least three major child and adolescent personal well-being literature reviews have been published. One focused mostly on QOL, another on well-being, and a third on satisfaction (Andelman et al. 1999; Huebner 2004; Pollard and Lee 2003). These three concepts, although considered different by some authors, are very often used as interchangeable without defining them. In the tradition of social sciences, QOL is usually considered the broadest concept, while satisfaction is related to the cognitive aspects of SWB (see also Sect. 20.2.3). In health sciences, it has often been considered differently, although at present the most used concept is health-related quality of life (HRQOL) (for details, see Sect. 20.3.6).

These reviews show that most studies on child and adolescent well-being and QOL in the English-language literature have been focused on very specific, small populations, such as children with particular health problems. The reviews also show that in health sciences there are a great variety of quite specific instruments to assess "well-being" as an output of very concrete interventions among particular clinical populations, for example, children with cancer or with transplanted organs. In contrast, the social sciences are more devoted to investigating nonclinical populations, with larger samples, although the number of such studies is not large.

A number of psychometric scales have been used among regular populations of children and adolescents from the hedonic perspectives. However, up till now, there has not been a single eudaimonic scale available to study age groups under 16 . Yet, a limited number of studies exploring different eudaimonic aspects of life have been undertaken. For example, one study addresses the relationship between future aspirations and SWB (Casas et al. 2007). Another study investigates associations between religion/spirituality and SWB (Casas et al. 2009). In different European countries, children were asked "Imagine that you are 21 years old. At that time, how much would you like people to appreciate the following aspects of you?" Unexpectedly, the most frequent answers chosen among lists of 1626 qualities were niceness or kindness. In addition, it has been shown that in some countries, using religion and spirituality as the same life domain as in the PWI may be very confusing to adolescents, who consider these issues as very different.

Asking children directly about their perceptions, opinions, and evaluations of aspects and conditions of their life has produced surprising results. This has forced us to think critically about adult-held stereotypes and beliefs that for no good reason may generate bias among researchers and affect scientific understanding. A highly unsettling example is the history of child witness testimony studies. For more than two decades, researchers were interested only in cases in which children's testimony was flawed. It was not until the 1980s that studies began to think from the point of view of the child. Then researchers were able to show that if children received an appropriate amount of support allowing them to feel comfortable, they could in fact be valid witnesses (Garbarino and Stott 1989). 


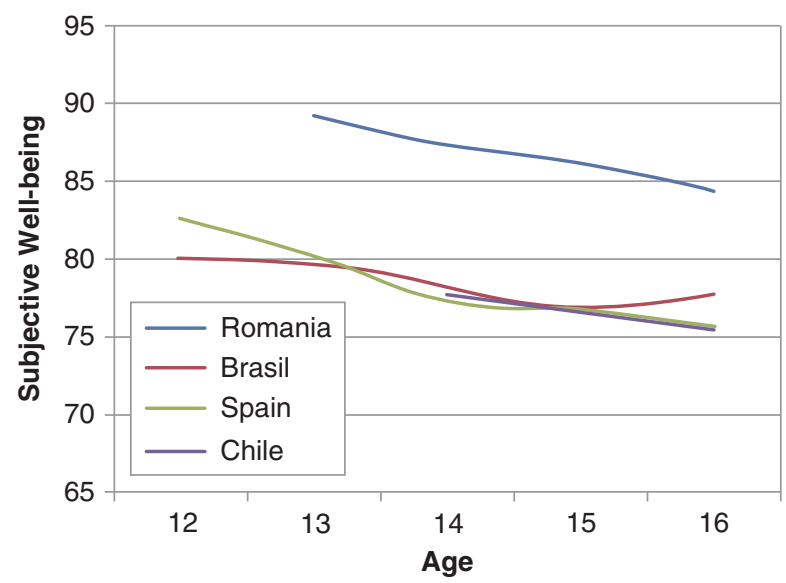

Fig. 20.1 Change in SWB across age. Standardized mean across measures in each country, not weighted for different n; Brazil (age 1216 years, $N \quad 1$ 588; scales BMSLSS5it, Fordyce, HOL, OLS, PW17gr, and SWLS), Chile (age 1416 years, $N \quad 853$; scales BMSLSS5it, Fordyce, HOL, OLS, PW17gr, and SWLS), Spain (age 1216 years, $N \quad 2$ 900; scales BMSLSS5it, Fordyce, HOL, OLS, PW17gr, PWIndex, and SWLS), and Romania (age 1316 years, $N$ 930; scales OLS and PWIndex). Argentina not included because of low n. For full name and references to measure, see text

Another example is the "discovery" of the decreasing life satisfaction from the age of 12 to the age of 16 . In the scientific literature throughout the 1980s and 1990 s, it was assumed that life satisfaction remains fairly stable throughout life, except for individuals with significant traumatic experiences. However, Petito and Cummins (2000) demonstrated that well-being decreased with age in an Australian sample of 1217 years old. Later on, it was reported that in different samples of 1216 years old from Catalonia, Spain $(2003, N=2,715 ; 2005, N=5,140 ; 2007$, $N=1,392 ; 2008, N=2,841$ ), using the PWI (Cummins et al. 2003), a decrease of overall life satisfaction with age was also observed (Casas 2011). More recently, SWB was assessed among adolescents using a range of six different instruments in Argentina, Brazil, Chile, and Spain. The aforementioned decreasing tendency was observed with all the instruments in all four different countries (Casas et al. 2012c). In the meantime, similar results have been reported also from Romania (Bălţătescu 2006), another Australian sample (Tomyn and Cummins 2011) (Fig. 20.1).

Recent findings from a large European study have identified similar trends (Currie et al. 2012). In the 2009/2010 survey of the Health Behavior in Schoolaged Children study (the HBSC study), satisfaction with life was measured in representative samples of 11-, 13-, and 15-year-olds from 39 countries. Life satisfaction was measured by the 11 steps of the "Cantril's Ladder." The top of the ladder indicates the best possible life and the bottom the worst. Respondents were asked to indicate the step of the ladder at which they would place their lives at present (from " 0 " to " $10 ")$. High life satisfaction was defined as reporting a score of "6" or more. More than $80 \%$ of 11-year-olds reported high life satisfaction in all countries except 
Romania and Turkey. In 13 countries including the Nordic countries and UK except Wales more than $90 \%$ of the children responded 6 or higher on the ladder. The proportion of children who reported high life satisfaction was highest in the Netherlands and lowest in Eastern European countries $97 \%$ among 13-year-old Dutch boys compared to $68 \%$ of Turkish boys. As in Argentina, Brazil, Chile, Spain, and Romania, prevalence of high life satisfaction significantly declined between ages 11 and 15 in almost all countries and regions for girls and in some for boys. Boys reported a significantly higher prevalence in most countries and regions at age 15 but in fewer than half at 13 . There was less evidence of a significant gender difference at age 11. Gender differences were not large at any age and only exceeded $10 \%$ in a few countries and regions at age 15 . Affluence was significantly positively associated with high life satisfaction in nearly all countries and regions for boys and girls (for more on cross-cultural comparisons, see Sect. 20.4.1).

How come that these strong tendencies have not been detected earlier? One explanation may be that during the past century, most authors were using four- or five-point scales to assess SWB, life satisfaction, or happiness. Because of the nonnormal distribution of the answers and the tendency in most populations to answer toward the positive end, the so-called optimistic bias (for details, see Sect. 20.4.4), such scales are not sensitive enough to catch differences in subgroups of the population. When researchers started to use eleven-point scales as recommended by Cummins and Gullone (2000), the age differences became visible, and the decreasing-with-age tendency became more and more obvious.

Taken together, these results pose a new question. Why is early adolescence a period of decreasing SWB including overall life satisfaction in so many countries? In addition, recent studies have cast doubt on the delicate assumption that parents transfer personal well-being to their children. In a sample of 12 16year-old Catalan children and their parents, no significant correlations between parents and their children were found on global life satisfaction and in most life domains. The only exceptions were satisfaction with health and satisfaction with future security (Casas et al. 2008). Later on, with a much larger sample and more sophisticated data analyses, similar results were found by Casas, Coenders, and colleagues (Casas et al. 2011a), although interesting differences between parents of a boy and parents of a girls appeared (for further discussion, see Sect. 20.4.7).

\subsubsection{Instruments: Ferran Casas}

Researchers have developed a number of scales for assessing well-being, which are specific for children or adolescents. Some examples are Perceived Life Satisfaction Scale (PLSS) (Adelman et al. 1989), Students' Life Satisfaction Scale (SLSS) (Huebner 1991b), Multidimensional Students' Life Satisfaction Scales (MSLSS) (Huebner 1994), Quality of Life Profile Adolescent Version (QOLP-Q) (Raphael et al. 1996), Comprehensive Quality of Life Scale Students Version (Com-QOL Students) (Cummins 1997; Gullone and Cummins 1999), and Brief Multidimensional Students' Life Satisfaction Scale (BMSLSS) 
(Seligson et al. 2003). Some studies have also taken general scales developed for the whole (adult) population and successfully used them on adolescent samples, including Satisfaction with Life Scale (SWLS) (Diener et al. 1985a), Personal Well-Being Index (PWI) (Cummins et al. 2003), and Fordyce's Happiness Scale (FHS) (Fordyce 1988). The most frequently used scale with adolescents in the psychological scientific literature up till now is probably the single item on overall life satisfaction (OLS), which can be found with different wordings. The most frequently used multi-item scales with adolescents seem to be the SLSS, BMSLSS, PWI, and SWLS. By content, they seem like quite different scales. However, when used together, they tend to correlate rather strongly, usually between 0.50 and 0.65 .

The OLS, SWLS (5 items), and SLSS (7 items) are context-free scales, while the MSLSS, BMSLSS, and PWI are based on the assumption that SWB or life satisfaction is composed by different life domains. The BMSLSS and the PWI seem to have fewer psychometric limitations when used with adolescents in international comparisons.

The SWLS was originally created to be used with adults and SLSS specifically for children and adolescents at 8 years old and on. The psychometric properties of the SWLS have been published in various articles. See, for example, Pavot and Diener (1993). The originally reported Cronbach $\alpha$ was 0.87 (Diener et al. 1985b). In the original testing, a single component accounted for $66 \%$ of the variance.

The SLSS was designed by Huebner (1991b) as a seven-item context-free onedimensional scale. Up until 1994, it was tested on small samples of children 1013 years old $(N=79)$ (Huebner 1991a) and 714 years old $(N=254)$ (Huebner 1991b) in the USA using a four-point frequency scale (from never to almost always). Reported Cronbach's alphas ranged from 0.73 (Terry and Huebner 1995) to 0.82 (Huebner 1991b; Huebner et al. 2003). In Fogle, Huebner, and Laughlin (2002), the scale is reported as a six-point scale from strongly agree to strongly disagree, and Cronbach's alpha is reported at $0.86(N=160,1015$ years old $)$. Gilman and Huebner (2000) suggested caution with respect to assuming the comparability of scores across the two formats.

PWI includes items on satisfaction with seven overall abstract life domains. These are health, standard of living, achievements in life, personal safety, community, security for the future, and relationships with other people. It has an eighth optional item which does not function in all countries, namely, satisfaction with spirituality or religion. These life domains need rewording or even reformulation in some countries. For example, in Spanish samples, satisfaction with community was not understood by most adolescents and had to be substituted by satisfaction with groups of people you belong to. The psychometric properties of the PWI have been reported in Lau, Cummins, and McPherson (2005) and in International Wellbeing Group (2006). Cronbach's $\alpha$ was originally reported to lie between 0.7 and 0.8 . The seven original domains form a single component which predicts over $50 \%$ of the variance for "satisfaction with life as a whole" with adult samples (Cummins et al. 2003). A School Children (PWI-SC), Preschool Children (PWI-PC), and Intellectual and Cognitive Disability (PWI-ID) versions are available in the Australian 
Centre on Quality of Life Web page (http://www.deakin.edu.au/research/acqol/ auwbi/index-translations/wbi-school-english.pdf), which have been tested in Australian and Chinese samples.

In contrast, BMSLSS is composed of five very concrete life satisfaction domains. These are family, friends, school, oneself, and the place you live in. Why such concrete items usually correlate strongly with the more abstract items in the PWI and how the two kinds of items may be included in a common model are still unresolved questions. The psychometric properties of this scale have been published in different articles. A 0.68 Cronbach's $\alpha$ was originally reported (Seligson et al. 2003).

The fact that most scales used with adolescents show a lower explained variance than the equivalent one with adults has raised a debate on what may be missing in the scales administered to adolescents. Currently, psychological literature is rich in publications that propose to include new life domains to the existing domain-based scales. For example, school satisfaction (Tomyn and Cummins 2011) and time use (Casas et al. 2011b) have been proposed to be included in the PWI. These scales have until now only been used with adolescents in a very limited number of countries. Yet, an increasing international testing has been observed during the recent years. The results obtained with these psychometric scales are promising and may lead to the development of well-grounded subjective indicators at the population level in countries that have versions adapted to their language and culture. Since most scales show a lower explained variance when used with adolescents than with adults, continue by discussing whether we should trust parents' reports about their children's well-being more than the children's own reports.

\subsubsection{Can We Trust in Parents' Report About Their Children's Well-Being?: Thomas Jozefiak}

Because of the substantial discrepancy between child and parent reports on children's well-being and QOL (Upton et al. 2008), a debate goes on in the literature about who is the most appropriate informant (Chang and Yeh 2005; Eiser and Morse 2001; Ellert et al. 2011). According to the World Health Organization, the concept of QOL is by definition based on the individual's own subjective perspectives. However, younger children's QOL report can be biased by several factors, among others their limited cognitive capacities and life experience (Spieth 2001). Therefore, for children up to ages 810 years, their parents are often asked to evaluate their children's well-being and QOL. Many studies of QOL in adolescents have also used only parent reports. Thus, it is very important to know how well we can trust in such "proxy" reports.

In the general population, research comparing child and parent proxy reports showed that parents evaluated their child's well-being and QOL as better than did the children themselves on most life domains (Ellert et al. 2011; Jozefiak et al. 2008; Upton et al. 2008). Further, parents in the general population reported only few changes related to one domain (school) of their children's well-being and QOL 
over a 6-month period, while the children reported changes in many life domains such as family, emotional well-being, self-esteem, and school (Jozefiak et al. 2009). Parents' own well-being has also been shown to be very weakly related to their children's well-being (Casas et al. 2012a), and relationships between parents' and children's values are highly culture specific (Coenders et al. 2005).

In contrast to general population research, discrepancies between child and parent reports are not so obvious in clinical population studies. Generally, it has been shown that the strongest correlate of referral to child mental health care is the impact of child symptoms on parents (Angold et al. 1998). Furthermore, parents of children with attention-deficit/hyperactivity disorder (ADHD) reported lower adult QOL than parents of healthy children (Schilling et al. 2006). That is, child problems appear to have an impact on parents and could bias the parent proxy report of child well-being and QOL. For example, mothers of children referred to child psychiatry evaluated their children's QOL as poorer than the children themselves reported (Jozefiak 2004). Also, parents' own problems can influence parents' proxy reports. Maternal depression was a significant predictor of total "proxy" QOL report, accounting for $12 \%$ of the variance (Davis et al. 2008). These examples show that parents in clinical populations may underestimate their child's "real" QOL. In somatic clinical populations, for example, obese children, these discrepancies may have different directions depending on the life domain being investigated (Hughes et al. 2007). There might be several interpretations of these findings, that is, the quality and psychometric properties of available parent child measures and known and yet unknown factors affecting parent child agreement levels and their direction (Upton et al. 2008). However, there is enough evidence indicating that parent proxy reports of child well-being and QOL are as biased as younger children's self-reports but of course by different factors than in the child. Therefore, there is good reason to distrust parent's report about their children's well-being.

However, despite these disadvantages of parents' reports, they obviously also have advantages, at least in the assessment of well-being and QOL in younger children. Parents have more developed evaluation capacities (consequence thinking, better sense of time past and future, etc.), while children perceive and evaluate the quality of their lives more in the present moment. This becomes obvious especially in children with neuropsychiatric problems such as ADHD but also applies to the younger child without mental health problems.

What should we do in regard to the discrepancy between child and parent reports, if there is no "objective" gold standard? Instead of discussing who is the most appropriate informant about children's well-being, it would be wiser to accept both advantages and disadvantages of both child and parent reports and consider them as valuable different perspectives, at least with regard to younger or severely ill children. By the definition of QOL, the child report should be considered as the prime authentic report whenever it can be obtained, and parent proxy report could represent important supplemental information about children's well-being and QOL. However, if the child's report cannot be obtained, maybe we could use the child's health as a proxy for child well-being? 


\subsubsection{Health-Related Quality of Life: Can Health Complaints be Used to Indicate Well-Being?: Arne Holte}

In epidemiological and clinical health research, symptom scales are among the most frequently used instruments to assess and monitor children's and adolescents' wellbeing. Several psychometrically sound scales and checklists are available, including the Strength and Difficulties Questionnaire (SDQ) (Goodman and Goodman 2009) and the Child Behavior Checklist (CBCL) (Achenbach 1991). Such symptom scales may tell us a lot about children's symptom profiles. Unfortunately, however, they tell us little about children's SWB or life satisfaction (LS). This is illustrated by a study of a representative sample of Norwegian 11 16-year-olds in 2009/2010 (part of the HBSC study; see Currie et al. 2012) the correlation between an eight-item checklist of subjective health complaints (the HBSC symptom checklist; see Haugland and Wold 2001) and life satisfaction (measured by the 11-step Cantril's Ladder; see Sects. 20.3.1 20.3.2) ranged from 0.39 among 11 -year-old boys to 0.53 among 15-year-old girls. In the same study, subjective health as measured by a generic question was even more weakly related to life satisfaction (correlations ranging from 0.22 among 11-year-old girls to 0.36 among 13-year-old boys).

Strong self-reported health may occur together with low well-being. Weak selfreported health may occur together with high well-being (Fig. 20.2). Although to some extent correlated, health and well-being, therefore, have to be differentiated conceptually and measured separately and independently. Obviously, if we would wish to assess the degree to which the two influence each other, anything else would also be tautological.

Yet, within the field of health, the most frequent way of defining well-being is in terms of health-related quality of life (HRQOL). Modeled on the WHO definition of health from 1947, the construction of HRQOL instruments was guided by a consensus statement from an International Board of Advisors (Goodman and Goodman 2009). According to this, four fundamental dimensions are essential to any measure of HRQOL, namely, physical, mental/psychological, and social health, as well as global perceptions of function and well-being. In addition, pain, energy/vitality, sleep, appetite, and symptoms relevant to the intervention and natural history of the disease or condition were listed as important domains but left to the individual investigator to include or exclude.

The PRO Harmonization Group (Achenbach 1991) defined HRQOL as "the patients' evaluation of the impact of a health condition and its treatment on daily life." Patients' evaluation implies that the patient is the preferred respondent to HRQOL questionnaires. Impact on daily life indicates that the domains assessed are relevant to the patient and that the assessment goes beyond a mere counting of events. The notion of multidimensionality is a key component of definition for HRQOL and means that a single domain cannot be considered as a HRQOL measure, even though it is a patient-reported outcome.

HRQOL scales may be generic or specific. The most frequently used generic scale is the SF-36 (Berzon et al. 1993). SF-36 is constructed to be used in a variety of patient groups and has also been used with adolescents. SF-36 consists of eight 
Fig. 20.2 Although to some extent correlated, self reported health and self reported well being must be conceptually differentiated and measured separately and independently

\begin{tabular}{c|c|c|}
\multicolumn{1}{c|}{$\begin{array}{c}\text { Low self-reported } \\
\text { health impairment }\end{array}$} & $\begin{array}{l}\text { High self-reported } \\
\text { health impairment }\end{array}$ \\
\cline { 2 - 3 } High well-being & $\begin{array}{l}\text { Low self-reported } \\
\text { health impairment } \\
\text { High well-being }\end{array}$ & $\begin{array}{l}\text { High self-reported } \\
\text { health impairment } \\
\text { High well-being }\end{array}$ \\
\cline { 2 - 3 } Low well-being & $\begin{array}{l}\text { Low self-reported } \\
\text { health impairment } \\
\text { Low well-being }\end{array}$ & $\begin{array}{l}\text { High self-reported } \\
\text { health impairment } \\
\text { Low well-being }\end{array}$ \\
\hline
\end{tabular}

subscales: physical functioning, physical role limitations, body pain, vitality, social functioning, emotional role limitations, mental health, and general health perception. The TNO-AZL Child Quality of Life Questionnaire (TACQOL) is an example of a generic HRQOL instrument designed specifically for children aged 815 years. It assesses the occurrence of functional problems, including negative emotional reactions. Here HRQOL is operationalized by seven dimensions pain and physical symptoms, motor functioning, autonomy, cognitive functioning, social functioning, global positive emotional functioning, and global negative emotional functioning each assessed by an eight-item scale (Vogels et al. 2000).

The broad cover of generic scales may weaken their sensitivity to specific changes. For example, an intervention which reduces symptoms specific to a certain illness (e.g., asthmatic breathing difficulties) may not be picked up adequately by the SF-36 or the TACQOL.

Condition-specific HRQOL scales have therefore been developed. These scales usually include items addressing specific symptom clusters, body parts, or biological systems (e.g., congenital heart disease). The relevance of items included in such instruments may often be clinically defined and not reflect a causal relationship with the underlying biological system in question. For instance, may symptom scales for congenital heart disease in children contain questions about anxiousness, even though there is no evidence that anxiousness is biologically associated with congenital heart disease.

HRQOL is most often limited to patient-reported health complaints, operationalized as scores on a symptom scale combined with self-assessment of associated functional impairments. Interpreted this way, an excellent level of HRQOL is indicated simply by absence of self-reported health complaints which are expected to occur more frequently in association with a specific clinical condition. Excellent HRQOL should therefore be considered conceptually different from excellent, positive physical and mental health and does not imply high well-being.

Within the fields of psychology and social sciences, well-being is normally defined independently from self-reported health complaints. As mentioned in Sect. 20.2.3, affective well-being (AWB) and cognitive well-being (CWB) (e.g., satisfaction with life) may be regarded as distinct constructs (Acquadro et al. 2003). 
These distinct constructs may differ both in their stability and variability across time (Ware and Sherbourne 1992) and in their relations with other variables (Eid and Diener 2004; Lucas et al. 1996; Schimmack et al. 2008). Among adults, specific life events such as marriage, divorce, bereavement, childbirth, unemployment, reemployment, retirement, and relocation/migration have differential effects on the affective and the cognitive components of well-being. In addition, adaptation of AWB and CWB to such life events does not occur at the same rate (Wiest et al. 2011).

Although both HRQOL and well-being rely on self-report, HRQOL cannot substitute either SWB or LS. Normally, perceived health defeats well-being only if onset of the health condition is sudden and/or intense. Otherwise, among adults, as compared to major life events such as marriage, divorce, bereavement, childbirth, unemployment, reemployment, retirement, and relocation/migration, health has only a modest impact on well-being. Data from 11 Canadian surveys illustrates this point. The surveys included between them 16 items of satisfaction representing a dozen specific life domains, for example, job satisfaction, family relations, and health. These items were used to predict happiness. Various combinations of the items were included in different surveys, but all the surveys included satisfaction with health.

For the 11 samples, multiple regression analyses explained on average $38 \%$ of the variance in reported happiness from some subset of the predictor variables. The top four predictors of happiness were self-esteem, satisfaction with partner, satisfaction with friendship, and financial security. Satisfaction with health was never the strongest predictor. Its maximum beta value was 0.18 . In 5 of the 11 surveys, the contribution of satisfaction with health was too low to enter into the regression equation (Luhmann et al. 2011).

The same review also considered studies revealing the importance of people's self-reported health to their overall happiness. In these studies, self-reported health was measured primarily by the eight dimensions of SF-36. When a variety of additional potential predictors were entered into the regression equation, $44 \%$ of the variance in happiness scores was explained. However, only one of the eight dimensions of SF-36 remained, namely, mental health. The latter accounted for a mere $4 \%$ points out of the total 44 . That is, selfreported health had relatively little to contribute to respondents' reported happiness, and its measured contribution was significantly affected by the number and kinds of potential predictors employed (Luhmann et al. 2011). Unfortunately, we do not have corresponding studies on children and adolescents. But if we were to hypothesize, health would be even less important in determining well-being in childhood than in adulthood as long as it is above a certain level and the social inequality in health is not too big.

As pointed out by one reviewer, no matter whether the pathology is subjective (e.g., perceived stress) or objective (e.g., degree of physical disability), pathology does not have a simple linear relationship to well-being (Luhmann et al. 2012). What we need now are population-based studies where measures of well-being are linked to measures of children's and adolescents' health to see whether the findings from adults can be generalized into children and adolescents. 


\subsection{Mechanisms and Explanations}

\subsubsection{Subjective Well-Being in Children and Adolescents from a Cross-Cultural Perspective: Gisela Trommsdorff}

Research on SWB has mostly focused on university students and adults in Westernized countries. Beyond the question whether SWB findings generalize across cultures (Diener 2012), the question is whether findings generalize across developmental ages. The majority of children and adolescents worldwide live in difficult developmental contexts, experiencing survival needs, health problems, and insufficient schooling potential risk factors for SWB. However, children's SWB has mostly been studied in "wealthy" Westernized countries (UNICEF 2007), thus restricting generalizations. Therefore, we take a culture-informed and developmental psychological perspective on children's and adolescents' SWB.

Methodological and theoretical shortcomings limit the cross-cultural comparability of SWB. Different conceptualizations relate to the structure (Ryff and Keyes 1995), to the contents, and to the various types of SWB. Usually, self-reports are used (Diener et al. in press) even though their validity for different cultural and age groups is unclear (Heine et al. 2002). Moreover, cultural conceptions of SWB are ignored (Lu and Gilmour 2004; Suh et al. 1998; Uchida et al. 2004). Longitudinal, experimental, and multilevel studies including representative samples are rare, and a theoretical framework is often missing.

Our integrative theoretical approach conceives of culture (including a nation's values and socioeconomic, political, and ecological characteristics) as structuring the socialization contexts (family, peers, school) of children's development (Trommsdorff 2007, 2012). This approach borrows from the ecological model of development (Bronfenbrenner 1979), the concept of the developmental niche (Super and Harkness 1993), and the cultural model of independence and interdependence (Markus and Kitayama 1991). We advocate a culture and developmental psychological perspective to study preconditions and consequences of SWB, assuming that SWB is related to needs, motivation, and resources.

Children's SWB depends partly on how the respective nation socializes its children. At the nation level (WVS), most of the pertinent dimensions of socialization goals for children were correlated with SWB (Bond and Lun 2012). This is in line with large-scale representative studies on the associations among cultural values, children's socialization, and SWB (Kasser 2011; Schwartz 2012).

Warm and responsive caretaking in early childhood, warm caretaker child relationships, and a harmonious family environment build resilience, buffering against stress and risk factors (Masten and Shaffer 2006; Richter 2010) and shaping life outcomes, including SWB (see also Sects. 20.4.6 20.4.7). Family cohesion was associated with better SWB in Italy and the UK (Manzi et al. 2006). In a longitudinal study, Chinese adolescents' SWB was poorer in non-intact compared to intact families (Shek 2008).

Adolescents favoring the family model of emotional interdependence (vs. independence) had the highest SWB across 10 countries (Value of Children (VOC) Study) 
(Mayer and Trommsdorff 2012, July). Satisfaction with peers was highest in cultures with a modal-independent model.

Parent child value similarities indicating positive parent child relationships were related to higher SWB of Russian minority adolescents in Germany and Israel (Hadjar et al. 2012). However, the similarities were stronger for children from majority versus minority families.

According to universalistic claims of attachment theory, sensitive, warm, and supportive caretaking fosters the development of a secure attachment, thus shaping positive beliefs about the self and the world and fostering positive developmental outcomes including dynamic resilience (which depends on interactions between genes and developmental experience; Cicchetti and Rogosch 2012) (for details, see Sects. 20.2.5 and 20.4.3). However, cross-cultural studies on relations between attachment style and SWB in children and adolescents are lacking.

Rothbaum, Weisz, Pott, Miyake, and Morelli's (2000) discussion on the culturespecific function of sensitivity and attachment has partially been tested in crosscultural comparisons of caretakers' implicit theories showing cultural differences in how caregivers foster appropriate development and well-being in children taking into account bilateral relations (Trommsdorff et al. 2012; Trommsdorff and Kornadt 2003; Ziehm et al. 2012).

Supportive interactions with peers can increase social competence and respective SWB, while exclusion and aggression may be a risk factor. No difference was found between Chinese and US American adolescents for the relation between peer acceptance and SWB (Greenberger et al. 2000). However, the strength of the overall positive association between peer acceptance and SWB on the individual level indicated cultural differences in the relative importance of peer acceptance for SWB (Schwarz et al. 2012). Cultural differences in the role of parents and peers for SWB were related to the importance of respective family values of interdependence versus independence. Peers were less influential for SWB when family importance was fostered by interdependent values. The higher the family values, the weaker were the positive associations of peer acceptance and SWB in the respective cultures. In line with Diener, Suh, Lucas, and Smith (1999), the quality of social relationships with parents and peers is important for SWB cross-culturally. However, Schwarz and colleagues (2012) also showed that strong traditional family values at the cultural level were related to higher SWB of adolescents, contradicting previous findings of higher SWB in individualistic versus collectivistic cultures (Suh and Koo 2008). More specific indicators of culture and SWB are needed to further delineate the role that peer relationships play in adolescents' SWB and vice versa (see also Sect. 20.4.9).

Cultural beliefs and religiosity are related to adolescents' SWB (Proctor et al. 2009). However, the direction and process of these relations are not clear (Trommsdorff 2012). In their VOC data-based cross-cultural study on religiosity and adolescents' SWB, Sabatier, Mayer, Friedlmeier, Lubiewska, and Trommsdorff (2011) showed that family values, especially interdependence, mediated the positive effects of religiosity on SWB and optimism both within and across cultures. Positive parent child relationships were also associated with optimism 
and SWB. Religiosity influencing adolescents' family orientation was positively related to higher SWB.

A cross-nation study (WVS) showed that religious values and practices predicted adolescents' SWB (Bond et al. 2012). Adolescents' traditionalism (vs. secularism) was positively associated to their SWB, indicating adolescents' need for a structured worldview. A positive effect of social religious engagement on SWB was moderated by societal religious restrictions, presumably fostered by socially supported worldviews. This is in line with assumptions of cultural fit and person culture match (Fulmer et al. 2010; Higgins 2012; Oishi 2000).

Experiencing warm caretaking and social support and aligning personal goals with cultural values foster SWB in childhood and adolescence cross-culturally. Future cross-cultural research should clarify the different types of children's and adolescents' SWB, respective socialization conditions, and effects of SWB on further developmental outcomes.

\subsubsection{An Evolutionary Perspective: Bjørn Grinde}

The prospect of happiness is an attribute bestowed upon us by evolution. If we can understand why we have the capacity to feel good or bad, we stand a better chance at making the most of the situation. A more detailed account of the biology of happiness can be found in Grinde (2012a, b).

The quest for improving personal well-being is a challenge throughout life; but the early years are arguably the most important. By offering children desirable conditions, they stand a better chance later in life as well. The evolutionary perspective is significant as it suggests what sort of environment is relevant for promoting positive feelings.

The original purpose of the nervous systems was to orchestrate muscle movements in order to direct the organism either toward something desirable or away from something obnoxious. Gradually, the simple systems developed into complex brains, with a substantial increase in the processing capacity allowing for more advanced decision-making. The basic dichotomy was retained. At one point, most likely at the amniotic stage (the ancestors of present reptiles, birds, and mammals), evolution introduced feelings as a strategy to evaluate options.

Feelings work on a "common currency" principle: Whatever is detrimental for the organism (i.e., have detrimental effects on the genes) is given a negative value, it feels bad, while whatever helps survival and procreation feels good. The resulting "moods" are referred to as punishing and rewarding, respectively. The brain is set up to weigh the expected outcome of various actions based on the principle of maximizing positive feelings. We seek sweet food, and we try to avoid breaking a leg. According to this model, well-being is a question of maximizing the sum of positive feelings in the long run.

Evolution presumably designed mammals to be in a good mood in the absence of negative events. A positive and confident attitude is to the advantage of the genes, that is, it promotes survival and procreation. The notion is substantiated by 
observations such as a tendency to optimism and that most people consider themselves happier than the midpoint on SWB scales (Lykken 2000). Eudaimonic happiness, as opposed to hedonic, may reflect this default state of contentment in combination with positive stimuli regarded as wholesome (e.g., friendship, empathy, and a meaning of life).

The brain is designed to adapt to environmental input. Neural circuits that are regularly activated tend to expand and gain impact. In other words, we can "exercise" the brain, which is useful if the purpose is to improve navigational skills but less useful if the result enhances the activity of negative emotions.

The first years of life are by far the most important when it comes to molding the brain. Early environment is consequently of primary importance for laying the foundations for later emotional life and well-being. The general flexibility of the human brain allows adults to compensate for a less than optimal childhood, but for the average person, childhood experiences will have considerable impact (Shonkoff 2011). We know a fair amount as to the neurological circuits that generate positive and negative feelings, that is, the brain's mood modules (Leknes and Tracey 2008). As the default is positive, well-being depends primarily on avoiding excessive activity in the negative mood modules.

Unfortunately, it is not that easy. Dire feelings, such as pain, fear, and low mood, are there to make sure you do not harm yourself. When excessively or inappropriately activated, the three may be referred to as chronic pain, anxiety, and depression, respectively. The problem is that their function implies that they are easily triggered: For the sake of the genes, it is more important to avoid a threatening situation than to exploit a potential benefit. You react faster and more strongly to the sight of a snake than the sight of an apple. Consequently, negative feelings are easily exercised. The high prevalence of anxiety and depression may reflect that the present child environment is not optimal for the development of these modules.

Fear is a suitable example. You may lock the door and tell the child that the house is safe, but evolution did not provide infants with that sort of perception. For them, safety depends on the proximity of caregivers, which preferably should be skin to skin as can be observed in present tribal people, infants tend to sleep together with parents and be carried during the day. Consequently, the fear function is easily activated if the baby is put in a separate room. This discord between the present environment and what humans are adapted to may help explain the prevalence of anxiety (Grinde 2005).

Presumably, there are particular neural circuits whose function is to either switch on or switch off fear. In nature, a frightening situation will generally resolve itself within a short time. In order to avoid that the accompanying fear obstructs other activities, the reaction needs to stop. Inappropriate development of the fear function (i.e., anxiety) presumably results when the on button is exercised, but not the off button. Being put to bed in a separate room as a small child may, for example, instigate fear without proper resolution.

According to the evolutionary perspective, the environment we would want for children is one that does not activate the negative mood modules unnecessarily, and if activated, there should be an appropriate endpoint. The pain module presumably 
functions today as it did in our ancestral environment, at least for the young. Fear and low mood, on the other hand, cause problems because of discords that is, troublesome differences between the way humans are designed by evolution to live and the present way of life. If we can describe these discords, they may be possible to resolve.

\subsubsection{Genetic Influences: Ragnhild Bang Nes}

Well-being runs in families. Using both quantitative (e.g., twin studies) and molecular genetic (e.g., linkage, genome-wide association studies) designs, behavior geneticists have shown family resemblance in well-being to be largely due to genes. Overall, studies on variation in well-being characteristics such as positive emotionality (PE), optimism, resilience, and SWB show the genetic influences to be considerable, in particular for stable, trait-like levels (Lykken and Tellegen 1996; Nes et al. 2006), and indicate that the genetic influences are partly shared (i.e., pleiotropy) with genetic influences on personality (e.g., extraversion, optimism) (Weiss et al. 2008). The genetic effect that is calculated in standard quantitative genetic studies the heritability estimate represents the part of the total variation attributable to genetic differences in a specific population at a specific point in time. The heritability of overall measures of well-being (e.g., SWB, PE) commonly accounts for $3550 \%$ of the total variation at least in adult and adolescent samples (Bartels and Boomsma 2009; Nes et al. 2010; 2006; Tellegen et al. 1988). One of the few studies using a child sample (12 18 years) and a multi-informant design has estimated the heritability of trait resilience to range between $50 \%$ and $75 \%$ in boys and between $41 \%$ and $66 \%$ in girls, with heritability varying somewhat across raters (highest from maternal ratings) (Waaktaar and Torgersen 2010). Genetic factors thus explain nearly half of the variation in well-being scores, consequently leaving the genetic effect sizes among the largest effects found in psychology overall. Remaining variation is commonly due to the non-shared environment, indicating that environmental influences usually contribute to make family members different rather than similar (i.e., environmental influences operate on an individual basis rather than more general). Most studies are conducted on adult and adolescent samples, however, and environmental influences causing family resemblance have sometimes been found for well-being-related characteristics in children (Burt 2009). Of note, these shared environmental effects are commonly moderate and usually vanish with age.

Little is still known about the actual genes and the specific environmental factors involved and even less about the complex interplay between them. This is perhaps mainly due to the fact that well-being is multifactorial (i.e., multiple genetic and environmental processes involved) and polygenetic (i.e., many genes with differing effects are involved) with risk and protective factors acting in a complex, probabilistic fashion rather than more deterministic. However, some studies have recently explored specific genes for well-being-related 
characteristics. One report suggests that the low-activity genotype (MAOA-L) of the catabolic enzyme monoamine oxidase A (MAOA) is associated with greater happiness in females (Chen et al. 2012). The serotonin transporterlinked polymorphic region $(5-H T T L P R)$ of the human serotonin transporter gene (SLC6A4) has also been shown to be important to variation in life satisfaction (De Neve 2011) and trait resilience (Stein et al. 2009). Additionally, individuals with the homozygous long variant of the 5-HTTLPR have been found to display a significant bias toward processing of positive information and selectively avoiding negative information (Fox et al. 2009). Other genetic variants are also likely to be important. According to Burgsdorf and Panksepp (2006), there are at least two distinct types of positive emotional states in the brain. One system is primarily involved in reward-seeking behavior (appetitive behavior, wanting) and associated, at least partly, with psychostimulants (e.g., cocaine and amphetamine). Another system involves the opiate and GABA system and appears to be involved in the processing of sensory pleasures (e.g., hedonic tastes, consummating, liking) (Burgdorf and Panksepp 2006). Genetic variants impacting on these two systems are likely to constitute important molecular foundations of positive emotional experiences.

The genetic and environmental influences are likely to transact and interplay through development, further complicating the picture. Children may vary in their responses to the same experiences, partly due to specific genes (gene environment interaction), and different family circumstances may allow for different expression of one's genetic potential (heritability environment interaction). Quantitative genetic studies have, for example, shown that adolescents' experience of parental positive regard and conflict moderate the genetic and environmental influences on both positive and negative emotionality (Krueger et al. 2008). In high-conflict families, for example, adolescents' positive emotionality was less influenced by genes and more influenced by the shared family environment.

The genotype may also influence exposure to environmental risk and protective factors (gene environment correlation, rGE). Passive rGE characterizes situations in which a child simply inherits both genes and environmental circumstance that reinforce each other, for example, when children of emotionally stable parents inherit genes related to emotional stability and are responded to in an emotionally supportive manner by their parents (i.e., double advantage). Children are also active agents in selecting and shaping their environments (active rGE) and in turn trigger responses to their behavior (evocative rGE) that amplify or strengthen genetically based dispositions. Children with temperaments high in positive emotionality actively seek situations matching their (partly genetic) disposition (active rGE) and elicit more positive responses in parents and others (evocative rGE).

Gene environment interaction $(\mathrm{GxE})$ refers to interaction between specific DNA sequences and specific measured environments. A number of GxE studies have been published in recent years, for example, showing that risk of adversity varies as a function of genotype (Caspi et al. 2003). Relevant to GxE, Pluess and Belsky (2012) has recently introduced the concept of vantage sensitivity which reflects the 
fact that some children, partly for genetic reasons, may benefit more than others from positive experiences. As opposed to resilience, which reflects what "protective" factors engender, vantage sensitivity does not refer to the potentially protective function of the same factors in the face of adversity. By contrast, differential susceptibility (Belsky 1997; Belsky and Pluess 2009) pertains to situations in which given factors (e.g., specific genetic variants) that increase risk of adversity in a negative environment will be the same as factors increasing vantage sensitivity in positive environments (i.e., factors that make some children resilient to adversity simultaneously make them less responsive to positive experiences). In accordance with the differential sensitivity hypothesis, a recent meta-analysis has shown that the DRD4 gene and other dopamine-related genes are related to greater vulnerability to negative environments and higher vantage sensitivity in positive environments in children 10 years and younger (Bakermans-Kranenburg and van Ijzendoorn 2011). Another recent study reported that the association between positive parenting and youths' positive affect varies as a function of 5-HTTLPR genotype, and suggesting that children with short 5-HTTLPR alleles is particularly sensitive to the benefits of positive parenting (Hankin et al. 2011). Vantage sensitivity associated with the 5-HTTLPR is also indicated in other studies and is not restricted to the parenting domain or to experiences in the childhood (Pluess and Belsky 2012).

Research on specific genes underpinning well-being-related characteristics is still in its infancy, and we will surely see many more studies on specific genes and gene environment interplay of importance to well-being and resilience in the near future. However, when dealing with the interaction of genetics with human agency and subjective meaning, with the relevant causal factors being innumerable, essentially nonadditive, and potentially relational and bidirectional, the outcomes are largely unpredictable.

\subsubsection{The Cognition of Well-Being: Jens Thimm and Catharina Elisabeth Arfwedson Wang}

For many psychological theories, it has been a hallmark of mental health and SWB that the individual is in touch with reality and construes events accurately and objectively (Taylor and Brown 1988). Accordingly, an important goal of many psychological treatments (e.g., cognitive therapy for depression, Beck et al. 1979) is to correct cognitive distortions and help the client to think in a more balanced way or more realistically.

However, the view that realistic thinking is common and crucial for adaptive functioning has been challenged in recent years. A wealth of research findings has shown that most people display a positivity bias or have "positive illusions" (Taylor and Brown 1988). For example, it has been observed that people use positive descriptors on average approximately $62 \%$ of the time when they rate themselves and others. The 62/38 ratio is also known as the golden section and is a robust empirical finding (Cromwell 2010). Most people tend to remember events 
from their life history as pleasant (Walker et al. 2003). When we see happy faces, we are prone to think that they are directed at us (Lobmaier and Perrett 2011). Importantly, positive illusions have been shown to be linked with psychological well adjustment, including different aspects of mental health (Taylor and Brown 1988) and SWB (Brookings and Serratelli 2006) but also with physical health (Taylor et al. 2000).

In their seminal paper, Taylor and Brown (1988) distinguish between three main areas of positive illusions: overly positive views of the self, perception of personal control, and unrealistic optimism. Unrealistic optimism involves an overly positive view of the future. For example, many people think that they are less likely than others to experience hazards (e.g., health problems; Weinstein 1987). Also, people often perceive that they have control in situations that are actually determined by chance (e.g., when trowing dice; Langer 1975). Another example of positivity bias is the so-called self-serving attributional bias, that is, people's tendency to attribute positive events to oneself and negative events to other causes (Mezulis et al. 2004). This inclination seems to be an important component of SWB, as it has been found that the self-serving attributional bias is present but significantly attenuated in individuals suffering from depression (Mezulis et al. 2004; Moore and Fresco 2012). This phenomenon is also known as "depressive realism" (Haaga and Beck 1995). In terms of the golden ratio model, depression involves a regression from $62 \%$ positive view of self toward $50 \%$ (Cromwell 2010). In a recent review of information processing in depression, Foland-Ross and Gotlib (2012) conclude that depression is specifically associated with difficulties in the processing of negatively valenced information including bias in attention, interpretation, cognitive control, and memory for negative material. This negativity bias has also been found in young children who are not themselves depressed but are at high risk for developing depression by virtue of having a depressed parent (Foland-Ross and Gotlib 2012).

Mezulis and colleagues (2004) also examined developmental trajectories in their meta-analysis on studies of the self-serving attributional bias. They found in their analyses that the bias is particularly large in the youngest age group (8 11 years), significantly weaker in adolescence (more markedly in females) and adulthood before it increases again in late adulthood. However, at all developmental stages, the effect size of the self-serving attributional bias is large, suggesting that this kind of positivity bias is a stable characteristic of normal cognitive functioning across the life-span.

More recent studies have extended the investigation of the positivity bias to preschool children. Findings suggest that a large majority of young children appraise their achievements as highly positive, and they also tend to favor positive trait attributions of others (Boseovski 2010). Studies suggest a high degree of similarity of general attributional style in children across cultures but also domain-specific cultural differences (e.g., self-rated competence; Boseovski 2010). Children's positivity bias is mirrored by a positive parental bias: Most parents are optimistic about their children and perceive positive characteristics as stable and inborn and undesired behaviors as transitory and extrinsically caused 
(Gretarsson and Gelfand 1988). A drawback of the parents' positivity bias is that they can overlook emotional problems their children might have. Results from a recent study by Lagattuta, Sayfan, and Bamford (2012) suggest that parents tend to underestimate worries and overestimate optimism in their children compared to self-report.

Obviously, the positivity bias has a shadow side. For example, unrealistic optimistic expectations may lead to individuals underestimating their vulnerability to risk and not taking appropriate precautions (Weinstein 1987). Further, economic crises and decisions on war have been related to positivity biases (Johnson and Fowler 2011).

So what contributes to the development of the positivity bias and why is it so pronounced in childhood? Evolutionary explanations emphasize its adaptive value (for details, see Sect. 20.4.2). For example, Johnson and Fowler (2011) demonstrated mathematically that overconfidence in one's own capabilities is advantageous in the competition for valuable resources. Bjorklund and Green (1992) propose that for children, the benefit of unrealistic thinking is primarily motivational. There are a number of tasks that they need to learn, and unrealistic optimism encourages them to attempt behaviors and practice skills which they wouldn't have tried if they had an accurate perception of their abilities.

In conclusion, the positivity bias or "positive illusions" seem to be crucial for SWB and have probably an adaptive value because the individual is motivated to take part in the challenges of life. On the other hand, the absence of the positivity bias seems to be associated with depression and withdrawal from life.

\subsubsection{The Happy Personality: Svenn Torgersen and Trine Waaktaar}

Most of us feel happy when we wake up to a nice, bright, sunny morning, not least if we live in northerly climes. A gray, cold, or stormy day may have the opposite effect. But not all of us react in this way. Some are generally more in a gloomy mood, while others are more enthusiastic and happy. Some people smile whatever happens, while others find a snake in every paradise.

In other words, "it is in the eyes of the beholder." Personality seems to influence how happy you are. This is not solely what people see unless their sight is too blurred by ideology, moral, wishful thinking, and "political correctness." Systematic studies have, namely, also demonstrated the correlations between a number of personality traits and happiness (DeNeve and Cooper 1998). The authors of the review found that repressive defensiveness, emotional stability, locus of control by chance (opposite), desire for control, hardiness, private collective self-esteem, and tension (opposite) were most strongly correlated to SWB, the broader concept, including happiness. They note that "repressive defensiveness" is generally described as "an unconscious avoidance of threatening information that leads to a denial of the experience of negative emotions associated with that experience" (DeNeve and Cooper 1998, page 216). The authors also reviewed the studies in relation to the so-called Big Five 
(personality traits) and found that extraversion and neuroticism (opposite), followed by agreeableness and conscientiousness, correlated with happiness. Already in 1980, Costa and McCrae reviewed studies suggesting that extraversion correlated with positive affect or satisfaction, while neuroticism correlated with negative affect or dissatisfaction. In fact, they postulated that positive affect was part of the concept "extraversion" and negative affect part of the concept "neuroticism." They could both be incorporated in the two broader personality dimensions. The same authors reviewed studies investigating the relationship between happiness and the whole realm of the Big Five or NEO Personality Inventory, their widely used questionnaire (McCrae and Costa 1991). They confirmed that extraversion was most strongly related to positive affect and neuroticism to negative affect. Conscientiousness and agreeableness were somewhat more weakly positively related to positive affect and negatively related to negative affect. Astonishingly, openness seemed related positively to both positive and negative affect. However, when spouses rated the Big Five, agreeableness appeared important, while extraversion appeared less important. Therefore, it seems as if the person himself combined extraversion and positive affect more strongly, while partners saw more relationship between good mood and agreeableness and bad mood and lack of agreeableness.

As happiness is related to a number of the Big Five personality dimensions, it is natural to look at the relationship between types based on the Big Five and happiness or more precisely the Giant Three, namely, neuroticism, extraversion, and conscientiousness. Torgersen $(1995,2008)$ created in a simple way eight types based on these three personality dimensions. Those higher than average on all three dimensions were called Complicated. The opposite type was called Spectator. Those similar to the complicated, except not being neurotic, were called Entrepreneur, the opposite type Insecure. Those similar to the Complicated except not being conscientious were called Impulsive. The opposite type was called Sceptic. Finally, those opposite to the Impulsive except not being neurotic were called Hedonist, the opposite was called Brooder. Studies have shown that the Entrepreneur is most happy, followed by the Sceptic, the Hedonist, the Spectator, the Complicated, the Impulsive, and last the Brooder and the Insecure (Torgersen and Vollrath 2006; Vollrath and Torgersen 2000).

Another aspect of personality is personality disorders. A study of the common population showed that, controlling for all usual sociodemographic variables, somatic health and axis I disorders, avoidant, borderline, paranoic, and dependent traits were negatively associated with SWB (Cramer et al. 2007).

What about children and youth? As the personality is surprisingly stable from childhood into adult age (Roberts and DelVecchio 2000) and personality traits among 3-year-old children predict adjustment up into adult age (Caspi 2000), we would expect that the same personality dimensions and traits were related to happiness among children and youth. Very few studies have been performed. Holder and Klassen (2010) found a relationship between social and active personality (extraversion) and happiness, and a somewhat weaker negative relationship was found to emotionality (neuroticism) among 9 12-year-old children. 
The same thing was observed among 7 14-year-old children in Northern India, only a weaker relationship to neuroticism (Holder et al. 2012). Unpublished data from a study of 3,000 children and youth between the ages of 12 and 18 years in Norway showed a strong positive relationship between SWB and stability (negative to neuroticism). The correlation was also high to agreeableness, extraversion, conscientiousness, and imagination (openness). The questionnaire HiPIC was applied (Mervilde and De Fruyt 2002). A hierarchical regression analysis showed that neuroticism (emotional stability) followed by agreeableness, extraversion, and conscientiousness was closely behind, while imagination (openness) disappeared in the regression analysis. When Torgersen's types were applied, a similar pattern was found as for adults. The Entrepreneur was most happy, followed by the Sceptic and the Hedonist. Then came the Complicated, the Spectator, the Brooder, the Impulsive, and finally the Insecure. However, being the agreeable and partly the imaginable (open) variant of the type increased the happiness, especially for the Impulsive and the Complicated. It did not particularly influence the Spectator and the Insecure much. There was a tendency that agreeableness and imagination (openness) were more strongly related to happiness when parents rated the children/youth compared to self-rating. This is similar to what was found for adults.

It is not easy to find any difference in observations between the studies of adults and of children/youth. Perhaps there exists a small tendency in direction of agreeableness and openness being more important and extraversion being less important among children/youth, as compared to adults. However, this is very tentative. Therefore, the conclusion must be that the personality pattern behind happiness is the same throughout life and most likely: The happy child will be the happy adult. As Caspi (2000) states in the title of his seminal paper: "The child is the father of the man."

\subsubsection{The Happy Family: Lucy Bowes and Mona Bekkhus}

Research suggests that the family plays a central role for child well-being. Family relationships in general and parent child relationships in particular influence multiple domains of child well-being, including psychological, social, and economic well-being (Sanders 1999). Overall, research suggests that secure attachment between children and their primary caregivers promotes well-being throughout the life-span (Bowlby 1969; Cohn et al. 1992; K. M. Love and Murdock 2004). Family relationships aside from that of the parent child dyad have also been shown to promote well-being, particularly in the context of risks to well-being. For example, sibling relationships characterized by high levels of warmth have also been found to promote more positive emotional and behavioral functioning among children exposed to peer victimization (Bowes et al. 2010; Cluver et al. 2010).

The structure of the family unit has been the focus of a body of research on child well-being. Compared to individuals from intact, biological families, numerous studies have found that children in step- and single-parent households score lower 
in terms of emotional, social, physical, and psychological well-being (Amato and Keith 1991; Magnuson and Berger 2009). The association between stepfamilies and poor well-being has been linked to children having less secure attachment with their parents compared to children from intact, biological families (Love and Murdock 2004).

Single parenthood has further been negatively associated with child well-being in some studies; however, this effect may be explained by the higher prevalence of poverty among single-parent families (Smith et al. 1997) and by reduced access to social support. Living with a grandparent has been found to reduce the impact of living in a single-parent family on children's well-being (Dunifon and Kowaleski-Jones 2002; Ruiz and Silverstein 2007). Children who experience multiple transitions in family structure may fare particularly poorly in terms of well-being, compared to children raised in stable, two-parent families and even children living in single-parent families. Further investigation of the possible mechanisms of this association revealed that much of the effect of multiple transitions could be explained by parent's preexisting behaviors and characteristics that increased their likelihood of separating from multiple partners (Fomby and Cherlin 2007).

Child well-being might also be influenced by the economic resources of the family. For example, low family income has been associated with low academic achievement, increases in socio-emotional problems, conduct problems, and teenage pregnancy (Dodge et al. 1994; Sampson and Laub 1987). It is thought that this effect can be explained by the increased strain financial pressures place on parenting (Conger et al. 1997) rather than a lack of material resources per se. In keeping with this suggestion, the effects of childhood poverty on health outcomes have been shown to be buffered by high maternal nurturance (Miller et al. 2011).

Identifying the mediating mechanisms through which family factors exert their influence on child well-being is clearly of fundamental importance. One important factor to consider is the direction of effects between family factors and children's well-being (Bell and Bell 1968). Children who are more happy and positive are likely to elicit more positive reactions from caregivers than children who are less so (Scarr and McCartney 1983). Longitudinal studies with repeated measures are needed to estimate the direction of effects between family factors and child wellbeing. Another important consideration is the risk of genetic confounding rather than true, environmentally mediated effects. Sensitive, warm parents may pass genes to their offspring associated with positive well-being. Indeed, this is somewhat likely given that the heritability estimates for measures of well-being are between $40 \%$ and $50 \%$ (Bartels and Boomsma 2009). That is, as much as one half of the variance in well-being measures may be accounted for by genetic factors. When investigating the mechanisms by which family factors may influence wellbeing, it is important to test for environmental mediation. This is because interventions designed to promote well-being among children are based on the assumption that the family factors targeted are causally related to well-being, not simply a result of confounding. 
In summary, families play a central role in child well-being. Of fundamental importance are positive, warm family relationships that help promote positive socio-emotional development and foster well-being. Economic or social factors that negatively impact on these relationships serve to reduce the likelihood of positive child development promoting child well-being.

\subsubsection{Happy Parenting: Bruce Headey, Ruud Muffels, and Gert G. Wagner}

National sample surveys of life satisfaction have been undertaken in all Western countries and many developing countries. In just a few of these surveys, parents and children from the same family have been interviewed. The largest such survey is the German Socio-Economic Panel, in which family members have been interviewed annually since 1984 (Wagner et al. 2007). The German data are unique in that they allow researchers to analyze not just the life satisfaction of parents and children living in the same home but also the long-term influence of parents on children who have grown up, left the parental home, and, in many cases, partnered themselves.

The German panel began with a sample of 12,541 individuals living in about 5,000 households. Everyone aged 16 and over is interviewed. The sample size has been boosted several times since 1984, and there are now over 60,000 respondents on file. "Children" continue to be interviewed even after they have left the parental home. As of 2008, there were 3,208 children for whom life satisfaction data were available both for them and their parents. Of these "children," 1,251 had left the parental home, the average age of the group being 30, with a range from 18 to 50 .

As well as life satisfaction, the questionnaire also includes variables which may account for interindividual differences in satisfaction: personality traits, normative values, a wide range of attitudes and behaviors, and recall data on parent child conflict.

Analyzing the German data, Winkelmann (2004) reported fairly strong correlations (around 0.350 .45 ) between the life satisfaction of parents and adolescent children living in the same household. These links were partly due to the personality traits of extroversion (sociable, outgoing) and neuroticism (emotional instability), both of which are about $50 \%$ genetic (Costa and McCrae 1991) (see also Sect. 20.4.5). Children whose parents were perceived as supportive had high levels of life satisfaction, whereas those who reported conflict with parents had lower levels (Aguche and Trommsdorff 2010). Interestingly, the satisfaction of parents and children covaried over time. When parents became more (or less) satisfied, so did their children.

Headey, Muffels, and Wagner (2012) focused on adult "children" who had left the parental home. They found that there were still substantial correlations (around 0.25 ) between parent and "child" satisfaction and that these linkages could not be accounted for solely by genetic personality traits. In searching for further explanations, they concentrated on normative values and behaviors known to be associated with life satisfaction (Diener and Seligman 2004; Headey et al. 2010; 
Nickerson et al. 2003). Adult children who shared their parents' commitment to altruistic values, and also to family values, were happier than those who, like their parents, gave priority to materialistic and career-oriented values. Behaviors modeled by parents, including active social and community participation and regular exercise, also helped to explain continuing positive associations between parent and "child" life satisfaction.

In line with much psychological theory about parenting, it was found that mothers had greater influence than fathers on the life satisfaction of both sons and daughters. Both parents appear to inculcate values and behaviors associated with happiness, but beyond that, the life satisfaction of mothers continues to directly affect their offspring (Headey et al. 2012).

Interestingly, the life satisfaction of adult "children" appears to have some influence on the satisfaction of their parents, as well as vice versa (Aguche and Trommsdorff 2010; Headey et al. 2012). In the German sample, fathers continued to be affected by the life satisfaction of their daughters, while mothers were being more affected by their sons' satisfaction levels.

The persistent influence of parents on the life satisfaction of their children well into adulthood suggests that "happy" parenting probably yields a lifelong happiness dividend, whereas unhappy parenting imposes long-term costs. In future work, it will be important to pinpoint other normative values, skills, and behaviors which parents may pass on to their children with lasting consequences for their well-being.

\subsubsection{Play: Anne Inger Helmen Borge}

Children play intensely and concentrated with their toys. Play and well-being are closely linked. Play and toys are essential ingredients for the developing child. In the British Museum, we can enjoy a collection of toys from Egypt dated 2,000 years BC. They created dolls of papyrus and made miniature elephant figures, horses, and soldiers with movable parts and mobile charts.

Caregivers have high knowledge about which toys go with which age (TamisLeMonda and Bornstein 1994). Adults create an optimal age-appropriate environment for play. Observation of the play environment indicates that it is very important for the child's well-being. Infants' synchronous imitation (mimicry) increases over the ages of 1628 months. Infants who invite adults to mimic increase their prosocial behavior and social competence (Fawett and Liszkowski 2012). A positive social connection is established between the child and the caregiver. The link between mimicry and well-being is mediated through positive family relationships. Thus, one should bear in mind that there is no direct causal link between play and well-being. Many other factors are involved. These factors are characteristics of the child (gender, temperament), family (harmony), and context (socioeconomic status). They will always influence play and contribute to whether or not the play will be associated with positive wellbeing. Children from abusing families engage in less child initiated play than 
neglecting and non-maltreating families (Valentino et al. 2011). These children have weak well-being and especially problems with peer relationships and social competence. Intervention efforts may improve and restore their well-being to acceptable levels.

In a study of preschool girls, measures of well-being and coping were significantly related to pretend play (Fiorelli and Russ 2012). Applying an "Affect in play scale" and a puppet play task, the girls were asked to suggest coping responses to potentially stressful situations. Imagination was frequently suggested as a coping mechanism related to their affect and emotional mood. Boys, on the other hand, who express greater affect in their play, had fewer complaints about pain and were less anxious than peers who did not invest affects in their play. For both girls and boys, a relationship exists between life satisfaction and positive affect and expressing more imagination and creativity in play.

Parents give boys and girls different toys. They expect children to show genderspecific play. The classic "baby X' experiment" (Smith and Lloyd 1978) illustrates why children get different life experiences. During 1 year, the children were dressed in flight suits and clothes that did not reveal their gender. They got typical boys and girls names, but, in half of the group, the name matched the gender in reality and, in the other half, it did not. Thus, the adults, who did not know this, were playing half of the time with children they thought were girls or boys. The results showed how adults treated even these very young children according to what they believed was their gender. In most cultures, parenting, play, and toys will be gender specific and reinforce cultural expectations to masculine and feminine behavior. Today, a risk to healthy development is not so much the gender issue but the decrease in free play and increase in passive entertainment by "intelligent baby television" or computer games for older children. Active, safe play should always be parallel to enriched academic stimulation.

Interestingly, today, cultures do not agree on the importance of pretend play for child well-being (Lancy 2007) and value pretending behavior differently. A recent survey (Singer et al. 2009) found that in only 5 of 16 countries, the majority of mothers reported that their child often participated in imaginative play. We need more knowledge about the association between variations in imagination and wellbeing. Methodological shortcomings are found in many studies, with different ways of defining well-being and imagination.

Play is like life and love, it cannot be easily defined. Krasnor and Pepler (1980) suggested four criteria in defining play, namely, flexibility, positive affect, nonliterality, and intrinsic motivation. Nonliterality refers to play behavior lacking its usual meaning while paradoxically retaining it (Lillard et al. 2013).

The criteria denote that play behavior can be exaggerated, fun, lack the usual meaning, and be an activity by choice for its own sake. Play can be solitary, peer related, free, or organized. During the first and second year, children's play can be categorized into three levels. The first level is dominated by exploratory activities, such as putting things into the mouth and manipulating toys. The second is nonsymbolic play. It comprises concrete and functional activities, such as playing with bricks. The third is symbolic play characterized by pretense 
and make-believe play. Thus, to understand variations among children in their wellbeing, there is a host of play types and psychological functions to choose among.

Among all the various levels, categories, and developmental stages of play behavior, pretend play has attracted much research attention (for review see Lillard et al. 2013). Pretend play is layered over reality. For example, a blanket over a table is a castle. Language development and play are associated, with pretend play preceding language (Lyytinen et al. 1997). Pretend play and constructs like coping ability, creativity, adjustment, and the regulation of emotions are related and demonstrated in several studies (Hoffmann and Russ 2012).

Few studies have directly examined the relationship between pretend play and SWB. The American Academy of Pediatrics has summarized the importance of play for promoting health. They suggest that play should be protected. They also underline the need to maintain strong bonds between parent and child. Time for free play has been reduced in many societies. Families and school systems have to assure that play is an important element in children's lives and to create an optimal developmental milieu (Ginsburg et al. 2007).

Play in general and pretend play in particular are central for the development of cognitive, social, and behavioral functions. Play has fascinated scientists for many decades. Vygotsky (1967) illustrated the importance of pretend play for cognitive development. For example, Vygotsky wrote that a banana could be a telephone showing that children could understand that actions and object can be separated from reality. The meaning of a given situation does not need to be based on the physical properties of objects. Jean Piaget's theory of cognitive development illustrates how the child through play assimilates reality to accommodate to new situations. Freud's theory is the basis of psychoanalytic play therapy. Children with social and mental problems reducing the quality of their well-being can be approached using dolls. Trivial and nonutilitarian, play and well-being are worthy of serious studies. It is an essential link in the developing child. Play or leisure activities and hobbies are strongly associated with SWB in all ages.

\subsubsection{Peer Relations: Anne Inger Helmen Borge}

Children's interactions with peers are free and based on their own choice of companion, compared to the interaction with their parents. The concept of "peer relations" covers a variety of relationships such as friendships, best friends, schoolmates, cliques, and neighborhood gangs that are examples of different contexts of peer relations (Bukowski et al. 1996; Schneider 2000).

Peer relations are an important part of children's positive adjustment and wellbeing. Even from the first years of life, infants form relations with other infants and toddlers. It is fascinating to look at the first encounters of infants, enthusiastically crawling toward one particular child in their peer group. Why infants show this early preference for one child in particular among many peers is not known. But older children in preschool seem to select peers with similar personality characteristics as themselves (Howes 1978). In the family context, the first interactive social 
and psychological relationship with another child at about the same age occurs with a sibling (Dunn 2005). In kindergarten and elementary school, girls and boys themselves choose friends among their peers, which is different from the given family context with siblings or neighboring children.

Friendship is one of the most important types of peer relationships. Friendship plays a special role in developing social competence and well-being during the preschool years. In adolescence, peer relations play an important role in children's development and socialization and can be both good and bad for child well-being (Vitaro et al. 2009). Closeness, intimacy, and trust become crucial. For example, romantic relationships can be a mixed blessing for girls' and boys' well-being. Cultural factors, ethnicity, gender, and activities are central in acceptance or rejection of peers. The good relationships are characterized by inclusion, acceptance, and prosocial behavior. Bad peer relationships are typically illustrated by rejection, isolation, exclusion, and aggression (Vitaro et al. 2000). Peers bully other peers and victimization occurs. Not just any friend can foster resilience among victimized peers. A best friend with physical strength and aggressiveness can protect a victimized child against being bullied and cyber-bullied (Olweus 2012). Together with a best friend, the vulnerable friend will maintain self-esteem and protection from the social context.

Girls have, however, an even more nuanced perspective of peer problems than boys. The cost of such caring among girls may entail a risk of empathic distress and internalizing problems (Smith and Rose 2011). Consequently, peer relations are important for children's well-being but, in addition, can carry negative sides.

Today, researchers examine how and why children's experiences with their peers affect their well-being. What friends do to each other is predictively related to their emotional well-being. By studying twins not only one single child in a family researchers have documented a strong environmental risk for aggressive behavior. The risk lies in the role of the friends' aggression maintaining a child's own aggressive behavior, rather than in the child's genotype (Vitaro et al. 2011). Success in peer relations is a function of the child's companionships, his and her social competence, level of well-being, interpersonal skills, and culture.

In different cultures, urban and rural peers may differ in cooperation, prosocial behavior, and opposite-sex friendships. In Japan and Latino cultures, parental values may play a more central role for peer groups than in USA, Canadian, and European cultures (Hetherington et al. 2006). Affiliating boys showing antisocial behavior with prosocial children may balance the potential negative socializing impact of having only antisocial friends (Eivers et al. 2012). Behavior problems in early school years appear to lead to peer rejection, lack of friends, and reduced well-being. This, in turn, may lead to early adolescent depression and loneliness (Pedersen et al. 2007). It is not a new idea that one should target elementary school children's peer relations to prevent later well-being problems. In 1953, Harry Stack Sullivan proposed that "chumships" help children overcome negative parenting. Peers especially best friends might explain and discuss together in intimacy how a negative context influences their self-concept. In this way, a positive relational context with peers or best friends represents a strong link to SWB (Swartz et al. 2000). 
More importantly, in the context of SWB, it is too hard for some children to understand that another child may have a different view on things and a different SWB than he/she has him/herself. Together peers develop psychological competences such as trust, endurance, confidence, conflict management, emotional regulation, and theory of mind.

\subsubsection{Early Childhood Education and Care: Henrik Daae Zachrisson and Ratib Lekhal}

Early Childhood Education and Care (ECEC) is a standard term used by OECD. ECEC include all provision of childcare with an educational content prior to school entry. As we use the term here, it includes day care, center care, preschool, pre-k, and kindergarten. ECEC have been growing rapidly over the last few decades. Today, more than $80 \%$ of all children in the Western world experience some form of ECEC prior to school entry (UNICEF 2008). ECEC is therefore an important developmental context that affects children's short- and long-term development, especially for children at social risk (Shonkoff and Phillips 2000). Despite a vast body of research on ECEC and child outcomes, there is a scarcity of studies which explicitly assess its impact on children's well-being. Rather, researchers have addressed the impact of ECEC on cognitive and academic achievements, socioemotional development, and behavior. Until further, we therefore have to limit ourselves to consider these outcomes as proxies for children's well-being.

Early cognitive skills including language development may facilitate the child's well-being in multiple areas both in short term by providing the basis for more successful social interactions (Liiva and Cleave 2005) and in longer term by increasing the chances of academic success (Dickinson 2011). Evidence on the influence of ECEC on cognitive and language development stems both from experimental and observational nonexperimental studies. In general, small-scale randomized trials demonstrate that ECEC improves cognitive and language skills in young children and that although some of the effects are fading over time benefits persist (Barnett 2011). Larger-scale observational studies support this finding. For instance, findings from the USA the NICHD Study of Early Child Care and Youth Development (SECCYD) which is the most comprehensive observational study in this area demonstrate that compared to children not attending ECEC, those who attend perform better on tests in various cognitive domains throughout early childhood (NICHD 2006) and through early adolescence (Vandell et al. 2010). Comparable results are reported in several other countries, for instance, the UK (Melhuish et al. 2008) and Norway (Lekhal et al. 2010).

An important caveat is that the positive gains of ECEC on cognitive development are conditioned on quality of ECEC. Indeed, high quality is a prerequisite for good cognitive and language development in ECEC (NICHD and Duncan 2003). In general, quality refers both to structural features (e.g., sufficient number of staff and staff training, stimulating learning materials, and child group sizes) and process 
features (e.g., the sensitivity and stimulation in the interaction between the children and the staff) (Layzer and Goodson 2006).

As important as the potential of ECEC for improving cognitive and language development in all children, is its potential for closing gaps between children growing up in social disadvantage and their peers (Burger 2010). For instance, a Canadian observational study found social differences in school readiness but not for children at social risk who had attended early ECEC (Geoffroy et al. 2010). Again, quality matters; in the NICHD SECCYD, children from low-income families who had experiences of high-quality care performed almost as good as their more affluent peers through early school age, whereas those who had no experiences of high-quality care performed worse (Dearing et al. 2009). In sum, there is strong evidence that high-quality ECEC benefits children's cognitive and language development, especially among children at social risk, and therefore makes a positive contribution to children's short- and long-term well-being.

As is the case for cognitive and language development, also socio-emotional and behavioral development serve as a proxies for children's subjective well-being. Although children exhibiting high levels of externalizing problems (e.g., aggression and disobedience) may score high on well-being, such behaviors are associated with increased risk for peer rejection (for details, see Sect. 20.4.9). Internalizing problems (e.g., anxiety and depression), as well as children's social competence and peer relationships, are more directly related to their wellbeing, yet not conceptually equivalent. Compared to the impact of ECEC on children's cognitive development, its impact on socio-emotional and behavioral development has been somewhat more questioned.

Participation in ECEC, as compared to parental care or in some studies nonformal care (e.g., nanny), has in some studies been associated with higher levels of behavior problems (e.g., NICHD Early Child Care Network, 2006; Magnuson et al. 2007). These findings are, however, likely to be conditional upon the sociopolitical context (Love et al. 2003). For instance in Norway with its like the other Nordic countries comprehensive universal access ECEC policy, no differences in behavior problems are found between children attending ECEC compared to parental care (Lekhal 2012). The potential negative impact of infant care and of large quantities of care has been debated (Belsky 2001). Whereas infant care has in observational studies consistently been associated with higher levels of behavioral problems (NICHD 2003), a quasi-experimental study has demonstrated that entry into ECEC during the first 3 years of life is unrelated to child outcomes (Jaffee et al. 2011). Other recent studies taking stricter approaches to causal inference also fail to support the association between high quantities of ECEC and behavior problems (McCartney et al. 2010; Zachrisson et al. 2013).

As is the case for cognitive outcomes, children from disadvantaged families tend to benefit from participation in ECEC when compared to parental care also in the socio-emotional and behavioral domain. For instance, Canadian observational studies have found that children from low-income families, or children with loweducated mothers, who attended ECEC have lower risk of developing externalizing problems than do children cared for at home (Borge et al. 2004; Cote et al. 2007). 
Similar results have also been found with quasi-experimental study designs in the USA (Crosby et al. 2010). Again, quality tends to matter. High-quality ECEC predicts healthy socio-emotional development in US children from low-income families, ages 2 , and that more hours spent in childcare are associated with fewer behavior problems (Votruba-Drzal et al. 2010).

In sum, evidence for the influence of ECEC on children's socio-emotional and behavioral development is somewhat less conclusive than with regard to cognitive development. There is, however, fairly consistent evidence that children from disadvantaged backgrounds benefit from ECEC also in this domain.

There is an urgent need for studies on the influence of ECEC on child well-being. Considering other child outcomes as proxies for well-being, the literature is quite consistent in finding high-quality ECEC to improve development of language, learning, and cognitive skills, especially for children from disadvantaged families. The literature leaves us with less strong evidence to argue that ECEC improves socio-emotional and behavioral development for most children. However, there is also little evidence of deterioration. Children from disadvantaged backgrounds may benefit from ECEC also in the socio-emotional and behavioral domains. Given the current increasing political attention paid to the positive opportunities for children provided by high-quality ECEC in many countries, the question for future debates should be how children's well-being can be sustained while maintaining the educational benefits of ECEC.

\subsubsection{The School: Margaret M. Barry}

Schools are one of the most important settings for promoting the well-being of young people (WHO 2001). The influence of the health-promoting schools initiative (WHO 1998) has brought a focus on the school environment as well as the curriculum as an important determinant of positive youth development. Schools have an important function in nurturing children's social and emotional development as well as their academic and cognitive development. The importance of both the hedonic and eudaimonic dimensions of well-being, including subjective emotional well-being and positive psychological and social functioning, is clearly embraced in current conceptualizations of positive mental health (Keyes 2007; Kovess-Masfety et al. 2005). Enhancing children's positive mental health and well-being improves their ability to learn and to achieve academically as well as their capacity to become responsible adults and citizens (Greenberg et al. 2003; Payton et al. 2008; Weissberg et al. 1991; Zins 2004). This section addresses how schools can promote and strengthen children's emotional, social, and mental wellbeing.

There is a growing body of international evidence that interventions which seek to promote young people's emotional and social well-being in schools, when implemented effectively, can produce long-term benefits for young people. These benefits include emotional and social functioning, improved academic performance, reduced school drop-out rates, and a range of health and social outcomes 
(Durlak et al. 2011; Durlak and Wells 1997; Greenberg et al. 2001; Harden et al. 2001; Lister-Sharp et al. 1999; Payton et al. 2008; Weare and Nind 2011; Wells et al. 2003; Wilson et al. 2001). The evidence indicates that long-term interventions promoting the positive mental health and well-being of all pupils and involving changes to the school environment are likely to be more successful than brief classroom-based prevention programs (Barry and Jenkins 2007; Jané-Llopis et al. 2005; Weare and Nind 2011; Wells et al. 2003).

A number of successful universal school-based programs have employed cognitive and social skills training in promoting children' social and emotional competencies (Aber et al. 1998; Bruene-Butler et al. 1997; Clarke and Barry 2010; Greenberg et al. 2001; Greenberg et al. 1995; Kellam et al. 1994; Mishara and Ystgaard 2006). Many of these programs have been evaluated using randomized controlled trials and have been replicated with a wide range of children in different school settings across countries.

Payton and coworkers (2008) report strong and consistent support for the value of social and emotional learning programs (SEL) when implemented by school staff, with research showing their sustained positive impact on multiple outcomes for diverse groups of students. Based on a meta-analysis of 213 universal schoolbased interventions involving 270,034 school children age 513 years, Durlak and colleagues (2011) reported the following significant positive effects for children participating in SEL programs: enhanced social and emotional skills (mean ES = 0.57); improved attitudes toward self, school, and others (mean $\mathrm{ES}=0.23$ ); enhanced positive social behavior (mean $\mathrm{ES}=0.24$ ); reduced conduct problems, misbehavior, and aggression (mean $\mathrm{ES}=0.22$ ); and reduced emotional distress, stress, and depression (mean ES $=0.24$ ). The review also found that in addition to improving students' social and emotional skills, SEL programs significantly improved children's academic performance (mean ES $=0.27$ ), with an average gain on standardized achievement test scores of 11 percentile points. It is interesting to note that only when delivered by school staff do students' academic performance improve significantly (Payton et al. 2008).

An example of a SEL program that has been implemented globally is Zippy's Friends, which is a universal emotional well-being school-based program for children age between 5 and 8 years of age (Bale and Mishara 2004). To date, the program has been evaluated in Canada, Denmark, Ireland, Lithuania, Norway, and the UK with key findings indicating significant positive effects on children's coping strategies, emotional literacy, social skills, reduced hyperactivity, and externalizing behaviors (Clarke 2011; Clarke and Barry 2010; Holen et al. 2012a; b; Holmes and Faupel 2005; Mishara and Ystgaard 2006). Evaluating the implementation of the Zippy's Friends program for school children in disadvantaged schools in Ireland revealed the importance of contextual factors operating in the whole-school environment, which can impact and influence program implementation and ultimately program outcomes (Clarke 2011; Clarke et al. 2010).

Characteristics of effective interventions include a focus on enhancing generic life skills and competencies and positive mental health, use of interactive teaching methodologies, balancing universal and targeted approaches, starting early with the 
youngest children, programs implemented continuously and long term in nature, embedding the work within a health-promoting whole-school approach focusing on the social and physical environment of the school, as well as family and community links with the schools and the school curriculum and pupils' knowledge (Barry and Jenkins 2007; Green et al. 2005; Weare and Nind 2011).

The evaluation of SEL programs highlights the need for supportive organizational and system-level practices and policies to ensure the sustainable implementation and integration of effective interventions. The importance of organizational-level change, including the school culture, environment, and school practices, is recognized as being critical for effective implementation and sustainability (Bumbarger and Perkins 2008; Durlak and DuPre 2008; Rowling 2008).

School-based interventions adopting a whole-school approach seek to enhance the social and emotional well-being and positive life skills of pupils and work to create supportive environments that foster positive youth development and a sense of connectedness with the family, community, and broader social context of young people's lives (Rowling et al. 2002). Interventions employing a comprehensive whole-school approach are designed to impact at the level of the individual pupil, the classroom, and the school as a whole. Review evidence supports the effectiveness of school-based interventions that take a whole-school approach (Lister-Sharp et al. 1999; Weare and Nind 2011; Wells et al. 2003). Examples of whole-school approaches that have been implemented successfully include the Australian MindMatters program (Wynn et al. 2000) and the Olweus Bullying Prevention Program (Olweus et al. 1998). While evidence relating to interventions that adopt a truly whole-school approach (i.e., include all elements) is quite limited, those that have been identified provide indication of a positive impact, with small to medium effect sizes being reported on outcome measures (Adi et al. 2007).

A review of the cost-effectiveness of whole-school approaches by McCabe (2007) suggests that interventions of this type can lead to health, academic, and social gains, which lead to savings for health and social services and for the criminal justice system. Lack of investment in promoting children's emotional and social well-being in schools is likely to lead to significant costs for society as young people who experience emotional and social problems are more likely, at some point, to misuse drugs and alcohol, to have lower educational attainment, and to be untrained, unemployed, and involved in crime.

The evidence attests to the value of interventions which promote the emotional and social well-being of young people in the school context. There is a need to integrate efforts to promote social and emotional well-being of young people with the school's educational mission of academic learning. This requires leadership at the policy and school level, together with the engagement of pupils, teachers, families, and local communities. Supportive policies and effective partnerships across the education and health sectors are needed to ensure the establishment of system-level practices that will support the sustainable integration and promotion of children's well-being in the school setting and ensure its long-term impact. 


\subsection{Application}

\subsubsection{Five Ways to Well-Being: Ragnhild Bang Nes and Nic Marks}

How do we practically promote well-being, build competence, enhance optimal functioning, and stimulate flourishing in children? A number of child-centered interventions have been developed in recent years. Many of these efforts reflect a movement within the health services toward more affirming and strength-building approaches, commonly emphasizing primary prevention and competence promotion.

Promotion of well-being and positive mental health constitutes an integral part of improving overall population health. There is a growing realization that wellbeing interventions which can be implemented and sustained at a reasonable cost will contribute substantially to better health and social gains for the population at large, thus representing a strong case for policy investment (Barry and Friedli 2008; WHO 2004). Childhood is commonly regarded as the optimal time to promote healthy attitudes and behavior as positive adaptation at one developmental stage is likely to provide a foundation for successful encounters also at subsequent stages, building enduring personal resources (1998, 2001). Practical applications of "positive psychology" are thus likely to be most efficacious when initiated early and when they are maintained over time. Not surprisingly, the public policy context has recently seen a surge of interest in psychological wellbeing. In the UK, National Children's Charities such as "The Children's Society" and "Action for Children" have also advocated policy changes in this realm. The Children's Society have researched and widely campaigned about the need for better measures of childhood well-being (http://www.childrenssociety.org.uk/ what-we-do/research/well-being/publications). Action for Children has made a detailed economic case for a more preventative approach to children's services (http://www.actionforchildren.org.uk/policy-research/policy-priorities/ backing-the-future).

A considerable number of interventions have been developed to promote positive mental health during childhood, for example, by means of promoting socioemotional competence in both parents and children (Barry 2013). There is no generalized empirical evidence of the efficacy of many of these interventions, but systematic reviews, effectiveness studies, and meta-analyses generally support the value of programs and interventions that promote positive mental health (Seligman et al. 2005; Sin and Lyubomirsky 2009). Additionally, experimental and clinical research has shown that various intervention tools (e.g., mindfulness-based approaches) simultaneously increase well-being and reduce symptoms of depression (Fredrickson et al. 2008).

In the following, we will focus on the program Five Ways to Well-Being (http://www.neweconomics.org/sites/neweconomics.org/files/Five Ways to Wellbeing Evidence 1.pdf). This program illustrates the potential to intervene around the same goal well-being across different sectors (e.g., health, education) at different levels, including individual children and parents, youth groups, kindergartens, 
schools, communities, and organizations, and at a strategic policy level across the lifespan. The Five Ways to Well-Being were originally designed by the new economics foundation (nef), a London-based think tank, who have conducted considerable research into well-being policy over the last decade. In 2008, the UK Government Office of Science commissioned a comprehensive and wide-ranging review of the academic literature on well-being as part of its 2008 Foresight program. Five Ways to Well-Being drew on the extensive evidence unearthed during the Foresight review as well as the wider literature on positive psychology. The main task was to create a short list of positively framed actions that target individuals of all ages and are universally applicable and evidence based and which individuals may build into their daily lives. The five action dimensions were intended to constitute a simple and accessible means of communicating the extensive recent evidence about specific activities that can improve and maintain mental health and well-being. The actions thus mainly influence well-being and mental capital by interacting at the level of "functioning." The five ways are the following:

Connect! Build social relationships and spend time with friends and family. There is extensive evidence that our social relationships are critical to our wellbeing (e.g., Seligman et al. 2005; Sin and Lyubomirsky 2009).

Be active! Engage in regular physical activity which is, for example, associated with lower rates of depression across all age groups and with better cognition in children (e.g., Fox 1999; Penedo and Dahn 2005).

Take notice! Be mentally "present" and focus on awareness and appreciation. Research, particularly on mindfulness and mediation, has been shown to have positive effects on children's well-being (Burke 2010).

Keep learning! Maintain curiosity about the world and try new things. Being willingly engaged with learning processes is good for people's cognitive and social skills as well as self-confidence and competency (e.g., Ryan and Deci 2000).

Give! Make a positive contribution to the lives of others. Neuroscience has shown that reward areas of our brain are stimulated when we engage in mutually cooperative actions and actions such as volunteering and helping others (e.g., Harbaugh et al. 2007).

The Five Ways to Well-Being are intended to be positive and engaging, flexible, non-prescriptive, empowering, participative, and collaborative, yet firmly grounded in extensive scientific evidence. Since launching in 2008, groups as diverse as general practitioners and other health-care professionals, mental health commissioners, arts practitioners, faith groups, community and voluntary organizations, and local authority departments have incorporated the Five Ways to Well-Being in their work. Strikingly, the range of uses has been broad, going well beyond just thinking of the Five Ways to Well-Being as a set of health promotion messages.

The Five Ways to Well-Being were not designed specifically with children in mind, and there has been no systematic measurement of their impact on children's well-being, but they are evidence-based actions resting on a substantial empirical foundation which indicate that incorporation of more Five-Ways-type activities into daily lives will improve well-being. In 2011, nef was commissioned by the UK's National Health Service Confederation and the National Mental Health 
Development Unit to systematically explore how different groups had used the Five Ways to Well-Being. Two primary dimensions were identified, the first being the point of intervention (i.e., individuals, groups, and/or strategic level) and the second principal purpose (i.e., increase well-being directly or indirectly). Several Five Ways projects, both small and large scale, have now been introduced in different countries. For example, a Five Ways to Well-Being project has recently been launched in 1600 Norwegian kindergartens, inviting 70000 children and their parents (http://www.psykiskhelse.no/index.asp?id=31627). Another project invited children (aged 5 11) from four primary schools in North of England. The latter project involved children throughout every stage of the production of a book called "Wit Wolf's Journey to Happiness." The story is retelling the well-known children's fairy tale about Little Red Riding Hood and the Wolf, and each subplot was based around one of the five ways (http://www.stockport-academy.org/upload/ files/newsletter march 2010.pdf).

These recent projects involve the children in the design of specific projects and interventions, working with them as "facilitators" of coproduced solutions. However, the focus of interventions need not be the individual. There is considerable scope for using the Five Ways to Well-Being to improve children's well-being in more strategic and indirect ways, both in terms of affecting the wider contexts in which children live to promote well-being and by informing processes and ways of living more generally.

\subsubsection{A Guide to Findings on Children's Happiness in the World Database of Happiness: Ruut Veenhoven}

The World Database of Happiness (Veenhoven 2012f) is a findings archive. That is, a collection of observations that result from scientific empirical research. The database focuses on research findings on happiness in the sense of subjective enjoyment of life. Its goal is to facilitate accumulation of knowledge on this subject.

The database consists of several collections. It builds on a collection of all scientific publications about happiness, called the "Bibliography of Happiness" (Veenhoven 2012a). To date this collection includes some 7,000 books and articles, of which half report an empirical investigation that used an acceptable measure of happiness, listed in the collection "Measures of Happiness" (Veenhoven 2012e). The findings yielded by some 3,500 studies that past this test for adequate measurement of happiness are described on separate "finding pages," using a standard format and a standard terminology. Two kinds of findings are discerned: distributional findings on how happy people are at a particular time and place and correlational findings about the things that go together with more or less happiness in these populations.

To date the database contains about 8,000 distributional findings, of which 5,000 on happiness in the general population of nations (Veenhoven 2012c) and 3,000 on happiness in particular social categories, such as students or psychiatric patients (Veenhoven 2012d). 
The collection "correlational findings" (Veenhoven 2012b) contains some 15,000 research results. These findings are sorted by subject, such as "Happiness and Age" and "Happiness and Income." The collection can also be searched on characteristics of the population investigated, that is, population, place, and time, and on methodological features such as sampling and measurement. Though far from complete, this is the best available source on conditions for happiness at present.

The database is free available on Internet at http://worlddatabaseofhappiness. eur.nl A detailed description is found with Veenhoven (2011).

The Bibliography of Happiness involves a detailed subject classification, among which a classification of populations studied. Part of that categorization is a distinction of age groups in which happiness is assessed, which is presented in Table 20.1. The numbers at the right in Table 20.1 refer to the number of publications. To date (November 2012) the Bibliography lists 290 publications in which the happiness of children is addressed. Most of these (178) are among adolescents, but there are also quite some publications on happiness in basic school children (58) and a few on preschool children (6).

The numbers at the right in Table 20.1 link to a list on which these publications are described. An example of such a list is presented on Table 20.2, the 6 publications on happiness in preschool children. For each publication, the usual bibliographic signature is given: author, title, source of publication, and year of publication. When possible links to the full text are added, use either the DOI links or a link to a Web site where the publication is available. If the publication involves research findings that are included in the findings collections of the World Database of Happiness, a link to the extracted findings pages is also added (WDH).

Investigations that used at least one acceptable measure of happiness are described on a "study page," and one of the descriptors is the "population" concerned. Populations can be "general" or "special"; the general population is all people living in a particular area at a certain time and special populations are particular kinds of people, such as intellectuals, homemakers, or people in certain ages. Studies among children are considered to concern a "special public" and classified under "age groups." For particular kinds of children, such as gifted children, additional classifications are made.

An overview is presented on Table 20.3. The number of studies mentioned in Table 20.3 is much lower than the number of publications in Table 20.1. One reason is that not all publications report an empirical investigation that used an acceptable measure of happiness. Another reason is that about half of the accepted studies is still waiting to be entered in the findings collections.

Each of these studies is described on a "study page" using a standard format and a standard terminology. The page starts with a short description of the investigation, which involves detail about the people investigated, the way of data gathering, and the measure of happiness used. On the page are links to further pages on which the findings are reported. An example is presented on Table 20.4.

Happiness is defined as "the enjoyment of one's life as a whole." Since this is something people have in mind, it can be measured using questions such as 
Table 20.1 Publications on happiness in age groups listed in the bibliography of happiness

\begin{tabular}{lr}
\hline Happiness in age groups & 5 \\
\hline In children & 40 \\
\hline Infants & 9 \\
\hline Preschool children & 6 \\
\hline Basic school children & 53 \\
\hline High school pupils, adolescents & 178 \\
\hline Mentally retarded children & 4 \\
\hline In young adults & 15 \\
\hline In middle aged people & 10 \\
\hline In elderly people & 802 \\
\hline
\end{tabular}

Table 20.2 Some publications on happiness in preschool children listed in the bibliography of happiness

\begin{tabular}{ll}
\hline \begin{tabular}{l} 
Overview of publications on happiness and preschool children \\
\hline Additional keywords:
\end{tabular} & Kindergarten, toddler \\
\hline Author(s) & Fekkes, M.; Brugman, E.; Theunissen, N.C.; Veen, S. \\
\hline Title & $\begin{array}{l}\text { Development and psychometric evaluation of the TAPQUOL: } \\
\text { a health related quality of life instrument for 1 5 year old } \\
\text { children }\end{array}$ \\
\hline Source & Quality of life research, 2000, Vol. 9, 961 972 \\
\hline Year & 2000 \\
\hline DOI link & DOI:10.1023/A:1008981603178 \\
\hline ISSN & 0962 9343 \\
\hline Author(s) & Henggeler, S.W.; Borduin, C.M. \\
\hline Title & $\begin{array}{l}\text { Satisfied working mothers and their preschool sons: interaction } \\
\text { and psychosocial adjustment. }\end{array}$ \\
\hline Source & Journal of Family Issues, 1981, Vol. 2, 322 335 \\
\hline Year & 1981 \\
\hline ISSN & $0192513 X$ \\
\hline WDH excerpt & HENGG 1981/1 HENGG 1981/2 \\
\hline Etc................ & \\
\hline Number of publications: & $\mathbf{6}$ \\
\hline
\end{tabular}

"Taking all together, how satisfied or dissatisfied are you with your life as a whole these days? Please rate with a number between 0 and 10, where 0 stand for extremely dissatisfied and 10 for extremely satisfied." Such questions are commonly used in surveys of the general population, some of which consider people from age 12 on. Questions of this kind are also being used in studies among adolescents. Such questions are classified as pertaining to "overall" happiness in the collection "Measures of Happiness" and coded "O."

The answering of these questions requires that the respondent has formed an idea about "overall satisfaction" and "life as a whole" and this is typically not the case with young children. Still school-age children do mostly have an idea of how happy 
Table 20.3 Links to findings on happiness of children in the collection of "Happiness in Publics"

\begin{tabular}{lr}
\hline$\oplus$ AGE groups & \\
\hline$\ominus$ AGE groups & 6 \\
\hline Infants & 21 \\
\hline Toddlers & 81 \\
\hline Basic school children & \\
\hline Teens, adolescents & 1 \\
\hline Etc............ & \\
\hline$\oplus$ CHILDREN & 2 \\
\hline CHILDREN & 2 \\
\hline Children living with single parent & \\
\hline Gifted children & Handicapped children \\
\hline Twins & \\
\hline Children of divorce & \\
\hline
\end{tabular}

Table 20.4 Example of a "study page" in collection of "Happiness in Publics" classified as regarding "children"

\begin{tabular}{ll}
\hline Investigation & Holder, M.D.; Coleman, B.; Wallace, J.M. \\
\hline $\begin{array}{l}\text { Author(s) } \\
\text { Title }\end{array}$ & $\begin{array}{l}\text { Spirituality, Religiousness, and Happiness in } \\
\text { Children aged } 812 \text { Years }\end{array}$ \\
\hline Public & 812 aged children, 2 schools, Canada \\
\hline Happiness measure used & A AOL g sq f 7 a, responses \\
\hline Happiness measure used & A AOL g rdf f 7 a, responses \\
\hline Correlational findings & \\
\hline How author named it & Our subject classification \\
\hline Activity & Active \\
\hline Communal spirituality & Perceived quality of intimate ties \\
\hline Emotionality & Emotional \\
\hline Environmental spirituality & Ecological values \\
\hline Gender & Sex (male vs. female) \\
\hline Parent rating of child happiness & Rating of happiness by parents \\
\hline Etc................ &
\end{tabular}

they "feel" most of the time, and at least from age 8 on, they appear to be able to respond to questions on that matter in a consistent way (VanVaalen 2011). Such questions tap what is called the "affective component" of happiness and are coded "A" in the collection Measures of Happiness.

Younger children are less able to estimate how well they feel most of the time but are still able to report how they feel at the moment. Therefore their happiness can be measured using multi-moment assessment, such as by repeatedly asking 
Table 20.5 Example of a distributional finding on happiness in children

\begin{tabular}{|c|c|}
\hline \multicolumn{2}{|c|}{ Happiness measure used in study HOLDE 2010} \\
\hline Full text & $\begin{array}{l}\text { Self report on single question: "Overall how do you usually feel?" } \\
\text { Rated on seven step faces scale ranging from sad to happy, without } \\
\text { verbal or numerical labels }\end{array}$ \\
\hline Classification & A AOL g sq f 7 a \\
\hline Focus & Affect: average overall level \\
\hline Time frame & Generally \\
\hline Mode & 1 question \\
\hline Scale type & Faces scale, range 7 \\
\hline Author's label & Faces scale \\
\hline Public & 812 aged children, 2 schools, Canada \\
\hline Page in source & 135,138 \\
\hline \multicolumn{2}{|l|}{ Distribution of happiness } \\
\hline$\%$ score 1 & 0 \\
\hline$\%$ score 2 & 0 \\
\hline$\%$ score 3 & 3 \\
\hline$\%$ score 4 & 7 \\
\hline$\%$ score 5 & 19 \\
\hline$\%$ score 6 & 47 \\
\hline$\%$ score 7 & 24 \\
\hline \% Don't know, No answer & 0 \\
\hline Mean on original scale & 5.82 \\
\hline Mean on scale 010 & 8.03 \\
\hline $\begin{array}{l}\text { Standard deviation on } \\
\text { original scale }\end{array}$ & 0.97 \\
\hline $\begin{array}{l}\text { Standard deviation on scale } \\
010\end{array}$ & 1.62 \\
\hline
\end{tabular}

"How happy do you feel right now?" Such repeated single questions are coded A-ARE for "Affect-Average Repeated Estimates" in the collection "Measures of Happiness."

Very young children, such as toddlers, cannot even report how they feel at the moment, and their affect level must therefore be inferred from behavioral indications, such as frequency of crying and facial expression. Measures of this kind are coded A-CA, for Affect- $C$ heerful Appearance. Such rating can be made by trained observers or by teachers and parents.

Studies on happiness in children that used acceptable measures are listed in the collection of "Happiness in Publics," in the section "Happiness in Age Groups," subsection "children." See Table 20.3. Scrolling these studies, one can see which particular measures have been applied as yet.

Each of the findings obtained in studies that used an acceptable measure of happiness is described on a separate "finding page." Findings on how happy children are are noted together with full detail about the measure used. An example of such a page is presented on Table 20.5. 
Table 20.6 Example of a correlational finding on happiness in children

\begin{tabular}{|c|c|c|}
\hline Study & & HOLDE 2010 \\
\hline Author(s) & & Holder, M.D.; Coleman, B.; Wallace, J.M. \\
\hline Title & & $\begin{array}{l}\text { Spirituality, religiousness, and happiness } \\
\text { in children aged } 812 \text { Years }\end{array}$ \\
\hline Source & & $\begin{array}{l}\text { Journal of Happiness Studies, 2010, } \\
\text { Vol.11, } 131150\end{array}$ \\
\hline $\mathrm{DOI}$ & & DOI:10.1007/s1090200891261 \\
\hline Public & & 812 aged children, 2 schools, Canada \\
\hline Sample & & Non probability purposive sample \\
\hline Nonresponse & & 11 \\
\hline Respondents $N$ & & 320 \\
\hline \multicolumn{3}{|l|}{ Correlate } \\
\hline Author's label & & Parent rating of child happiness \\
\hline Page in source & & 138 \\
\hline Our classification & & $\begin{array}{l}\text { Rating of happiness by parents, code } \\
\text { H8.2.1 }\end{array}$ \\
\hline Operationalization & & $\begin{array}{l}\text { Overall how does your child usually feel? } \\
\text { Rating by parents in response to single } \\
\text { question: } \\
1 \text { sad face } \\
2 \\
3 \\
4 \\
5 \\
6 \\
7 \text { happy face } \\
\text { Seven faces presented ranging from sad to } \\
\text { happy, without verbal or numerical labels }\end{array}$ \\
\hline Observed distribution & & $\mathrm{M} \quad 5,74, \mathrm{SD} \quad 0.77$ \\
\hline Remarks & & $\begin{array}{l}\text { Assessed } 10 \text { days before children rated } \\
\text { their happiness }\end{array}$ \\
\hline \multicolumn{3}{|c|}{ Observed relation with happiness } \\
\hline Happiness measure & Statistics & Elaboration/remarks \\
\hline A AOL g sq f 7 a & $\mathrm{r} \quad+.35 p<.05$ & $\begin{array}{l}\text { Child's self rating of happiness on the } \\
\text { same scale }\end{array}$ \\
\hline
\end{tabular}

These pages can be assessed in several ways. One way is through the "study pages" listed in the collection of findings on "Happiness in Publics." The finding pages can also be accessed through the collection of findings on "Happiness in Nations." Select a nation and an overview of findings in that nation will appear. Select "distributional findings" and next under "special publics" the category "age group" and within that category the subcategory "children."

To date (November 2012) $n$ option for comparison of average happiness in children across nations is in preparation. As yet, most of these data concern adolescents. 
Correlational findings are also presented on a "finding page," an example of which is presented on Table 20.6. On top of this page is a description of the "study," with reference to the publication in which the finding was reported and a short description of the investigation. Next on the page is a description of the "correlate." That is, the factor of which the relationship with happiness was investigated, in this case the parents' estimate of how happy their child is. At the bottom of the real finding, in this case, a surprisingly low correlation with the child's own rating of how happy it feels most of the time.

On the Web site of the World Database of Happiness are instructions for adding findings to the archive.

Acknowledgements We are grateful to Mette Lemser who assisted in the technical editing of this chapter and to Jeanette Ziehm, Hannah Meurer, Evelyn Raichle, and Holly Bunje for their valuable assistance with the section on "Subjective Well Being in Children and Adolescents from a Cross Cultural Perspective" (20.4.1).

\section{References}

Aber, J. L., Jones, S. M., Brown, J. L., Chaudry, N., \& Samples, F. (1998). Resolving conflict creatively: Evaluating the developmental effects of a school based violence prevention pro gram in neighborhood and classroom context. Development and Psychopathology, 10(2), 187 213. doi:10.1017/s0954579498001576.

Achenbach, T. M. (1991). Manual for the child behavior checklist/4 18 and 1991 profile. Bur lington, VT: Department of Psychiatry, University of Vermont.

Acquadro, C., Berzon, R., Dubois, D., Leidy, N. K., Marquis, P., Revicki, D., \& Grp, P. R. O. H. (2003). Incorporating the patient's perspective into drug development and communication: An ad hoc task force report of the patient reported outcomes (PRO) harmonization group meeting at the Food and Drug Administration, February 16, 2001. Value in Health, 6(5), 522531. doi:10.1046/j.1524 4733.2003.65309.x.

Adamson, P. (2007). Child poverty in perspective: an overview of child well being in rich countries: A comprehensive assessment of the lives and well being of children and adolescents in the economically advanced nations. Florence, Italy: UNICEF Innocenti Research Centre.

Adelman, H. S., Taylor, L., \& Nelson, P. (1989). Minora dissatisfaction with their life circum stances. Child Psychiatry and Human Development, 20(2), 135 147. doi:10.1007/bf00711660.

Adi, Y., Killoran, A., Janmohamed, K., \& Stewart Brown, S. (2007). Systematic review of the effectiveness of interventions to promote mental wellbeing in children in primary education: Report 1: Universal approaches. Non violence related outcomes. London: NICE (National Institute for Health and Clinical Excellence.

Agache, A., \& Trommsdorff, G. (2010, June 30 July 1). Transmission of well being between mothers, fathers and adolescent children: the role of parenting and personality factors, 9 th International German Socio Economic Panel User Conference.

Ahern, N. R., Kiehl, E. M., Sole, M. L., \& Byers, J. (2006). A review of instruments measuring resilience. Issues in Comprehensive Pediatric Nursing, 29(2), 103125.

Amato, P. R., \& Keith, B. (1991). Parental divorces and the well being of children a metaanalysis. Psychological Bulletin, 110(1), 26 46. doi:10.1037/0033 2909.110.1.26.

Andelman, R. B., Attkisson, C. C., Zima, B. T., \& Rosenblatt, A. B. (1999). Quality of life of children: Toward conceptual clarity. In M. E. Maruisch (Ed.), The use of psychological testing for treatment planning and outcomes assessment. London: LEA.

Andrews, F. M., \& Withey, S. B. (1976). Social indicators of well being. New York: Plenum Press. 
Angold, A., Messer, S. C., Stangl, D., Farmer, E. M. Z., Costello, E. J., \& Burns, B. J. (1998). Perceived parental burden and service use for child and adolescent psychiatric disorders. American Journal of Public Health, 88(1), 75 80. doi:10.2105/ajph.88.1.75.

Aristotle. (1996). Nicomachean ethics (W. D. Ross, Trans): Wordsworth Editions Limited.

Bakermans Kranenburg, M. J., \& van Ijzendoorn, M. H. (2011). Differential susceptibility to rearing environment depending on dopamine related genes: New evidence and a meta analysis. Devel opment and Psychopathology, 23(1), 3952.

Bale, C., \& Mishara, B. (2004). Developing an international mental health promotion programme for young children. International Journal of Mental Health Promotion, 6(2), 1216.

Bălţătescu, S. (2006). Comparative results and psychometric properties of the Personal Well Being Index Romania (old and new versions) with an adolescent sample a preliminary analysis. Retrieved from http://www.sergiubaltatescu.info/content/comparativePWI website.

Barnett, W. S. (2011). Effectiveness of early educational intervention. Science, 333(6045), 975978.

Barry, M. M. (2013). Promoting positive mental health and well being: Practice and policy. In C. L. M. Keyes (Ed.), Mental well being: International contributions to the study of positive mental health. Netherlands: Springer.

Barry, M. M., \& Friedli, L. (2008). The influence of social, demographic and physical factors on positive mental health in children, adults and older people. Foresight Mental Capital and Wellbeing Project. State of Science Review. SR B3. London, UK: Government Office of Science and Innovation.

Barry, M. M., \& Jenkins, R. (2007). Implementing mental health promotion. Edinburgh: Churchill Livingstone.

Bartels, M., \& Boomsma, D. I. (2009). Born to be happy? The etiology of subjective well being. Behavior Genetics, 39(6), 605615.

Bauer, R. A. (1966). Social indicators. Cambridge, MA: MIT Press.

Beck, A. T., Rush, A. J., Shaw, B. F., \& Emery, G. (1979). Cognitive therapy of depression. New York: Guilford.

Beckett, C., Maughan, B., Rutter, M., Castle, J., Colvert, E., Groothues, C., \& Sonuga Barke, E. J. S. (2006). Do the effects of early severe deprivation on cognition persist into early adolescence? Findings from the English and Romanian adoptees study. Child Development, 77, 696711.

Bell, R. Q. (1968). A reinterpretation of the direction of effects in studies of socialization. Psychological Review, 75(2), 8195.

Belsky, J. (1997). Theory testing, effect size evaluation, and differential susceptibility to rearing influence: The case of mothering and attachment. Child Development, 68(4), 598600.

Belsky, J. (2001). Emanuel Miller Lecture Developmental risks (still) associated with early child care. Journal of Child Psychology and Psychiatry, and Allied Disciplines, 42(7), 845859.

Belsky, J., \& Pluess, M. (2009). Beyond diathesis stress: Differential susceptibility to environ mental influences. Psychological Bulletin, 135(6), 885908.

Belsky, J., Bakermans Kranenburg, M. J., \& van Ijzendoorn, M. H. (2007). For better and for worse: Differential susceptibility to environmental influences. Current Directions in Psycho logical Science, 16(6), 300 304. doi:10.1111/j.1467 8721.2007.00525.x.

Ben Arieh, A. (2000). Beyond welfare: Measuring and monitoring the state of children New trends and domains. Social Indicators Research, 52(3), 235 257. doi:10.1023/a:1007009414348.

Ben Arieh, A. (2001). Measuring and monitoring children's well being. Dordrecht: Kluwer.

Ben Arieh, A. (2005). Where are the children? Children's role in measuring and monitoring their well being. Social Indicators Research, 74(3), 573 596. doi:10.1007/s11205 004 46456.

Ben Arieh, A. (2008). The child indicators movement: Past, present, and future. Child Indicators Research, 1(1), 3 16. doi:10.1007/s12187007 90031.

Ben Arieh, A., \& Frones, I. (2007). Indicators of children's well being Concepts, indices and usage. Social Indicators Research, 80(1), 1 4. doi:10.1007/s11205006 9069 z. 
Benenson, J. F., Markovits, H., Roy, R., \& Denko, P. (2003). Behavioural rules underlying learning to share: Effects of development and context. International Journal of Behavioral Development, 27(2), 116 121. doi:10.1080/01650250244000119.

Berzon, R., Hays, R. D., \& Shumaker, S. A. (1993). International use, application and performance of health related quality of life instruments preface. Quality of Life Research, 2(6), 367368. doi:10.1007/bf00422214.

Bjorklund, D. F., \& Green, B. L. (1992). The adaptive nature of cognitive immaturity. American Psychologist, 47(1), 46 54. doi:10.1037/0003 066x.47.1.46.

Block, J. H. (1951). An experimental study of a topological representation of ego structure. Stanford University, US: Unpublished doctoral dissertation.

Bond, M. H., \& Lun, V. M. C. (2012). Citizen making: The role of national goals for socializing children: Manuscript submitted for publication.

Bond, M. H., Lun, V. M. C., \& Li, L. M. W. (2012). The role of secularism in values and engagement in religious practices for the life satisfaction of young people: The moderating role of national societal factors. In G. Trommsdorff \& X. Chen (Eds.), Values, religion, and culture in adolescent development (pp. 123 145). New York: Cambridge University Press.

Borge, A. I. H., Rutter, M., Cote, S., \& Tremblay, R. E. (2004). Early childcare and physical aggression: Differentiating social selection and social causation. Journal of Child Psychology and Psychiatry, 45(2), 367376.

Boseovski, J. J. (2010). Evidence for "Rose colored glasses": An examination of the positivity bias in young children's personality judgments. Child Development Perspectives, 4(3), 212218. doi:10.1111/j.1750 8606.2010.00149.x.

Bowes, L., Maughan, B., Caspi, A., Moffitt, T. E., \& Arseneault, L. (2010). Families promote emotional and behavioural resilience to bullying: Evidence of an environmental effect. Journal of Child Psychology and Psychiatry, 51(7), 809 817. doi:10.1111/j.1469 7610.2010.02216.x.

Bowlby, J. (1969). Attachment and loss. London: Hogarth Press.

Bradburn, N. M. (1969). The structure of psychological well being (Vol. 15). Chicago: Aldine.

Bradshaw, J., \& Hatland, A. (2006). Social policy, employment and family change in comparative perspective. Cheltenham: Edward Elgar.

Bronfenbrenner, U. (1979). The ecology of human development: Experiments by nature and design. Cambridge, MA: Harvard University Press.

Brookings, J. B., \& Serratelli, A. J. (2006). Positive illusions: Positively correlated with subjective well being, negatively correlated with a measure of personal growth. Psychological Reports, 98(2), 407 413. doi:10.2466/pro.98.2.407 413.

Bruene Butler, L., Hampson, J., Elias, M. J., Clabby, J., \& Schuyler, T. (1997). The 'Improving social awareness social problem solving' project. In G. W. Albee \& T. P. Gullotta (Eds.), Primary prevention works (Vol. 6). California: Sage.

Bukowski, W. M., Newcomb, A. F., \& Hartup, W. W. (1996). The company they keep: Friendships in childhood and adolescence. Cambridge: Cambridge University Press.

Bumbarger, B. K., \& Perkins, D. F. (2008). After randomised trials: Issues related to dissemination of evidence based interventions. Journal of Children's Services, 3(2), 5564.

Burgdorf, J., \& Panksepp, J. (2006). The neurobiology of positive emotions. Neuroscience and Biobehavioral Reviews, 30(2), 173187.

Burger, K. (2010). How does early childhood care and education affect cognitive development? An international review of the effects of early interventions for children from different social backgrounds. Early Childhood Research Quarterly, 25, 140165.

Burke, C. A. (2010). Mindfulness based approaches with children and adolescents: A preliminary review of current research in an emergent field. Journal of Child and Family Studies, 19(2), 133144.

Burt, S. A. (2009). Rethinking environmental contributions to child and adolescent psychopathology: A meta analysis of shared environmental influences. Psychological Bulletin, 135(4), 608637.

Campbell, A. (1976). Subjective measures of well being. American Psychologist, 31, 117124. 
Campbell, A., Converse, P., \& Rodgers, W. (1976). The quality of American life: Perceptions, evaluations, and satisfactions. New York: Russell Sage Foundation.

Cantril, H. (1965). The pattern of human concerns. New Brunswick, NJ: Rutgers University Press.

Carlo, G., Crockett, L. J., Randall, B. A., \& Roesch, S. C. (2007). A latent growth curve analysis of prosocial behavior among rural adolescents. Journal of Research on Adolescence, 17(2), 301 323. doi:10.1111/j.1532 7795.2007.00524.x.

Casas, F. (2000). Quality of life and the life experience of children. In E. Verhellen (Ed.), Fifth international interdisciplinary course on children's rights. Belgium: University of Ghent.

Casas, F. (2011). Subjective social indicators and child and adolescent well being. Child Indica tors Research, 4(4), 555 575. doi:10.1007/s12187 $0109093 \mathrm{z}$.

Casas, F., Figuer, C., Gonzalez, M., \& Malo, S. (2007). The values adolescents aspire to, their well being and the values parents aspire to for their children. Social Indicators Research, 84(3), 271 290. doi:10.1007/s11205007 91413.

Casas, F., Coenders, G., Cummins, R. A., Gonzalez, M., Figuer, C., \& Malo, S. (2008). Does subjective well being show a relationship between parents and their children? Journal of Happiness Studies, 9(2), 197 205. doi:10.1007/s10902 00790447.

Casas, F., Gonzalez, M., Figuer, C., \& Malo, S. (2009). Satisfaction with spirituality, satisfaction with religion and personal well being among spanish adolescents and young university stu dents. Applied Research in Quality of Life, 4(1), 23 45. doi:10.1007/s11482 0099066 x.

Casas, F., Coenders, G., González, M., Malo, S., Bertran, I., \& Figuer, C. (2011a). Testing the relationship between parent's and their own children subjective well being. Journal of Hap piness Studies, 13, 1031 1051. doi:10.1007/s10902 01193053.

Casas, F., Sarriera, J. C., Alfaro, J., González, M., Malo, S., Bertran, I., \& Valdenegro, B. (2011b). Testing the personal wellbeing index on 1216 year old adolescents in 3 different countries with 2 new items. Social Indicators Research, 105, 461482.

Casas, F., Coenders, G., Gonzáles, M., Malo, S., Bertran, I., \& Figuer, C. (2012a). Testing the relationship between parents' and their children's subjective well being. Journal of Happiness Studies, 13, 10311051.

Casas, F., González, M., Navarro, D., \& Aligué, M. (2012b). Children as advisers of their researchers: Assuming a different status for children. Child Indicators Research. doi:10.1007/s1218701291680.

Casas, F., Sarriera, J. C., Abs, D., Coenders, G., Alfaro, J., Saforcada, E., \& Tonon, G. (2012c). Subjective indicators of personal well being among adolescents. Performance and results for different scales in Latin language speaking countries: A contribution to the international debate. . Child Indicators Research, 5(1), 1 28. doi:DOI 10.1007/s12187 01191191.

Caspi, A. (2000). The child is father of the man: Personality continuities from childhood to adulthood. Journal of Personality and Social Psychology, 78(1), 158 172. doi:10.1037//0022 3514.78.1.158.

Caspi, A., Sugden, K., Moffitt, T. E., Taylor, A., Craig, I. W., Harrington, H., \& Poulton, R. (2003). Influence of life stress on depression: Moderation by a polymorphism in the 5 HTT gene. Science, 301(5631), 386389.

Cederblad, M. (2003). Från barndom till vuxenliv: En översikt av longitudinell forskning [Eng: From childhood to adulthood: An overview of longitudinal research]. Stockholm: Gothia.

Chang, P. C., \& Yeh, C. H. (2005). Agreement between child self report and parent proxy report to evaluate quality of life in children with cancer. Psycho Oncology, 14(2), 125134. doi:10.1002/pon.828.

Chen, H., Pine, D. S., Ernst, M., Gorodetsky, E., Kasen, S., Gordon, K., \& Cohen, P. (2012). The MAOA gene predicts happiness in women. Progress in Neuro Psychopharmacology \& Bio logical Psychiatry, 40, 122125.

Cherubini, J. (2009). Positive psychology and quality physical education. Journal of Physical Education, Recreation \& Dance, 80, 4247.

Cicchetti, D., \& Rogosch, F. A. (2012). Gene x environment interaction and resilience: Effects of child maltreatment and serotonin, corticotropin releasing hormone, dopamine, and oxytocin genes. Development and Psychopathology, 24(2), 411427. 
Clarke, A. M. (2011). An evaluation of the Zippy's Friends emotional wellbeing programme for primary schools in Ireland. (PhD Thesis), National University of Ireland Galway.

Clarke, A. M., \& Barry, M. M. (2010). An evaluation of the Zippy's friends emotional wellbeing programme for primary schools in Ireland. Retrieved from www.nuigalway.ie/hprc database.

Clarke, A. M., O’Sullivan, M., \& Barry, M. M. (2010). Context matters in programme implemen tation. Health Education, 110(4), 273293.

Cluver, L., Bowes, L., \& Gardner, F. (2010). Risk and protective factors for bullying victimization among AIDS affected and vulnerable children in South Africa. Child Abuse \& Neglect, 34(10), 793 803.doi:10.1016/j.chiabu.2010.04.002.

Coenders, G., Casas, F., Figuer, C., \& Gonzalez, M. (2005). Relationships between parents' and children's salient values for future and children's overall life satisfaction. a comparison across countries. Social Indicators Research, 73(2), 141 177. doi:10.1007/s11205 00432330.

Cohn, D. A., Cowan, P. A., Cowan, C. P., \& Pearson, J. (1992). Mothers and fathers working models of childhood attachment relationships, parenting styles, and child behavior. Develop ment and Psychopathology, 4(3), 417 431. doi:10.1017/s0954579400000870.

Conger, R. D., Conger, K. J., \& Elder, G. H. (1997). Family economic hardship and adolescent adjustment: Mediating and moderating processes. Consequences of growing up poor, 34 .

Costa, P. T., \& McCrae, R. R. (1991). The NEO PI R. Odessa, Fl.: PAR.

Cote, S., Tremblay, R. E., Nagin, D., Zoccolillo, M., \& Vitaro, F. (2002a). Childhood behavioral profiles leading to adolescent conduct disorder: Risk trajectories for boys and girls. Journal of the American Academy of Child and Adolescent Psychiatry, 41(9), 1086 1094. doi:10.1097/ 01.chi.0000020260.43550.79.

Cote, S., Tremblay, R. E., Nagin, D., Zoccolillo, M., \& Vitaro, F. (2002b). The development of impulsivity, fearfulness, and helpfulness during childhood: Patterns of consistency and change in the trajectories of boys and girls. Journal of Child Psychology and Psychiatry, and Allied Disciplines, 43(5), 609 618. doi:10.1111/1469 7610.00050.

Cote, S. M., Boivin, M., Nagin, D. S., Japel, C., Xu, Q., Zoccolillo, M., \& Tremblay, R. E. (2007). The role of maternal education and nonmaternal care services in the prevention of children's physical aggression problems. Archives of General Psychiatry, 64(11), 13051312.

Cramer, V., Torgersen, S., \& Kringlen, E. (2007). Socio demographic conditions, subjective somatic health, axis I disorders and personality disorders in the common population: The relationship to quality of life. Journal of Personality Disorders, 21(5), 552 567. doi:10.1521/ pedi.2007.21.5.552.

Cromwell, R. (2010). Being human: Human being. Manifesto for a new psychology. New York: iUniverse.

Crosby, D. A., Dowsett, C. J., Gennetian, L. A., \& Huston, A. C. (2010). A tale of two methods: comparing regression and instrumental variables estimates of the effects of preschool child care type on the subsequent externalizing behavior of children in low income families. Developmental Psychology, 46(5), 10301048.

Cummins, R. A. (1997). Comprehensive quality of life scale Student (Grades 7 12): ComQol S5 (5th ed.). Melbourne: School of Psychology, Deakin University.

Cummins, R. A. (2010). Subjective wellbeing, homeostatically protected mood and depression: A synthesis. Journal of Happiness Studies, 11(1), 1 17. doi:10.1007/s10902 00991670.

Cummins, R. A., \& Gullone, E. (2000). Why we should not use 5 point Likert scales: The case for subjective quality of life measurement. Proceedings Second International Conference on Quality of Life in Cities Singapore: National University of Singapore.

Cummins, R. A., Eckersley, R., van Pallant, J., Vugt, J., \& Misajon, R. (2003). Developing a national index of subjective well being: The Australian Unity Well being Index 64, 159 190. Retrieved from http://www.deakin.edu.au/research/acqol/instruments/ wellbeing index.htm website.

Currie, C., Zanotti, C., Morgan, A., Currie, D., de Looze, M., Roberts, C. Rasmussen, V. B. (2012). Social determinants of health and well being among young people. Health Behaviour in School aged Children (HBSC) study: international report from the 2009/2010 survey. 
In W. R. O. f. Europe (Ed.), Health Policy for Children and Adolescents (Vol. 6). Copenhagen: WHO Regional Office for Europe.

Davis, E., Davies, B., Waters, E., \& Priest, N. (2008). The relationship between proxy reported health related quality of life and parental distress: Gender differences. Child: Care, Health and Development, 34(6), 830 837. doi:10.1111/j.1365 2214.2008.00866.x.

De Neve, J. E. (2011). Functional polymorphism (5 HTTLPR) in the serotonin transporter gene is associated with subjective well being: Evidence from a US nationally representative sample. Journal of Human Genetics, 56(6), 456459.

Dearing, E., McCartney, K., \& Taylor, B. A. (2009). Does higher quality early child care promote low income children's math and reading achievement in middle childhood? Child Develop ment, 80(5), 13291349.

Deci, E., \& Ryan, R. M. (2012). Motivation, personality, and development within embedded social contexts: An overview of self determination theory. In R. M. Ryan (Ed.), The Oxford handbook of human motivation (pp. 85 107). Oxford: OUP USA.

DeNeve, K. M., \& Cooper, H. (1998). The happy personality: A meta analysis of 137 personality traits and subjective well being. Psychological Bulletin, 124(2), 197 229. doi:10.1037/0033 2909.124.2.197.

Dickinson, D. K. (2011). Teachers' language practices and academic outcomes of preschool children. Science, 333(6045), 964967.

Diener, E. (1984). Subjective well being. Psychological Bulletin, 95, 542575.

Diener, E. (2006). Guidelines for national indicators of subjective well being and ill being. Journal of Happiness Studies, 7, 397404.

Diener, E. (2012). New findings and future directions for subjective well being research. American Psychologist, 67, 590 597. doi:10.1037/a0029541.

Diener, E., \& Seligman, M. E. (2004). Beyond money: Toward an economy of well being. Psychological Science in the Public Interest, 5(1), 131.

Diener, E., Emmons, R., Larsen, R., \& Smith, H. L. (1985a). The satisfaction with life scale. Journal of Personality Assessment, 49(1), 7175.

Diener, E., Emmons, R. A., Larsen, R. J., \& Griffin, S. (1985b). The satisfaction with life scale. Journal of Personality Assessment, 49(1), 71 75. doi:10.1207/s15327752jpa4901 13.

Diener, E., Suh, E. M., Lucas, R. E., \& Smith, H. L. (1999). Subjective well being: Three decades of progress. Psychological Bulletin, 125(2), 276302.

Diener, E., Inglehart, R., \& Tay, L. (2012). Theory and validity of life satisfaction scales. Social Indicators Research, Onlin.

Diener, E., Inglehart, R., \& Tay, L. (in press). The validity of life satisfaction measures. Social Indicators Research.

Dodge, K. A., Pettit, G. S., \& Bates, J. E. (1994). Socialization mediators of the relation between socioeconomic status and child conduct problems. Child Development, 65(2), 649665. doi:10.1111/j.1467 8624.1994.tb00774.x.

Dunifon, R., \& Kowaleski Jones, L. (2002). Who's in the house? Race differences in cohabitation, single parenthood, and child development. Child Development, 73(4), 12491264. doi:10.1111/1467 8624.00470.

Dunn, J. (2005). Childrens' friendships: The beginnings of intimacy. Oxford, UK: Blackwell.

Durlak, J. A., \& DuPre, E. P. (2008). Implementation matters: A review of research on the influence of implementation on program outcomes and the factors affecting implementation. American Journal of Community Psychology, 41(3 4), 327 350. doi:10.1007/s10464 00891650.

Durlak, J. A., \& Wells, A. M. (1997). Primary prevention mental health programs for children and adolescents: A meta analytic review. American Journal of Community Psychology, 25(2), 115 152. doi:10.1023/a:1024654026646.

Durlak, J. A., Weissberg, R. P., Dymnicki, A. B., Taylor, R. D., \& Schellinger, K. B. (2011). The impact of enhancing students' social and emotional learning: A meta analysis of school based universal interventions. Child Development, 82(1), 405432 . doi:10.1111/j.1467 8624.2010.01564.x. 
Egeland, B. E., Sroufe, L. A., \& Erickson, M. (1983). The developmental consequence of different patterns of maltreatment. Child Abuse \& Neglect, 7, 459469.

Eid, M., \& Diener, E. (2004). Global judgments of subjective well being: Situational variability and long term stability. Social Indicators Research, 65(3), 245 277. doi:10.1023/B: SOCI.0000003801.89195.bc.

Eid, M., \& Larsen, R. J. (Eds.). (2008). The science of subjective well being. New York: The Guilford Press.

Eisenberg, N., \& Fabes, R. A. (1998). Prosocial development. In N. Eisenberg (Ed.), Handbook of child psychology (5th ed., Vol. 3, pp. 701 778). New York: Wiley.

Eisenberg, N., Fabes, R. A., \& Spinard, T. L. (2006). Prosocial development. In N. Eisenberg (Ed.), Handbook of child psychology (6th ed., Vol. 3, pp. 646 718). New York: Wiley.

Eiser, C., \& Morse, R. (2001). Can parents rate their child's health related quality of life? Results of a systematic review. Quality of Life Research, 10, 347357.

Eivers, A. R., Brendgen, M., Vitaro, F., \& Borge, A. I. H. (2012). Concurrent and longitudinal links between children's and their friends' antisocial and prosocial behaviour in preschool. Early Childhood Research Quarterly, 27, 137146.

Ellert, U., Ravens Sieberer, U., Erhart, M., \& Kurth, B. M. (2011). Determinants of agreement between self reported and parent assessed quality of life for children in Germany results of the German Health Interview and Examination Survey for Children and Adolescents (KiGGS). Health and Quality of Life Outcomes, 9. doi:10.1186/1477 75259102.

Ellis, B. J., Boyce, W. T., Belsky, J., Bakermans Kranenburg, M. J., \& van Ijzendoorn, M. H. (2011). Differential susceptibility to the environment: An evolutionary neurodevelopmental theory. Development and Psychopathology, 23(1), 7 28. doi:10.1017/s0954579410000611.

Fawett, C., \& Liszkowski, U. (2012). Mimicry and play initiation in 18 month old infants. Infant Behavior \& Development, 35, 689696.

Feldman, F. (2010). What is this thing called happiness? Oxford: Oxford University Press.

Fiorelli, J. A., \& Russ, S. W. (2012). Pretend play, coping and subjective well being in children. A follow up study. American Journal of Play, 5(1), 81103.

Fogle, L. M., Huebner, S. E., \& Laughlin, J. E. (2002). The relationship between temperament and lifesatisfaction in early adolescence: Cognitive and behavioral mediation models. Journal of Happiness Studies, 3, 373392.

Foland Ross, L. C., \& Gotlib, I. H. (2012). Cognitive and neural aspects of information processing in major depressive disorder: An integrative perspective. Frontiers in Psychology, 3. doi:10.3389/fpsyg.2012.00489.

Fomby, P., \& Cherlin, A. J. (2007). Family instability and child well being. American Sociological Review, 72(2), 181204.

Fordyce, M. W. (1988). A review of research on the happiness measures: A sixty second index of happiness and mental health. Social Indicators Research, 20(4), 355381.

Fox, K. R. (1999). The influence of physical activity on mental well being. Public Health Nutrition, 2(Supplement 3a), 411418.

Fox, E., Ridgewell, A., \& Ashwin, C. (2009). Looking on the bright side: Biased attention and the human serotonin transporter gene. Proceedings of the Royal Society B Biological Sciences, 276(1663), 17471751.

Fredrickson, B. L., Cohn, M. A., Coffey, K. A., Pek, J., \& Finkel, S. M. (2008). Open hearts build lives: Positive emotions, induced through loving kindness meditation, build consequential personal resources. Journal of Personality and Social Psychology, 95(5), 10451062.

Friborg, O., Hjemdal, O., Rosenvinge, J. H., \& Martinussen, M. (2003). A new rating scale for adult resilience: What are the central protective resources behind healthy adjustment? Inter national Journal of Methods in Psychiatric Research, 12(2), 6576.

Friborg, O., Barlaug, D., Martinussen, M., Rosenvinge, J. H., \& Hjemdal, O. (2005). Resilience in relation to personality and intelligence. International Journal of Methods in Psychiatric Research, 14(1), 2942. 
Friborg, O., Hjemdal, O., Rosenvinge, J. H., Martinussen, M., Aslaksen, P. M., \& Flaten, M. A. (2006). Resilience as a moderator of pain and stress. Journal of Psychosomatic Research, 61(2), 213219.

Frones, I. (2007). Theorizing indicators On indicators, signs and trends. Social Indicators Research, 83(1), 5 23. doi:10.1007/s11205 00690617.

Fulmer, C. A., Gelfand, M. J., Kruglanski, A. W., Kim Prieto, C., Diener, E., Pierro, A., \& Higgins, E. T. (2010). On "feeling right" in cultural contexts: How person culture match affects self esteem and subjective well being. Psychological Science, 21(11), 15631569. doi: $10.1177 / 0956797610384742$.

Garbarino, J., \& Stott, F. M. (1989). What children can tell us: Eliciting, interpreting, and evaluating information from children. San Francisco: Jossey Bass.

Geoffroy, M. C., Cote, S. M., Giguere, C. E., Dionne, G., Zelazo, P. D., Tremblay, R. E., \& Seguin, J. R. (2010). Closing the gap in academic readiness and achievement: The role of early childcare. Journal of Child Psychology and Psychiatry, 51(12), 13591367.

Gilman, R., \& Huebner, E. S. (2000). Review of life satisfaction measures for adolescents'. Behaviour Change, 17(3), 178 195. doi:10.1375/bech.17.3.178.

Gilman, R., \& Huebner, S. (2003). A review of life satisfaction research with children and adolescents. School Psychology Quarterly, 18(2), 192 205. doi:DOI 10.1521/ scpq.18.2.192.21858.

Ginsburg, K. R., Comm, C., \& Comm Psychosocial Aspects, C. (2007). The importance of play in promoting healthy child development and maintaining strong parent child bonds. Pediatrics, 119(1), 182 191. doi:10.1542/peds.2006 2697.

Gjerde, P. F., \& Block, J. (1991). Preadolescent antecedents of depressive symptomatology at age 18 a prospective study. Journal of Youth and Adolescence, 20(2), 217 232. doi:10.1007/ bf01537609.

Goodman, A., \& Goodman, R. (2009). Strengths and difficulties questionnaire as a dimensional measure of child mental health. Journal of the American Academy of Child and Adolescent Psychiatry, 48(4), 400 403. doi:10.1097/CHI.0b013e3181985068.

Green, J., Howes, F., Waters, E., Maher, E., \& Oberklaid, F. (2005). Promoting the social and emotional health of primary school aged children: reviewing the evidence base for school based interventions. International Journal of Mental Health Promotion, 7(3), 3036.

Greenberg, M. T., Kusche, C. A., Cook, E. T., \& Quamma, J. P. (1995). Promoting emotional competence in school aged children the effects of the paths curriculum. Development and Psychopathology, 7(1), 117136.

Greenberg, M. T., Domitrovich, C. E., \& Bumbarger, B. (2001). The prevention of mental disorders in school aged children: Current state of the field. Prevention and Treatment, 4(1).

Greenberg, M. T., Weissberg, R. P., O’Brien, M. U., Zins, J. E., Fredericks, L., Resnik, H., \& Elias, M. J. (2003). Enhancing school based prevention and youth development through coordinated social, emotional, and academic learning. American Psychologist, 58(6 7), 466474. doi:10.1037/0003 066x.58.6 7.466.

Greenberger, E., Chen, C., Tally, S., \& Dong, Q. (2000). Family, peer, and individual correlates of depressive symptomatology in U.S. and Chinese adolescents. Journal of Consulting and Clinical Psychology, 68, 202219.

Gretarsson, S. J., \& Gelfand, D. M. (1988). Mothers attributions regarding their childrens social behavior and personality characteristics. Developmental Psychology, 24(2), 264269. doi:10.1037/0012 1649.24.2.264.

Grinde, B. (2005). An approach to the prevention of anxiety related disorders based on evolution ary medicine. Preventive Medicine, 40(6), 904 909. doi:10.1016/j.ypmed.2004.08.001.

Grinde, B. (2012a). The biology of happiness. Netherlands/Dordrecht: Springer.

Grinde, B. (2012b). Darwinian happiness (2nd ed.). Princeton: The Darwin Press.

Gullone, E., \& Cummins, R. A. (1999). The comprehensive quality of life scale: A psychometric evaluation with an adolescent sample. Behaviour Change, 16(2), 127 139. doi:10.1375/ bech.16.2.127. 
Haaga, D. A. F., \& Beck, A. T. (1995). Perspectives on depressive realism implications for cognitive theory of depression. Behaviour Research and Therapy, 33(1), 41 48. doi:10.1016/ 0005 7967(94)e0016 c.

Hadjar, A., Boehnke, K., Knafo, A., Daniel, E., Musiol, A. L., Schiefer, D., \& Möllering, A. (2012). Parent child value similarity and subjective well being in the context of migration: An exploration. Family Science, 3(1), 55 63. doi:10.180/ 19424620.2011.671502.

Hankin, B. L., Nederhof, E., Oppenheimer, C. W., Jenness, J., Young, J. F., Abela, J. R. Z., \& Oldehinkel, A. J. (2011). Differential susceptibility in youth: evidence that 5 HTTLPR x positive parenting is associated with positive affect /'for better and worse/'. Transl Psychiatry, 1, e44.

Harbaugh, W. T., Mayr, U., \& Burghart, D. R. (2007). Neural responses to taxation and voluntary giving reveal motives for charitable donations. Science, 316(5831), 16221625.

Harden, A., Rees, R., Shepherd, J., Brunton, G., Oliver, S., \& Oakley, A. (2001). Young people and mental health: A systematic review on barriers and facilitators. England: EPPI Centre.

Haugland, S., \& Wold, B. (2001). Subjective health complaints in adolescence reliability and validity of survey methods. Journal of Adolescence, 24, 611624.

Hay, D. F., Castle, J., Davies, L., Demetriou, H., \& Stimson, C. A. (1999). Prosocial action in very early childhood. Journal of Child Psychology and Psychiatry, 40(6), 905 916. doi:10.1017/ s0021963099004254.

Headey, B., Muffels, R., \& Wagner, G. G. (2010). Long running German panel survey shows that personal and economic choices, not just genes, matter for happiness. Proceedings of the National Academy of Sciences of the United States of America, 107(42), 1792217926. doi:10.1073/pnas.1008612107.

Headey, B., Muffels, R., \& Wagner, G. (2012). Parents transmit happiness along with associated values and behaviors to their children: a lifelong happiness dividend? IZA Discussion Paper No 694.

Heine, S. J., Lehman, D. R., Peng, K., \& Greenholtz, J. (2002). What's wrong with cross cultural comparisons of subjective Likert scales? The reference group effect. Journal of Personality and Social Psychology, 82, 903918.

Hetherington, E. M., Parke, R. D., Gauvain, M., \& Locke, V. O. (2006). Child psychology: A contemporary viewpoint (6th ed.). New York: McGraw Hill.

Higgins, E. T. (2012). Beyond pleasure and pain. New York: Oxford University Press.

Hjemdal, O., Aune, T., Reinfjell, T., Stiles, T. C., \& Friborg, O. (2007). Resilience as a predictor of depressive symptoms: A correlational study with young adolescents. Clinical Child Psychol ogy and Psychiatry, 12(1), 91104.

Hjemdal, O., Friborg, O., \& Stiles, T. C. (2012). Resilience is a good predictor of hopelessness even after accounting for stressful life events, mood and personality (NEO PI R). Scandina vian Journal of Psychology, 53(2), 174180.

Hoffmann, J., \& Russ, S. (2012). Pretend play, creativity, and emotion regulation in children. Psychology of Aesthetics Creativity and the Arts, 6(2), 175 184. doi:10.1037/ a0026299.

Holder, M. D., \& Klassen, A. (2010). Temperament and happiness in children. Journal of Happiness Studies, 11(4), 419 439. doi:10.1007/s10902 00991492.

Holder, M. D., Coleman, B., \& Singh, K. (2012). Temperament and happiness in children in India. Journal of Happiness Studies, 13(2), 261 274. doi:10.1007/s10902 0119262 x.

Holen, S., Lervag, A., Waaktaar, T., \& Ystgaard, M. (2012a). Exploring the associations between coping patterns for everyday stressors and mental health in young schoolchildren. Journal of School Psychology, 50(2), 167193.

Holen, S., Waaktaar, T., Lervag, A., \& Ystgaard, M. (2012b). The effectiveness of a universal school based programme on coping and mental health: A randomised controlled study of Zippy's Friends. Educational Psychology, 32(5), 657677.

Holmes, D., \& Faupel, A. (2005). Zippy's friends: Southampton Evaluation Report, Year 2 (2004 2005). Southampton: Southampton Psychology Service. 
Howes, C. (1978). Social competence with peers in young children. Developmental consequences. Developmental Review, 7, 252272.

Huebner, E. (1991a). Correlates of life satisfaction in children. School Psychology Quarterly, 6, 103111.

Huebner, E. (1991b). Initial development of the Student's Life Satisfaction Scale. School Psy chology International, 12, 231240.

Huebner, E. S. (1994). Preliminary development and validation of a multidimensional life satisfaction scale of children. Psychological Assessment, 6(2), 149158.

Huebner, E. S. (2004). Research on assessment of life satisfaction of children and adolescents. Social Indicators Research, 66(1 2), 3 33. doi:10.1023/B:SOCI.0000007497.57754.e3.

Huebner, E. S., Suldo, S. M., \& Valois, R. F. (2003). Psychometric properties of two brief measures of children's life satisfaction: The Students' Life Satisfaction Scale (SLSS) and the Brief Multidimensional Students Life Satisfaction Scale (BMSLSS). Indicators of Positive Development Conference. DC: Washington.

Hughes, A. R., Farewell, K., Harris, D., \& Reilly, J. J. (2007). Quality of life in a clinical sample of obese children. International Journal of Obesity, 31(1), 39 44. doi:10.1038/sj.ijo.0803410.

Huppert, F. A., \& So, T. T. C. (2013). Flourishing across Europe: Application of a new conceptual framework for defining well being. Social Indicators Research, 110, 837 862. doi: 10.1007/ s112050119966 7

Huta, V., \& Ryan, R. M. (2010). Pursuing pleasure or virtue: The differential and overlapping well being benefits of hedonic and eudaimonic motives. Journal of Happiness Studies, 11(6), 735 762. doi:10.1007/s10902009 91714.

International Wellbeing Group (2006). Personal wellbeing index adult Manual, 4th version. : Melbourne: Australian Centre on Quality of Life, Deakin University. http://www.deakin.edu. $\mathrm{au} / \mathrm{research/acqol/instruments/well} \mathrm{being} \mathrm{index.htm.}$

Jaffee, S. R., Van, H. C., \& Rodgers, J. L. (2011). Effects of nonmaternal care in the first 3 years on children's academic skills and behavioral functioning in childhood and early adolescence: a sibling comparison study. Child Development, 82(4), 10761091.

Jahoda, M. (1958). Current concepts of positive mental health. New York: Basic Books.

Jané Llopis, E., Barry, M. M., Hosman, C., \& Patel, V. (2005). Mental health promotion works: A review. In E. Jané Llopis, M. M. Barry, C. Hosman \& V. Patel (Eds.), The evidence of mental health promotion effectiveness: Strategies for action. Promotion and education IUHPE special issue, supplement 2 (pp. 9 25).

Johnson, D. D. P., \& Fowler, J. H. (2011). The evolution of overconfidence. Nature, 477(7364), 317320 .

Jones, H. M. (1953). The pursuit of happiness. Cambridge, MA: Harvard University Press.

Jozefiak, T. (2004). Quality of life among children and adolescents in a psychiatric outpatient sample. In H. Remschmidt \& M. Belfer (Eds.), Book of abstracts of the 16th World congress of the Interna tional Association for Child and Adolescent Psychiatry (pp. 177). Berlin: Darmstadt: Steinkopf.

Jozefiak, T., Larsson, B., Wichstrom, L., Mattejat, F., \& Ravens Sieberer, U. (2008). Quality of life as reported by school children and their parents: A cross sectional survey. Health and Quality of Life Outcomes, 6. doi:8610.1186/1477 7525634.

Jozefiak, T., Larsson, B., \& Wichstrom, L. (2009). Changes in quality of life among Norwegian school children: A six month follow up study. Health and Quality of Life Outcomes, 7. doi:10.1186/1477 752577 .

Kahneman, D. (1999). Objective happiness. In D. Kahneman, E. Diener, \& N. Schwarz (Eds.), Well being: The foundations of hedonic psychology (pp. 3 25). New York: Russell Sage Foundation.

Kahneman, D. (2012). A machine for jumping to conclusions, APA Monitor. 43(2), 2427. Retrieved from http://www.apa.org/monitor/2012/02/conclusions.aspx website.

Kahneman, D., Krueger, A. B., Schkade, D. A., Schwarz, N., \& Stone, A. A. (2004). A survey method for characterizing daily life experience: The day reconstruction method. Science, 306(5702), 1776 1780. doi:DOI 10.1126/science.1103572. 
Kasser, T. (2011). Cultural values and the well being of future generations: A cross national study. Journal of Cross Cultural Psychology, 42(2), 206215.

Kellam, S. G., Rebok, G. W., Ialongo, N., et al. (1994). The course and malleability of aggressive behavior from early first grade into middle school: Results of a developmental epidemiolog ically based preventive trial. Journal of Child Psychology and Psychiatry, 35, 259281.

Keyes, C. L. M. (2007). Promoting and protecting mental health as flourishing A complementary strategy for improving national mental health. American Psychologist, 62(2), 95108. doi:10.1037/0003 066x.62.2.95.

Keyes, C. L. M., \& Annas, J. (2009). Feeling good and functioning well: Distinctive concepts in ancient philosophy and contemporary science. The Journal of Positive Psychology, 4(3), 197 201. doi:10.1080/17439760902844228.

Killingsworth, M. A., \& Gilbert, D. T. (2010). A wandering mind is an unhappy mind. Science, 330(6006), 932 932. doi:DOI 10.1126/science.1192439.

Knafo, A., Israel, S., \& Ebstein, R. P. (2011). Heritability of children's prosocial behavior and differential susceptibility to parenting by variation in the dopamine receptor D4 gene. Devel opment and Psychopathology, 23(1), 53 67. doi:10.1017/s0954579410000647.

Kovess Masfety, M., Murray, M., \& Gureje, O. (2005). Positive mental health. In H. Herrman, S. Saxena, \& R. Moodie (Eds.), Promoting mental health: Concepts, emerging evidence, prac tice. A report of the world health organization, department of mental health and substance abuse in collaboration with the Victorian Health Promotion Foundation and University of Melbourne (pp. 35 45). Geneva: World Health Organization.

Krasnor, L. R., \& Pepler, D. J. (1980). The study of children's play: Some suggested future directions. In K. H. Rubin (Ed.), Children's play. New directions for child development (pp. 85 95). San Francisco, CA: Jossey Bass.

Krueger, R. F., South, S., Johnson, W., \& Iacono, W. (2008). The heritability of personality is not always $50 \%$ : Gene environment interactions and correlations between personality and par enting. Journal of Personality, 76(6), 14851521.

Lagattuta, K. H., Sayfan, L., \& Bamford, C. (2012). Do you know how I feel? Parents underes timate worry and overestimate optimism compared to child self report. Journal of Experimen tal Child Psychology, 113(2), 211 232. doi:10.1016/j.jecp. 2012.04.001.

Lancy, D. F. (2007). Accounting for variability in mother child play. American Anthropologist, 109(2), 273 284. doi:10.1525/aa.2007.109.2.273.

Langer, E. J. (1975). Illusion of control. Journal of Personality and Social Psychology, 32(2), 311 328. doi:10.1037//0022 3514.32.2.311.

Lau, A. L. D., Cummins, R. A., \& McPherson, W. (2005). An investigation into the cross cultural equivalence of the personal wellbeing index. Social Indicators Research, 72(3), 403430. doi:10.1007/s11205004 $0561 \mathrm{z}$.

Laub, J. H., \& Sampson, R. J. (2003). Shared beginnings, divergent lives: Delinquent boys to age 70. Cambridge, US: Harvard University Press.

Layzer, J. I., \& Goodson, B. D. (2006). The "quality" of early care and education settings Definitional and measurement issues. Evaluation Review, 30(5), 556576.

Lekhal, R. (2012). Do type of childcare and age of entry predict behavior problems during early childhood? Results from a large Norwegian longitudinal study. International Journal of Behavioral Development, 36, 197204.

Lekhal, R., Zachrisson, H. D., Wang, M. V., Schjølberg, S., \& von Soest, T. (2011). Does universally accessible child care protect children from late talking? Results from a Norwegian population based prospective study. Early Child Development and Care, 181(8), 10071019.

Leknes, S., \& Tracey, I. (2008). Science \& society A common neurobiology for pain and pleasure. Nature Reviews Neuroscience, 9(4), 314 320. doi:9810.1038/nrn2333.

Liiva, C. A., \& Cleave, P. L. (2005). Roles of initiation and responsiveness in access and participation for children with specific language impairment. Journal of Speech, Language, and Hearing Research, 48(4), 868 883. doi:10.1044/1092 4388(2005/060). 
Lillard, A. S., Lerner, M. D., Hopkins, E. J., Dore, R. A., Smith, E. D., \& Palmquist, C. M. (2013). The impact of pretend play on children's development: A review of the evidence. Psycholog ical Bulletin, 139(1), 1 34. doi:10.1037/a0029321

Lister Sharp, D., Chapman, S., Stewart Brown, S., \& Sowden, A. (1999). Health promoting schools and health promotion in schools: Two systematic reviews. Health Technology Assess ment, 3(22), 1207.

Lobmaier, J. S., \& Perrett, D. I. (2011). The world smiles at me: Self referential positivity bias when interpreting direction of attention. Cognition \& Emotion, 25(2), 334 341. doi:10.1080/ 02699931003794557.

Love, K. M., \& Murdock, T. B. (2004). Attachment to parents and psychological well being: An examination of young adult college students in intact families and stepfamilies. Journal of Family Psychology, 18(4), 600 608. doi:10.1037/0893 3200.18.4.600.

Love, J. M., Harrison, L., Sagi Schwartz, A., van Ijzendoorn, M. H., Ross, C., Ungerer, J. A., \& Chazan Cohen, R. (2003). Child care quality matters: How conclusions may vary with context. Child Development, 74(4), 10211033.

Lu, L., \& Gilmour, R. (2004). Culture and conceptions of happiness: Individual oriented and social oriented swb. Journal of Happiness Studies, 5, 269291.

Lucas, R. E., Diener, E., \& Suh, E. (1996). Discriminant validity of well being measures. Journal of Personality and Social Psychology, 71(3), 616 628. doi:10.1037/0022 3514.71.3.616.

Luhmann, M., Schimmack, U., \& Eid, M. (2011). Stability and variability in the relationship between subjective well being and income. Journal of Research in Personality, 45(2), 186 197. doi:10.1016/j.jrp. 2011.01.004.

Luhmann, M., Hofmann, W., Eid, M., \& Lucas, R. E. (2012). Subjective well being and adaptation to life events: A meta analysis. Journal of Personality and Social Psychology, 102(3), 592 615. doi:10.1037/a0025948.

Luthar, S. S. (2006). Resilience in development: A synthesis of research across five decades. In D. J. Cohen \& D. Cicchetti (Eds.), Developmental psychopathology: Risk, disorder, and adaptation (2nd ed., Vol. 3, pp. 739 795). Hoboken, US: Wiley.

Luthar, S. S., Doernberger, C. H., \& Zigler, E. (1993). Resilience is not a unidimensional construct: Insights from a prospective study of inner city adolescents. Development and Psychopathology, 5(4), 703717.

Lykken, D. (2000). The nature and nurture of joy and contentment. New York: St Martin's Griffin.

Lykken, D., \& Tellegen, A. (1996). Happiness is a stochastic phenomenon. Psychological Science, 7(3), 186189.

Lyytinen, P., Poikkeus, A. M., \& Laakso, M. L. (1997). Language and symbolic play in toddlers. International Journal of Behavioral Development, 21(2), 289302.

Magnuson, K., \& Berger, L. M. (2009). Family structure states and transitions: Associations with children's well being during middle childhood. Journal of Marriage and Family, 71(3), 575591.

Magnuson, K. A., Ruhm, C., \& Waldfogel, J. (2007). Does prekindergarten improve school preparation and performance? Economics of Education Review, 26(1), 3351.

Manzi, C., Vignoles, V. L., Regalia, C., \& Scabini, E. (2006). Cohesion and enmeshment revisited: Differentiation, identity, and well being in two european cultures. Journal of Marriage and Family, 68(3), 673 689. doi:10.1111/j.1741 3737.2006.00282.x.

Markus, H. R., \& Kitayama, S. (1991). Culture and the self: Implications for cognition, emotion, and motivation. Psychological Review, 98, 224253.

Masten, A., \& Shaffer, A. (2006). How families matter in child development: Reflections from research on risk and resilience. In A. Clarke Stewart \& J. Dunn (Eds.), Families count: Effects on child and adolescent development (pp. 5 25). New York, NY: Cambridge Univer sity Press.

Masten, A. S., Cutuli, J. J., Herbers, E. J., \& Reed, M. G. J. (2011). Resilience in development. In C. R. Snyder \& S. J. Lopez (Eds.), Oxford handbook of positive psychology (pp. 117 132). New York: Oxford University Press. 
Mayer, B., \& Trommsdorff, G. (2012, July). The relations between adolescents' family models and their well being in 10 cultures. Paper presented at the 7th International Conference on Child and Adolescent Psychopathology, Roehampton University, London, UK.

McCabe, C. (2007). A systematic review of cost effectiveness analyses of whole school interventions to promote children's mental health. Leeds: Leeds Institute of Health Sciences, University of Leeds.

McCartney, K., Burchinal, M., Clarke Stewart, A., Bub, K. L., Owen, M. T., \& Belsky, J. (2010). Testing a series of causal propositions relating time in child care to children's externalizing behavior. Developmental Psychology, 46(1), 117.

McCrae, R., \& Costa, J. P. (1991). Adding Liebe und Arbeit: The full five factor model and well being. Personality and social psychology bulletin, 17, 227232.

McGill, V. J. (1967). The idea of happiness. New York: F.A. Praeger.

McMahon, D. (2006). The pursuit of happiness. A history from the Greeks to the present. London: Allen Lane.

Melhuish, E. C., Sylva, K., Sammons, P., Siraj Blatchford, I., Taggart, B., Phan, M. B., \& Malin, A. (2008). The early years Preschool influences on mathematics achievement. Science, 321(5893), 11611162.

Mervilde, I., \& De Fruyt, F. (2002). Assessing children's traits with the hierarchical personality inventory for children. In B. D. Raad \& M. Perugini (Eds.), Big five assessment (pp. 129 146). Bern: Hogrefe and Huber.

Mezulis, A. H., Abramson, L. Y., Hyde, J. S., \& Hankin, B. L. (2004). Is there a universal positivity bias in attributions? A meta analytic review of individual, developmental, and cultural differences in the self serving attributional bias. Psychological Bulletin, 130(5), 711 747. doi:10.1037/0033 2909.130.5.711.

Michalec, B., Keyes, C. L. M., \& Nalkur, S. (2009). Flourishing. In S. J. Lopez (Ed.), The encyclopedia of positive psychology (Vol. 1, pp. 391 394). Malden, MA: Wiley Blackwell.

Michalos, A. C. (1985). Multiple discrepancies theory (MDT). Social Indicators Research, 16, 347413.

Miller, G. E., Lachman, M. E., Chen, E., Gruenewald, T. L., Karlamangla, A. S., \& Seeman, T. E. (2011). Pathways to resilience: Maternal nurturance as a buffer against the effects of childhood poverty on metabolic syndrome at midlife. Psychological Science, 22(12), 15911599. doi:10.1177/0956797611419170.

Mishara, B. L., \& Ystgaard, M. (2006). Effectiveness of a mental health promotion program to improve coping skills in young children: Zippy's friends. Early Childhood Research Quar terly, 21(1), 110 123. doi:10.1016/j.ecresq.2006.01.002.

Moore, M. T., \& Fresco, D. M. (2012). Depressive realism: A meta analytic review. Clinical Psychology Review, 32(6), 496 509. doi:10.1016/j.cpr.2012.05.004.

Nantel Vivier, A., Kokko, K., Caprara, G. V., Pastorelli, C., Gerbino, M. G., Paciello, M., \& Tremblay, R. E. (2009). Prosocial development from childhood to adolescence: A multi informant perspective with Canadian and Italian longitudinal studies. Journal of Child Psy chology and Psychiatry, and Allied Disciplines, 50(5), 590598.

Nes, R. B., Roysamb, E., Tambs, K., Harris, J. R., \& Reichborn Kjennerud, T. (2006). Subjective well being: Genetic and environmental contributions to stability and change. Psychological Medicine, 36(7), 10331042.

Nes, R. B., Czajkowski, N., \& Tambs, K. (2010). Family matters: Happiness in nuclear families and twins. Behavior Genetics, 40(5), 577590.

NICHD. (2003). Nichd early child care network: Does amount of time spent in child care predict socioemotional adjustment during the transition to kindergarten? Child Development, 74(4), 9761005.

NICHD. (2006). Nichd early child care network: Child care effect sizes for the NICHD study of early child care and youth development. American Psychologist, 61(2), 99116.

NICHD, \& Duncan, G. J. (2003). Nichd early child care network \& Duncan: Modeling the impacts of child care quality on children's preschool cognitive development. Child Development, 74(5), 14541475 . 
Nickerson, C., Schwarz, N., Diener, E., \& Kahneman, D. (2003). Zeroing in on the dark side of the American dream: A closer look at the negative consequences of the goal for financial success. Psychological Science, 14(6), 531 536. doi:10.1046/j.0956 7976.2003. psci 1461.x.

Nowlis, V., \& Nowlis, H. (1956). The description and analysis of mood. Annals of the New York Academy of Science, 55, 345355.

O'Neill, J. (2011). The overshadowing of needs. In F. Rauschmayer, I. Omann, \& J. Frühmann (Eds.), Sustainable development. Capabilities, needs and well being (pp. 25 42). London: Routledge.

Oishi, S. (2000). Goals as cornerstones of subjective well being: Linking individuals and cultures. In E. Diener \& E. M. Suh (Eds.), Culture and subjective well being (pp. 87 112). Cambridge, MA: The MIT Press.

Olweus, D. (2012). Cyberbullying: An overrated phenomenon? The European Journal of Devel opmental Psychology, 9(5), 520 538. doi:10.1080/17405629.2012.682358.

Olweus, D., Limber, S., \& Mihalic, S. (1998). Blueprints for violence prevention. Boulder, CO: Center for the Study and Prevention of Violence, Institute of Behavioral Science, University of Colorado at Boulder.

Ong, A. D., \& van Dulmen, M. H. M. (Eds.). (2007). Oxford handbook of methods in positive psychology. Oxford: Oxford University Press.

Pavot, W., \& Diener, E. (1993). Review of the satisfaction with life scale. Psychological Assess ment, 5(2), 164172.

Payton, J., Weissberg, R. P., Durlak, J. A., Dymnicki, A. B., Taylor, R. D., Schellinger, K. B., \& Pachan, M. (2008). The positive impact of social and emotional learning for kindergarten to eight grade students: Findings from three scientific reviews Chicago, IL: Collaborative for Academic, Social, and Emotional Learning.

Pedersen, S., Vitaro, F., Barker, E. D., \& Borge, A. I. H. (2007). The timing of middle childhood peer rejection and friendship: linking early behavior to early adolescent adjustment. Child Development, 78(4), 10371051.

Penedo, F. J., \& Dahn, J. R. (2005). Exercise and well being: A review of mental and physical health benefits associated with physical activity. Current Opinion in Psychiatry, 18(2), 189193.

Petito, F., \& Cummins, R. A. (2000). Quality of life in adolescence: The role of perceived control, parenting style, and social support. Behaviour Change, 17(3), 196 207. doi:10.1375/ bech.17.3.196.

Pluess, M., \& Belsky, J. (2009). Differential susceptibility to rearing experience: The case of childcare. Journal of Child Psychology and Psychiatry, 50(4), 396 404. doi:10.1111/j.1469 7610.2008.01992.x.

Pluess, M., \& Belsky, J. (2012). Vantage sensitivity: Individual differences in response to positive experiences. Psychological Bulletin, Oct 1, 2012. doi: 10.1037/a0030196

Pollard, E. L., \& Lee, P. D. (2003). Child well being: A systematic review of the literature. Social Indicators Research, 61(1), 59 78. doi:10.1023/a:1021284215801.

Proctor, C. L., Linley, P. A., \& Maltby, J. (2009). Youth life satisfaction: A review of the literature. Journal of Happiness Studies, 10, 583630.

Raphael, D., Rukholm, E., Brown, I., HillBailey, P., \& Donato, E. (1996). The quality of life profile adolescent version: Background, description, and initial validation. Journal of Ado lescent Health, 19(5), 366 375. doi:10.1016/s1054 139x(96)00080 8.

Richter, L. M. (2010). Global perspectives on the well being of children. In C. M. Worthman, P. M. Plotsky, D. S. Schechter, \& C. A. Cummings (Eds.), Formative experiences: The interaction of caregiving, culture, and developmental psychobiology (pp. 531 548). New York, NY: Cambridge University Press.

Roberts, B. W., \& DelVecchio, W. F. (2000). The rank order consistency of personality traits from childhood to old age: A quantitative review of longitudinal studies. Psychological Bulletin, 126(1), 3 25. doi:10.1037//0033 2909.126.1.3. 
Roberts, M. C., Brown, K. J., Johnson, R. J., \& Reinke, J. (2002). Positive psychology for children. In C. R. Snyder \& S. J. Lopez (Eds.), Handbook of positive psychology (pp. 663 675). New York: Oxford University Press.

Romano, E., Babchishin, L., Pagani, L. S., \& Kohen, D. (2010). School readiness and later achievement: Replication and extension using a nationwide Canadian survey. Developmental Psychology, 46(5), 9951007.

Rothbaum, F., Weisz, J., Pott, M., Miyake, K., \& Morelli, G. (2000). Attachment and culture: Security in the United States and Japan. American Psychologist, 55(10), 10931104.

Rowling, L. (2008). Prevention science and implementation of school mental health promotion: Another way. Advances in School Mental Health Promotion, 1(3), 2937.

Rowling, L., Martin, G., \& Walker, L. (2002). Mental health promotion and young people: Concepts and practice. Sydney: McGraw Hill.

Ruiz, S. A., \& Silverstein, M. (2007). Relationships with grandparents and the emotional well being of late adolescent and young adult grandchildren. Journal of Social Issues, 63(4), 793808.

Rutter, M. (2006). Genes and behavior: Nature nurture interplay explained. Malden, MA: Blackwell.

Rutter, M., Beckett, C., Castle, J., Colvert, E., Kreppner, J., Mehta, M., \& Sonuga Barke, E. (2007). Effects of profound early institutional deprivation: An overview of findings from a UK longitudinal study of Romanian adoptees. The European Journal of Developmental Psychol ogy, 4(3), 332350.

Ryan, R. M., \& Deci, E. L. (2000). Self determination theory and the facilitation of intrinsic motivation, social development, and well being. American Psychologist, 55(1), 6878.

Ryan, R. M., \& Deci, E. L. (2001). On happiness and human potentials: A review of research on hedonic and eudaimonic well being. Annual Review of Psychology, 52, 141 166. doi:DOI 10.1146/annurev.psych.52.1.141

Ryff, C. D. (1989). Happiness is everything, or is it Explorations on the meaning of psycholog ical well being. Journal of Personality and Social Psychology, 57(6), 1069 1081. doi:10.1037/ 0022 3514.57.6.1069.

Ryff, C. D., \& Keyes, C. L. M. (1995). The structure of psychological well being revisited. Journal of Personality and Social Psychology, 69(4), 719 727. doi:Doi 10.1037/0022 3514.69.4.719.

Sabatier, C., Mayer, B., Friedlmeier, M., Lubiewska, K., \& Trommsdorff, G. (2011). Religiosity, family orientation, and life satisfaction of adolescents in four countries. Journal of Cross Cultural Psychology, 42, 13751393.

Sampson, R., \& Laub, J. H. (1997). A life course theory of cumulative disadvantage and the stability of delinquency. In P. T. Thornberry (Ed.), Developmental theories of crime and delinquency (pp. 133 162). Brunswick, NJ: Transaction Publishers.

Sanders, M. R. (1999). Triple P positive parenting program: Towards an empirically validated multilevel parenting and family support strategy for the prevention of behavior and emotional problems in children. Clin Child Fam Psychol Rev, 2(2).

Scarr, S., \& McCartney, K. (1983). How people make their own environments: A theory of genotype greater than environment effects. Child Development, 54, 424435.

Schilling, V., Petermann, F., \& Hampe, P. (2006). Psychosocial situation in families of children with ADHD. Zeitschrift Fur Psychiatrie Psychologie Und Psychotherapie, 54(4), 293301. doi:10.1024/1661 4747.54.4.293.

Schimmack, U., Schupp, J., \& Wagner, G. G. (2008). The influence of environment and person ality on the affective and cognitive component of subjective well being. Social Indicators Research, 89(1), 41 60. doi:10.1007/s11205007 92303.

Schneider, B. (2000). Friends and enemies: Peer relations in childhood. London: Arnold.

Schwartz, S. H. (2012). Values and religion in adolescent development: Cross national and comparative evidence. In G. Trommsdorff \& X. Chen (Eds.), Values, religion, and culture in adolescent development (pp. 97 122). New York: Cambridge University Press.

Schwarz, B., Mayer, B., Trommsdorff, G., Ben Arieh, A., Friedlmeier, M., Lubiewska, K., \& Peltzer, K. (2012). Does the importance of parent and peer relationships for adolescents' life satisfaction vary across cultures? Journal of Early Adolescence, 32, 5580. 
Seligman, M. E. P. (2002a). Authentic happiness: Using the new positive psychology to realize your potential for lasting fulfillment. New York: Free Press.

Seligman, M. E. P. (2002b). Positive psychology, positive prevention, and positive therapy. In C. R. Snyder \& S. J. Lopez (Eds.), Handbook of positive psychology (pp. 3 9). New York: Oxford University Press.

Seligman, M. E. P. (2011). Flourish. A visionary new understanding of happiness and well being. New York: Free Press.

Seligman, M. E. P., Steen, T. A., Park, N., \& Peterson, C. (2005). Positive psychology progress Empirical validation of interventions. American Psychologist, 60(5), 410421.

Seligson, J. L., Huebner, E. S., \& Valois, R. F. (2003). Preliminary validation of the brief multidimensional student's life satisfaction scale. Social Indicators Research, 61, 121145.

Sen, A. (2000). Development as freedom. New York: Anchor Books.

Sen, A., Hawthorn, G., \& Muellbauer, J. (1987). The standard of living. Cambridge: Cambridge University Press.

Shek, D. T. L. (2008). Perceived parental control processes, parent child relational qualities, and adolescent psychological well being in intact and nonintact families: Longitudinal findings in the Chinese culture. Journal of Divorce \& Remarriage, 49(1 2), 171 189. doi:10.1080/ 10502550801973187.

Shonkoff, J. P. (2011). Protecting brains, not simply stimulating minds. Science, 333(6045), 982 983. doi:10.1126/science.1206014.

Shonkoff, J. P., \& Phillips, D. A. (2000). From neurons to neighborhoods. The science of early childhood development. Washington, DC: National Academy Press.

Sin, N. L., \& Lyubomirsky, S. (2009). Enhancing well being and alleviating depressive symptoms with positive psychology interventions: A practice friendly meta analysis. Journal of Clinical Psychology, 65(5), 467487.

Singer, D. G., Singer, J. L., D’Agostino, H., \& Delong, R. (2009). Children's pastimes and play in sixteen nations: Is free play declining? American Journal of Play, 1, 283312.

Smith, C., \& Lloyd, B. (1978). Maternal behaviour and the perceived sex of infant: Revisited. Child Development, 49, 12631266.

Smith, J. R., Brooks Gunn, J., \& Klebanov, P. K. (1997). Consequences of living in poverty for young children's cognitive and verbal ability and early school achievement. In J. G. Duncan \& J. Brooks Gunn (Eds.), Consequences of growing up poor (pp. 132 189). New York: Russell Sage Foundation.

Smith, R. L., \& Rose, A. J. (2011). The "Cost of Caring" in Youths' friendships: Considering associations among social perspective taking, co rumination, and empathetic distress. Devel opmental Psychology, 47(6), 1792 1803. doi:10.1037/a0025309.

Snyder, C. R., \& Lopez, S. J. (2002). Handbook of positive psychology. New York: Oxford University Press.

Spieth, L. E. (2001). Generic health related quality of life measures for children and adolescents. In H. M. Koot \& J. L. Wallander (Eds.), Quality of life in child and adolescent illness (pp. 49 88). New York: Brunner Routledge.

Stein, M. B., Campbell Sills, L., \& Gelernter, J. (2009). Genetic variation in 5HTTLPR is associated with emotional resilience. American Journal of Medical Genetics. Part B, Neuro psychiatric Genetics, 150B(7), 900906.

Stepp, S. D., Pardini, D. A., Loeber, R., \& Morris, N. A. (2011). The relation between adolescent social competence and young adult delinquency and educational attainment among at risk youth: The mediating role of peer delinquency. Canadian Journal of Psychiatry, 56(8), 457465.

Stiglitz, J. E., Sen, A., \& Fitoussi, J. P. (2009). Report by the commission on the measurement of economic performance and social progress. Paris, France: OECD.

Suh, E., Diener, E., Oishi, S., \& Triandis, H. C. (1998). The shifting basis of life satisfaction judgments across cultures: Emotions versus norms. Journal of Personality and Social Psy chology, 74(2), 482493. 
Suh, E. M., \& Koo, J. (2008). Comparing subjective well being across cultures and nations: The "what" and "why" questions. In M. Eid \& R. J. Larsen (Eds.), The science of subjective well being (pp. 414 430). New York: The Guilford Press.

Super, C. M., \& Harkness, S. (1993). The developmental niche: A conceptualization at the interface of child and culture. In R. A. Pierce \& M. A. Black (Eds.), Life span development: A diversity reader (pp. 61 77). Dubuque, IA: Kendall/Hunt.

Svetlova, M., Nichols, S. R., \& Brownell, C. A. (2010). Toddlers' prosocial behavior: From instrumental to empathic to altruistic helping. Child Development, 81(6), 18141827.

Swartz, D., Dodge, K., Pettit, G., Bates, J. E., \& Group, t. C. D. P. R. (2000). Friendship as a moderating factor in the pathway between early harsh home environment and later victim ization in the peer group. Developmental Psychology, 36, 646662.

Tamis LeMonda, C., \& Bornstein, M. (1994). Specificity in mother toddler language play rela tions across the second year. Developmental Psychology, 30, 283292.

Taylor, S. E., \& Brown, J. D. (1988). Illusion and well being: A social psychology perspective on mental health. Psychological Bulletin, 103(2), 193 210. doi:10.1037/0033 2909.103.2.193.

Taylor, S. E., Kemeny, M. E., Reed, G. M., Bower, J. E., \& Gruenewald, T. L. (2000). Psycho logical resources, positive illusions, and health. American Psychologist, 55(1), 99109. doi:10.1037//0003 066x.55.1.99.

Tellegen, A., Lykken, D. T., Bouchard, T. J., Wilcox, K. J., Rich, S., \& Segal, N. L. (1988). Personality similarity in twins reared apart and together. Journal of Personality and Social Psychology, 54(6), 10311039.

Terry, T., \& Huebner, E. S. (1995). The relationship between self concept and life satisfaction in children. Social Indicators Research, 35(1), 39 52. doi:10.1007/bf01079237.

Thomas, W. I., \& Thomas, D. S. (1928). The child in America; Behavior problems and programs. New York: Knopf.

Tiberius, V. (2013). Recipes for a good life: Eudaimonism and the contribution of philosophy. In A. Waterman (Ed.), The best within us. Positive psychology perspectives on eudaimonia. Washington, DC: APA Books.

Tiberius, V., \& Mason, M. F. (2009). Eudaimonia. In S. J. Lopez (Ed.), The encyclopedia of positive psychology (Vol. 1, pp. 351 355). Malden, MA: Wiley Blackwell.

Tomyn, A. J., \& Cummins, R. A. (2011). The subjective wellbeing of high school students: Validating the personal wellbeing index school children. Social Indicators Research, 101(3), 405 418. doi:10.1007/s1120501096686.

Torgersen, S. (1995, 2008). Personlighet og personlighetsforstyrrelser. Oslo: Gyldendal akademisk.

Torgersen, S., \& Vollrath, M. (2006). Personality types, personality traits, and risky health behavior. In M. Vollrath (Ed.), Handbook of personality and health. New York: Wiley.

Trommsdorff, G. (2007). Entwicklung im kulturellen Kontext. In G. Trommsdorff \& H. J. Kornadt (Eds.), Enzyklopädie der Psychologie: Themenbereich C Theorie und Forschung, Serie VII Kulturvergleichende Psychologie. Band 2: Kulturelle Determinanten des Erlebens und Verhaltens (pp. 435 519). Göttingen, Germany: Hogrefe.

Trommsdorff, G. (2012). Cultural perspectives on values and religion in adolescent development: A conceptual overview and synthesis. In G. Trommsdorff \& X. Chen (Eds.), Values, religion, and culture in adolescent development (pp. 3 45). New York, NY: Cambridge University Press.

Trommsdorff, G., Cole, P. M., \& Heikamp, T. (2012). Cultural variations in mothers' intuitive theories: A preliminary report on interviewing mothers from five nations about their sociali zation of children's emotions. Global Studies of Childhood, 2, 158 69. doi:http://dx.doi.org/ 10.2304/gsch.2012.2.2.158.

Trommsdorff, G., \& Kornadt, H. J. (2003). Parent child relations in cross cultural perspective. In L. Kuczynski (Ed.), Handbook of dynamics in parent child relations (pp. 271 306). Thousand Oaks, CA: Sage. 
Uchida, Y., Norasakkunkit, V., \& Kitayama, S. (2004). Cultural constructions of happiness: Theory and evidence. Journal of Happiness Studies, 5, 223239.

UNICEF. (2007). Child poverty in perspective: An overview of child well being in rich countries Innocenti report card 7. Florence, IT: The United Nations Children's Fund.

UNICEF. (2008). Innocenti research center. Report Card 8: The child care transition.

Upton, P., Lawford, J., \& Eiser, C. (2008). Parent child agreement across child health related quality of life instruments: a review of the literature. Quality of Life Research, 17(6), 895913. doi:10.1007/s11136 00893505.

Valentino, K., Cicchetti, D., Toth, S. L., \& Rogosch, F. A. (2011). Mother child play and maltreatment: A longitudinal analysis of emerging social behavior from infancy to toddler hood. Developmental Psychology, 47(5), 1280 1294. doi:10.1037/a0024459.

van der Mark, I. L., van Ijzendoorn, M. H., \& Bakermans Kranenburg, M. J. (2002). Development of empathy in girls during the second year of life: Associations with parenting, attachment, and temperament. Social Development, 11(4), 451468.

Vandell, D. L., Belsky, J., Burchinal, M., Steinberg, L., \& Vandergrift, N. (2010). Do effects of early child care extend to age 15 years? Results from the NICHD study of early child care and youth development. Children Development, 81(3), 737756.

VanVaalen, M. (2011). Geluk op basischool. (Happiness in elementary school). Tijdschrift voor Orthopedagogiek, 50, 100104

Veenhoven, R. (1984). Conditions of happiness. Dordrecht: Reidel.

Veenhoven, R. (2011). World database of happiness: Example of a focussed findings archive, Working paper no. 169. German data Forum RatSWD.

Veenhoven, R. (2012a). Bibliography of happiness. Available from http://worlddatabaseof happiness.eur.nl/hap bib/bib fp.php, from Erasmus University Rotterdam.

Veenhoven, R. (2012b). Correlates of happiness. Available from http://worlddatabaseofhappiness. eur.nl/hap cor/cor fp.htm, from Erasmus University Rotterdam.

Veenhoven, R. (2012c). Happiness in Nations. http://worlddatabaseofhappiness.eur.nl/hap nat/ nat fp.php, from Erasmus University Rotterdam.

Veenhoven, R. (2012d). Happiness in publics. http://worlddatabaseofhappiness.eur.nl/hap pub/ pub fp.php, from Erasmus University Rotterdam.

Veenhoven, R. (2012e). Measures of happiness. Available from http://worlddatabaseofhappiness. eur.nl/hap quer/hqi fp.htm, from Erasmus University Rotterdam.

Veenhoven, R. (2012f). World database of happiness. Available from http://worlddatabaseof happiness.eur.nl, from Erasmus University Rotterdam.

Vitaro, F., Boivin, M., \& Bukowski, W. M. (2009). The role of friendship in child and adolescent psychosocial development. In K. H. Rubin, W. M. Bukowski, \& B. Laursen (Eds.), Handbook of peer interactions, relationships and groups (pp. 568 588). New York, NY: Guilford Press.

Vitaro, F., Brendgen, M., Boivin, M., Cantin, S., Dionne, G., Tremblay, R. E., \& Perusse, D. (2011). A monozygotic twin difference study of friends' aggression and children's adjustment problems. Child Development, 82(2), 617 632. doi:10.1111/j.1467 8624.2010.01570.x.

Vitaro, F., Brendgen, M., \& Tremblay, R. E. (2000). Influence of deviant friends on delinquency: Searching for moderator variables. Journal of Abnormal Child Psychology, 28(4), 313325. doi:10.1023/a:1005188108461.

Vogels, T., Verrips, G. H. W., Koopman, H. M., Theunissen, N. C., Fekkes, M., \& Kamhuis, R. P. (2000). TACQOL Manual parent form and child form. Leiden: LUMC TNO.

Vollrath, M., \& Torgersen, S. (2000). Personality types and coping. Personality and Individual Differences, 29(2), 367 378. doi:10.1016/s0191 8869(99)00199 3.

Votruba Drzal, E., Coley, R. L., Maldonado Carreno, C., Li Grining, C. P., \& Chase Lansdale, P. L. (2010). Child care and the development of behavior problems among economically disadvantaged children in middle childhood. Child Development, 81(5), 14601474.

Vygotsky, L. S. (1967). Play and its role in the mental development of the child. Soviet Psychol ogy, 12, 6276 . 
Waaktaar, T., \& Torgersen, S. (2010). How resilient are resilience scales? The Big Five scales outperform resilience scales in predicting adjustment in adolescents. Scandinavian Journal of Psychology, 51(2), 157163.

Wagner, G. G., Frick, J. R., \& Schupp, J. (2007). The German socio economic panel study (SOEP) scope, evolution and enhancements (vol 1): Schmollers Jahrbuch 127.

Walker, W. R., Skowronski, J. J., \& Thompson, C. P. (2003). Life is pleasant and memory helps to keep it that way! Review of General Psychology, 7(2), 203 210. doi:10.1037/1089 2680.7.2.203.

Ware, J. E., \& Sherbourne, C. D. (1992). The MOS 36 item short form health survey (SF 36) 1.1 Conceptual framework and item selection. Medical Care, 30(6), 473 483. doi:10.1097/ 0000565019920600000002.

Waterman, A. (2013). The best within us. Positive psychology perspectives on eudaimonia. Washington DC: American Psychological Association.

Waterman, A. S. (1993). Two conceptions of happiness: Contrasts of personal expressiveness (Eudaimonia) and hedonic enjoyment. Journal of Personality and Social Psychology, 64, 678691.

Waterman, A. S., Schwartz, S. J., \& Conti, R. (2008). The implications of two concepts of happiness (Hedonic enjoyment and eudaimonia) for the understanding of intrinsic motivation. Journal of Happiness Studies, 9, 4179.

Watson, D., Clark, L. A., \& Tellegen, A. (1988). Development and validation of brief measures of positive and negative affect the Panas scales. Journal of Personality and Social Psychology, 54(6), 1063 1070. doi:Doi 10.1037/0022 3514.54.6.1063.

Watson, J. (1895). Hedonistic theories. From Aristippus to Spencer. London: MacMillan.

Weare, K., \& Nind, M. (2011). Mental health promotion and problem prevention in schools: What does the evidence say? Health Promotion International, 26, I29 I69. doi:10.1093/heapro/ dar075.

Weinstein, N., \& Ryan, R. M. (2010). When helping helps: Autonomous motivation for prosocial behavior and its influence on well being for the helper and recipient. Journal of Personality and Social Psychology, 98(2), 222 244. doi:10.1037/a0016984.

Weinstein, N. D. (1987). Unrealistic optimism about susceptibility to health problems: Conclu sions from a community wide sample. Journal of Behavioral Medicine, 10(5), 481500. doi: $10.1007 / \mathrm{bf} 00846146$.

Weiss, A., Bates, T. C., \& Luciano, M. (2008). Happiness is a personal(ity) thing The genetics of personality and well being in a representative sample. Psychological Science, 19(3), 205210.

Weissberg, R. P., Caplan, M., \& Harwood, R. L. (1991). Promoting competent young people in competence enhancing environments a system based perspective on primary prevention. Journal of Consulting and Clinical Psychology, 59(6), 830 841. doi:10.1037//0022 006x.59.6.830.

Wells, J., Barlow, J., \& Stewart Brown, S. (2003). A systematic review of universal approaches to mental health promotion in schools. Health Education, 103(4), 197220.

Werner, E. E. (1993). Risk, resilience, and recovery: Perspectives from the Kauai longitudinal study. Development and Psychopathology, 5(4), 503515.

Werner, E. E., \& Smith, R. S. (1992). Overcoming the odds: High risk children from birth to adulthood. Ithaca, US: Cornell University Press.

WHO. (1998). WHO's global school health initiative: Health promoting schools. Geneva: World Health Organization.

WHO. (2001). The world health report 2001: Mental health: New understanding, new hope. Geneva: World Health Organization.

WHO. (2004). Promoting Mental Health: Concepts, Emerging evidence, Practice. (Summary Report). A Report of the World Health Organisation, Department of Mental Health and Substance Abuse in collaboration with the Victorian Health Promotion Foundation and The University of Melbourne Geneva: WHO. 
Wiest, M., Schuz, B., Webster, N., \& Wurm, S. (2011). Subjective well being and mortality revisited: Differential effects of cognitive and emotional facets of well being on mortality. Health Psychology, 30(6), 728 735. doi:10.1037/a0023839.

Wilson, D. B., Gottfredson, D. C., \& Najaka, S. S. (2001). School based prevention of problem behaviors: A meta analysis. Journal of Quantitative Criminology, 17(3), 247272. doi:10.1023/a:1011050217296.

Winkelmann, R. (2004). Subjective well being and the family: results from an ordered probit model with multiple random effects, IZA Discussion Paper No. 1016.

Wynn, J., Cahill, H., Holdsworth, R., Rowling, L., \& Carson, S. (2000). MindMatters, a whole school approach to promoting mental health and well being. Australia and New Zealand Journal of Psychiatry, 34, 594601.

Zachrisson, H. D., Dearing, E., Lekhal, R., \& Toppelberg Claudio, O. (2013). Little evidence that time in child care causes externalizing problems during early childhood in Norway. Child \& Development. doi: 10.1111/cdev.12040

Zahn Waxler, C., \& Smith, K. D. (1992). The development of prosocial behavior. In V. B. V. Hasselt \& M. H. Hersen (Eds.), Handbook of social development: A lifespan perspective (pp. 229 256). New York: Plenum Press.

Ziehm, J., Trommsdorff, G., Heikamp, T., \& Park, S. Y. (2012). German and Korean mothers' intuitive theories about parenting: Maternal sensitivity and related parenting goals: Manu script in preparation.

Zins, J. E. (2004). Building academic success on social and emotional learning: What does the research say? New York: Teachers College Press. 